Document downloaded from:

http://hdl.handle.net/10251/165611

This paper must be cited as:

Zhang, Q.; Yu, J.; Corma Canós, A. (2020). Applications of Zeolites to C1 Chemistry: Recent Advances, Challenges, and Opportunities. Advanced Materials. 32(44):1-31. https://doi.org/10.1002/adma.202002927

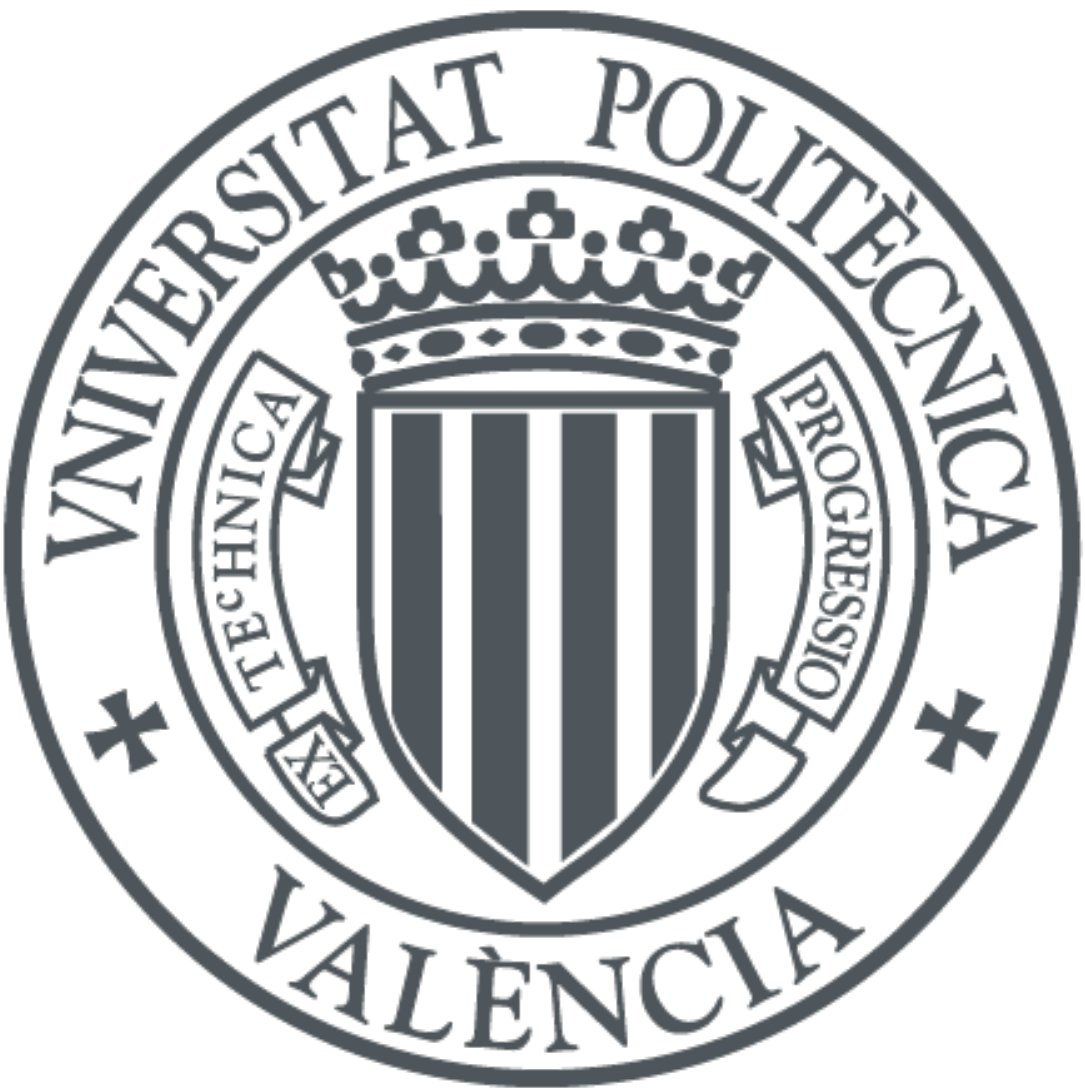

The final publication is available at

https://doi.org/10.1002/adma.202002927

Copyright John Wiley \& Sons

Additional Information 


\section{Applications of Zeolites to C1 Chemistry: Recent Advances, Challenges, and Opportunities}

Qiang Zhang, Jihong Yu, * Avelino Corma*

Dr. Q. Zhang, Prof. J. Yu

State Key Laboratory of Inorganic Synthesis and Preparative Chemistry

College of Chemistry

Jilin University

2699 Qianjin Street, Changchun 130012, P. R. China

E-mail: jihong@jlu.edu.cn

Prof. J. Yu

International Center of Future Science

Jilin University

2699 Qianjin Street, Changchun 130012, P. R. China

Dr. Q. Zhang, Prof. A. Corma

Instituto de Tecnología Química

Universitat Politècnica de València-Consejo Superior de

Investigaciones Científicas

Avenida de los Naranjos s/n, 46022 València, Spain

E-mail: acorma@itq.upv.es

Abstract: $\mathrm{C} 1$ chemistry, which is the catalytic transformation of $\mathrm{C} 1$ molecules including $\mathrm{CO}$,

$\mathrm{CO}_{2}, \mathrm{CH}_{4}, \mathrm{CH}_{3} \mathrm{OH}$, and $\mathrm{HCOOH}$, plays an important role in providing energy and chemical supplies while meeting environmental requirements. Zeolites are highly efficient solid catalysts used in the chemical industry. The design and development of zeolite-based mono-, bi-, and multi-functional catalysts have led to a booming application of zeolite-based catalysts to $\mathrm{C} 1$ chemistry. Combining the advantages of zeolites and metallic catalytic species has promoted the catalytic production of various hydrocarbons (e.g., methane, light olefins, aromatics, and liquid fuels) and oxygenates (e.g., methanol, dimethyl ether, formic acid, and higher alcohols) from C1 molecules. The key zeolite descriptors that influence catalytic performance, such as framework topologies, nano-confinement effects, Brønsted acidities, secondary-pore systems, particle sizes, extra-framework cations and atoms, hydrophobicity and hydrophilicity, and proximity between acid and metallic sites are discussed to provide a deep understanding of the significance of zeolites to $\mathrm{C} 1$ chemistry. We also present our 
outlook regarding challenges and opportunities for the conversion of $\mathrm{C} 1$ resources using zeolite-based catalysts to meet emerging energy and environmental demands.

Keywords: Zeolite, C1 chemistry, Catalytic transformation, Hydrocarbons, Oxygenates

\section{Introduction}

Crude oil has afforded unprecedented prosperity and rapid human societal development by providing liquid fuels (gasoline, jet fuel, and diesel fuel), oxygenates (methanol, dimethyl ether, and higher alcohols), and building-block chemicals (light olefins and aromatics) for several decades. ${ }^{[1]}$ However, due to growing concerns regarding crude oil depletion and increasing environmental requirements, finding abundant fossil hydrocarbons with high $\mathrm{H}_{2} / \mathrm{C}$ ratios as well as alternative carbon resources has become crucial to maintaining sustainable, environmentally benign systems that can aid human development. ${ }^{[2]}$ Thus, one-carbon $(\mathrm{C} 1)$ chemistry, which is the chemistry of $\mathrm{C} 1$ molecules that can be derived from sources other than fossil hydrocarbons, including carbon monoxide $(\mathrm{CO})$, carbon dioxide $\left(\mathrm{CO}_{2}\right)$, methane $\left(\mathrm{CH}_{4}\right)$, methanol $\left(\mathrm{CH}_{3} \mathrm{OH}\right)$, and formic acid $(\mathrm{HCOOH})$, has emerged and plays important roles in the energy supply and high-value chemical preparation. ${ }^{[1,3]}$ These $\mathrm{C} 1$ resources can be obtained from natural gas, shale gas, coal, biomass, solid wastes, and $\mathrm{CO}_{2}$ emissions. ${ }^{[3 \mathrm{a}, 4]}$ Extensive studies have been dedicated to the catalytic conversion of $\mathrm{C} 1$ molecules, including production of dimethyl ether (DME) and liquid fuels from syngas (a mixture of $\mathrm{CO}$ and $\mathrm{H}_{2}$ ); production of methanol, light olefins, and even aromatics from $\mathrm{CH}_{4}$; and production of hydrogen from $\mathrm{HCOOH} \cdot{ }^{[5]}$ All of these transformations require metallic catalytic species such as single atoms; clusters; or oxides, carbides, or alloy particles (e.g., $\mathrm{Rh}-$, $\mathrm{AuPd}-, \mathrm{Fe}_{3} \mathrm{O}_{4-}$, and $\mathrm{Fe}_{5} \mathrm{C}_{2}$-based catalysts). However, these isolated metallic species suffer from severe sintering due to a lack of confinement effects from supports, which leads to poor catalytic stability and decreased selectivities towards their target products. The efficient production of a specific range of hydrocarbons or oxygenates remains a difficult scientific and technical challenge. 
Overcoming product selectivity limitations and improving catalyst stabilities via catalyst designs are important areas of research.

Zeolites are an important class of shape-selective catalysts with uniform micropores, tunable acidities, and high thermal and hydrothermal stabilities. Over the past decade, they have gained broad popularity and been applied to various industrially important catalytic processes. ${ }^{[6]}$ In particular, the design and development of zeolite-based mono-, bi-, and multifunctional catalysts that combine the advantages of zeolites with those of metallic catalytic species have boosted the application of zeolites to $\mathrm{C} 1$ chemistry. As shown in Figure 1, value-added hydrocarbons and oxygenates can be produced from $\mathrm{C} 1$ molecules via various catalytic routes over zeolite-based catalysts. By May of 2020, the Structure Commission of the International Zeolite Association (IZA-SC) had approved 252 distinct zeolite framework topologies, ${ }^{[7]}$ which feature distinct channel systems, pore openings, and cavities. Zeolites possess varied sieving and intrapore spatial confinement effects, which can control reaction intermediates and provide specific anchoring positions for metallic species, thus hindering their aggregation and deactivation during $\mathrm{C} 1$ molecule conversion. This significantly promotes selectivity towards target products and improves catalytic stabilities. Structural information for several commercial zeolites (CHA, MFI, *BEA, MOR, and AEI) that are widely utilized to perform C1 chemistry are summarized in Table $\mathbf{1 .}$

There have been several excellent reviews regarding the catalytic conversion of $\mathrm{C} 1$ molecules. ${ }^{[1-3,8]}$ These tend to be organized based on a specific reaction route, focused on one type of representative $\mathrm{C}_{1}$ or $\mathrm{C}_{2+}$ product, or specify a particular heterogeneous catalyst system. These reviews generally discuss the conversion of only one type of $\mathrm{C} 1$ molecule. Therefore, a comprehensive review that covers the application of zeolite-based catalysts to transformation of all $\mathrm{C} 1$ molecules into various value-added chemicals is highly needed to emphasize the substantial impact of zeolites on the entire $\mathrm{C} 1$ chemistry field. Various zeolite descriptors that influence the catalytic transformation of $\mathrm{C} 1$ molecules into hydrogen energy and specific 
ranges of hydrocarbons and oxygenates are presented in Figure 2. These include framework topologies, nano-confinement effects, Brønsted acidities, secondary-pore systems, particle sizes, extra-framework cations and atoms, hydrophobicity and hydrophilicity, and proximity between acid and metallic sites. Significantly, selecting a suitable zeolite with the desired characteristics may afford enormous opportunities to improve conversion of $\mathrm{C} 1$ molecules and maximize the production of a specific product. In this review, we present advances, challenges, and prospects for application of zeolite-based catalysts to $\mathrm{C} 1$ chemistry, with an emphasis on addressing the significance of and opportunities for zeolite catalysts and supports in conversion of $\mathrm{C} 1$ resources. After this brief introduction in Section 1, Sections 2-6 present recent progress in the use of zeolite-based catalysts for the conversion of syngas, $\mathrm{CO}_{2}, \mathrm{CH}_{4}$, $\mathrm{CH}_{3} \mathrm{OH}$, and $\mathrm{HCOOH}$, respectively. In the conclusion and outlook section, facile strategies for improving the catalytic conversion of $\mathrm{C} 1$ molecules based on existing mature zeolitebased catalytic systems, and deep unraveling of reaction mechanisms via in-situ characterization techniques, DFT calculations, and machine learning will be proposed. We will point out the methodologies for the design and discovery of new types of highperformance catalysts via modification of zeolites by tuning their pore openings, pore and cavity sizes and shapes, and hydrophilicities or hydrophobicities. These methods allow researchers to adjust the adsorption and desorption behaviors of reactants and products, as well as their reactivities. We will discuss fabrication of bi- and multi-functional zeolite-based catalysts with designable control of porosity, size, shape, and active site spatial arrangement using $3 \mathrm{D}$ printing technology, as well as how this can meet the significant demand for $\mathrm{C} 1$ molecule-derived chemicals.

\section{Syngas Conversion over Zeolite-Based Catalysts}

Syngas can be obtained easily via reforming of natural gas, gasification of coal, biomass, or solid waste, and electrochemical or thermochemical reduction of $\mathrm{CO}_{2}$ emissions, as shown in Figure 3. Catalytic transformation of syngas into hydrocarbons (light olefins, aromatics, and 
liquid fuels) and oxygenates (higher alcohols and DME) via Fischer-Tropsch (FT) and nonFT synthesis routes are significant $\mathrm{C} 1$ chemistry technologies. ${ }^{[1,3 a, 8 a, 9]}$ It is generally accepted that FT synthesis proceeds via the following reaction steps over metallic (Fe-, $\mathrm{Co}-$, and $\mathrm{Ru}-$ based) catalyst surfaces: (1) dissociative adsorption of $\mathrm{CO}$ and $\mathrm{H}_{2}$; (2) formation of $\mathrm{CH}_{\mathrm{x}}$ species $(x=0-3)$; (3) chain growth to form $\mathrm{C}_{n} \mathrm{H}_{m}$ intermediates $(n>2)$ via coupling of $\mathrm{CH}_{x}$ species or formation of $\mathrm{CH}_{4}$ via hydrogenation of $\mathrm{CH}_{x}$; and (4) dehydrogenation of $\mathrm{C}_{\mathrm{n}} \mathrm{H}_{\mathrm{m}}$ to an alkene or hydrogenation of $\mathrm{C}_{\mathrm{n}} \mathrm{H}_{\mathrm{m}}$ to an alkane. ${ }^{[1]}$ Due to the lack of confinement effects when FT metallic catalysts are used for hydrocarbon chain growth, controlling the product selectivity remains a great challenge. The hydrocarbon product distributions follow the Anderson-Schulz-Flory (ASF) equation, in which the maximum selectivities of products are limited to $58 \%$ for $\mathrm{C}_{2}-\mathrm{C}_{4}, 48 \%$ for $\mathrm{C}_{5}-\mathrm{C}_{11}$ (gasoline), $41 \%$ for $\mathrm{C}_{8}-\mathrm{C}_{16}$ (jet fuel), and $40 \%$ for $\mathrm{C}_{10}-\mathrm{C}_{20}$ (diesel fuel). ${ }^{[10]}$ To this end, design of bi- and multi-functional catalysts by coupling FT metallic species with zeolites has proven to be an effective way to break the limits of the ASF distribution. ${ }^{[11]}$ Zeolites with controllable Brønsted acid sites and spatial confinement effects work for the cleavage of $\mathrm{C}-\mathrm{C}$ bonds of formed heavier hydrocarbons via hydrocracking or isomerization, enabling the selective synthesis of a specific range of hydrocarbon products. ${ }^{[12]}$ In addition to Brønsted acid sites, large micropore volumes and high specific surface areas make these zeolites good candidates for supporting active metallic atoms, clusters, and particles with high dispersion. ${ }^{[13]}$ This gives the zeolite-supported catalysts long-term catalytic stability. Hydrocarbons can also be produced via a two-step nonFT route, in which methanol or DME can be synthesized as intermediates from syngas over metallic (e.g., $\mathrm{Zn}_{\mathrm{x}} \mathrm{Ce}_{2-\mathrm{y}} \mathrm{Zr}_{\mathrm{y}} \mathrm{O}_{4}, \mathrm{ZnAlO}_{\mathrm{x}}, \mathrm{CuO}-\mathrm{ZnO}-\mathrm{Al}_{2} \mathrm{O}_{3}, \mathrm{ZnO}, \mathrm{ZnCr}_{2} \mathrm{O}_{4}, \mathrm{Zr}-\mathrm{In}_{2} \mathrm{O}_{3}, \mathrm{Zn}-\mathrm{ZrO}_{2}$ ) species in the first step, and then methanol or DME is further converted to hydrocarbons over zeolite catalysts (e.g., SAPO-34, SAPO-5, SSZ-13, ZSM-5) in the second step. ${ }^{[14]}$ This section mainly discusses syngas conversion into hydrocarbons via FT route and higher alcohols via FT and non-FT routes. We focus on the effects of zeolite descriptors and acid and 
metallic site proximity effects on syngas catalytic conversion performance. The properties of some representative zeolite-based catalysts and their corresponding performance in production of hydrocarbons and higher alcohols from syngas are summarized in Table 2.

\subsection{Syngas Conversion to Hydrocarbons}

Petroleum-derived hydrocarbons generally contain sulfur and nitrogen impurities alongside molecules that can be precursors to particulate matter emissions. However, syngas-derived hydrocarbons are almost free of these environmently harmful impurities, and thus meet emerging environmental requirements.

\subsubsection{Effect of the Zeolite Brønsted/Lewis Acidity}

C-C cleavage capabilities are determined by the Brønsted acidities of zeolites. Hydrocarbons with specific ranges can be produced by tuning zeolite Brønsted acidities. Weak zeolite Brønsted acidities cause mild hydrocracking of the heavier hydrocarbon intermediates that are formed over active metallic sites, leading to high selectivity for $\mathrm{C}_{5}-\mathrm{C}_{11}$ hydrocarbon products. In contrast, strong Brønsted acidities can cause over-cracking, giving a high yield of lighter at $\mathrm{C}_{2}-\mathrm{C}_{4}$ hydrocarbons. For example, Montané and co-workers found that increasing the Brønsted acidities of Fe/ZSM-5 bi-functional catalysts aided in cracking of heavy hydrocarbon intermediates and formation of aromatics via oligomerization, cyclization, and dehydrogenation of primary light olefins. Low Brønsted acidities favored higher selectivities towards gasoline-range products. ${ }^{[15]}$ Notice that, the direct catalytic transformation of syngas to aromatics suffers from a low aromatic yield due to the ASF distribution. To solve this problem, Ma and co-workers fabricated a bi-functional catalyst that combined $\mathrm{Na}-\mathrm{Zn}-\mathrm{Fe}_{5} \mathrm{C}_{2}$ and $\mathrm{HZSM}-5$ zeolite, leading to a $51 \%$ aromatic selectivity and substantially less heavy hydrocarbon production. The authors tuned the Brønsted acidity precisely via post-treatment, adjusting the $\mathrm{Si} / \mathrm{Al}$ ratio of $\mathrm{ZSM}-5$ to investigate its effects on catalytic performance. They found that appropriate Brønsted acid strength, and more importantly density, were the main factors that produced such high aromatic yields. ${ }^{[16]}$ More 
recently, ZSM-5 zeolites containing Lewis acid sites were found to be effective in improving aromatic production from syngas. With a Na-Fe- $\mathrm{ZrO}_{2} / \mathrm{ZSM}-5$ catalyst system, the aromatic production rate increased linearly with the quantity of Lewis acid sites. This may be due to the positive effect of Lewis acid sites on transformation of $\mathrm{C}_{6+}$ alkenes into aromatics via dehydroaromatization. ${ }^{[17]}$ Ion exchange can also be used to tune zeolite Brønsted acidity to control product selectivity. ${ }^{[18]}$ For instance, Tsubaki and co-workers studied the performance of mesoporous zeolite $\mathrm{Y}$-supported cobalt catalysts $\left(\mathrm{Co} / \mathrm{Y}_{\text {meso }}\right)$ on syngas conversion. ${ }^{[18 b]}$ After exchanging $\mathrm{Ce}^{3+}$ and $\mathrm{La}^{3+}$ into the $\mathrm{Y}_{\text {meso }}$ zeolites, $\mathrm{Co} / \mathrm{Y}_{\text {meso }}-\mathrm{Ce}$ and $\mathrm{Co} / \mathrm{Y}_{\text {meso }}-\mathrm{La}$ catalysts with relatively low Brønsted acidities were obtained. This can be attributed to partial hydrolysis of hydrated rare-earth cations in the $\mathrm{Co} / \mathrm{Y}_{\text {meso }}$ catalyst. $\mathrm{Co} / \mathrm{Y}_{\text {meso }}$ catalysts with stronger Brønsted acidities led to over-cracking of heavy hydrocarbons, resulting in low $\mathrm{C}_{5}-$ $\mathrm{C}_{20}$ (liquid fuel) selectivity (64\%) and higher selectivities for undesirable methane and $\mathrm{C}_{2}-\mathrm{C}_{4}$ hydrocarbons (sum of 36\%). In contrast, $\mathrm{Co} / \mathrm{Y}_{\text {meso }}-\mathrm{Ce}$ and $\mathrm{Co} / \mathrm{Y}_{\text {meso }}-\mathrm{La}$ catalysts with mild Brønsted acidities exhibited higher selectivities for liquid fuel of $82 \%$ and $86 \%$, respectively. More importantly, selectivity for gasoline during reactions over $\mathrm{Co} / \mathrm{Y}_{\text {meso-Ce reached as high }}$ as $74 \%$, and selectivity for jet fuel over $\mathrm{Co} / \mathrm{Y}_{\text {meso-La reached } 72 \%}{ }^{[18 \mathrm{~b}]}$

\subsubsection{Effect of the Zeolite Framework Topology}

Zeolite topology control is an efficient way to influence reaction pathways and consequently product distributions. ${ }^{[19]}$ A specific catalytic environment such as a cavity or pocket directs a specific intermediate due to its strong confinement effects, significantly affecting subsequent reaction pathways and the final hydrocarbon product selectivity. Recently, Bao and co-workers increased the selectivity for ethylene to $73 \%$ when reacting syngas over $\mathrm{ZnCrO}_{\mathrm{x}}$-mordenite (MOR) bi-functional catalysts. ${ }^{[20]}$ The authors found that such high ethylene selectivity was derived from ketene intermediates generated on active sites in the 8-membered ring (8-MR) side pockets of the MOR structure rather than from methanol intermediates in the 8-MR or 12-MR channels (Figure 4). The zeolite channel dimensions 
also significantly affect product distributions in syngas conversion. Zeolites with intersectional channels (2D or 3D) favor aromatic formation, while zeolites with 1D channels favor the formation of aliphatic $\mathrm{C}_{5}-\mathrm{C}_{11}$ hydrocarbons. For instance, Bao and co-workers studied the influence of zeolite channel systems on product selectivity during syngas conversion over metal oxide-zeolite catalysts. In this study, SAPO-11 (AEL) and ZSM-22 (TON) zeolites with 1D 10-MR channel systems afforded high selectivity for gasoline production from syngas over $\mathrm{Zn}_{2} \mathrm{Mn}_{1} \mathrm{O}_{\mathrm{x}}$-zeolite bi-functional catalyst systems. ${ }^{[21]}$ In contrast, the $\mathrm{Zn}_{2} \mathrm{Mn}_{1} \mathrm{O}_{\mathrm{x}}$ combined with ZSM-5 (MFI) and ZSM-11 (MEL) featuring 3D 10-MR channels facilitated much higher aromatic contents. Another key factor affecting the reaction performance is the zeolite pore opening. Compared to medium or large pores (10- or 12-MR) that favor the formation of gasoline-range hydrocarbons, small 8-MR channels promote the formation of light hydrocarbons. In this case, a $\mathrm{Zn}_{2} \mathrm{Mn}_{1} \mathrm{O}_{\mathrm{x}}$ catalyst combined with $\mathrm{ZSM}-35$ (FER) featuring 2D 8-MR channels gave a high selectivity (68.0\%) for $\mathrm{C}_{2}-\mathrm{C}_{4}$ light hydrocarbons and a low selectivity $(11.7 \%)$ for gasoline. ${ }^{[21]}$ In addition, T atoms sitting at different environments generally lead to different zeolite acidities. ${ }^{[22]}$ Comparing $\mathrm{ZnCrO}_{x} /$ low-Si AlPO-18 (AEI) and $\mathrm{ZnCrO}_{x} /$ low-Si AlPO-34 (CHA) catalysts with similar acid densities, the $\mathrm{ZnCrO}_{\mathrm{x}} /$ low-Si AlPO-18 exhibited a higher $\mathrm{CO}$ conversion rate as well as a higher selectivity for light olefin products. This because the Si atom locations differ between AEI and CHA topologies and the acid strength of low-Si AlPO-18 is weaker than that of lowSi AlPO-34, ${ }^{[23]}$ which is favorable for the formation of light olefins during syngas conversion. In addition, diffusional constraints differ greatly among various zeolite frameworks because of the difference in void structures and small zeolite pores, which strongly influences product distributions during syngas conversion. Small pores or void structures in zeolites hinder the molecular diffusion egress of primary hydrocarbon products from acid domains, thus leading to secondary hydrocracking and isomerization events. ${ }^{[24]}$

\subsubsection{Effect of the Proximity between Brønsted Acid Sites and Metallic Species}


In the bi-functional catalyst systems, suitable proximity between catalytic active sites can be used to enhance the efficiencies of tandem reactions that produce specific ranges of hydrocarbons. The proximity between FT metallic active sites and zeolite Brønsted acid sites can be altered via the following methods: (1) a dual-bed configuration in which the zeolite lies below the metallic catalysts; (2) physical mixing of metallic catalysts and zeolites; (3) construction of core-shell structures with metallic catalysts as cores and zeolites as shells (or the reverse arrangement); or (4) directly loading the metallic catalysts onto zeolite surfaces or inside zeolite channels. ${ }^{[1]}$ Several groups have investigated the influence of the proximity between zeolite acid and metallic active sites on syngas conversion performance. ${ }^{[25]}$ Compared to catalysts produced via physical mixing of metallic species and acidic zeolites, the core-shell structures obtained by depositing SAPO-34 layers on $\mathrm{Fe}_{3} \mathrm{C}$ catalysts offer enhanced $\mathrm{C}_{2}-\mathrm{C}_{4}$ hydrocarbon selectivity and decreased $\mathrm{C}_{6+}$ production. ${ }^{[25 \mathrm{~b}]}$ The SAPO-34 zeolite shells benefited the rapid transfer of light hydrocarbons, thus suppressing the formation of $\mathrm{C}_{6+}$ hydrocarbons. A similar work also reported that core-shell structured Fe@SAPO-34 catalysts exhibited higher selectivity to light olefins than a bare Fe catalyst and a simple Fe/SAPO-34 mixture. ${ }^{[26]}$ In a recent work, Khodakov and co-workers systematically studied the effects of the proximity between $\mathrm{Ru}$ sites and Brønsted acid sites on product distributions by generating core-shell structures in which the shell was a ZSM-5 or silicalite-1 zeolite. ${ }^{[27]}$ The proximity between $\mathrm{Ru}$ sites and acid sites significantly improved the selectivity towards iso-paraffins in low-temperature FT systems. It was proposed that paraffins and olefins are formed simultaneously on Ru catalytic sites, and that the subsequent isomerization of these hydrocarbons requires the presence of both $\mathrm{Ru}$ and acid sites. Thus, close proximity favors isomerization and enhances selectivity towards iso-products. However, in a Fe-zeolite catalyst system when iron catalysts were mixed with zeolites such that the two were in close proximity, the selectivity towards methane increased, while that towards aromatics decreased. ${ }^{[28]}$ This indicates that proximity effect works differently in different 
catalyst systems and should be carefully considered for maximizing target product selectivities. Since benzene, toluene, and xylene (BTX) are indispensable and widely used high-value raw materials in the synthetic chemistry, BTX selectivity improvements are highly desired. In a FeMn/HZSM-5 catalyst system, BTX can be produced via a tandem reaction process that includes syngas conversion to light olefin intermediates over FeMn sites followed by light olefin aromatization to produce aromatics over zeolite acid sites. Tuning the proximity between the FeMn catalyst and HZSM-5 zeolite may significantly enhance BTX production from syngas. ${ }^{[29]}$ Increasing the proximity between the FeMn catalyst and HZSM-5 zeolite enhanced the BTX selectivity from $64 \%$ to $68.9 \%$. This is attributed to slow light olefin diffusion from FeMn sites to the HZSM-5 zeolite due to increased proximity, which may cause a relative low concentration of light olefins around benzene and toluene products. Consequently, the alkylation reactions of benzene and toluene that produce multi-branched aromatics were suppressed.

\subsubsection{Effects of the Zeolite Secondary-Pore System and Particle Size}

Since Brønsted acid sites are mostly located at the internal surfaces within zeolite micropores, the hydrocarbon intermediates formed on metallic catalysts likely must diffuse into the zeolitic microporous systems, where they undergo further hydrocracking and isomerization. The final products can then diffuse out of the micropores. The diffusion path length and residence time of the hydrocarbon intermediates within microporous zeolites significantly affect the product distributions. Hierarchical and nanosized zeolites with shortened diffusion paths can effectively relieve the mass transfer limitations, and thus tend to reduce over-cracking of hydrocarbon intermediates. ${ }^{[30]}$ For instance, Wang and co-workers found that incorporation of mesopores into ZSM-5 zeolites significantly increased the gasoline selectivity up to $70 \%$ by suppressing formation of methane and $\mathrm{C}_{2}-\mathrm{C}_{4}$ products during FT synthesis over Co/H-meso-ZSM-5 bi-functional catalysts. ${ }^{[31]}$ Similarly, syngas conversion to diesel fuel with high selectivity (60\%) while keeping a low $\mathrm{CH}_{4}$ selectivity 
(5\%) can be attained by using mesoporous zeolite Y-supported cobalt catalysts. ${ }^{[32]}$ Mesoporosity in H-type zeolites not only worked for hydrocracking but also affected isomerization such that branched alkane formation was enhanced. A recent work pointed out that the introduction of mesopores into a Co/ZSM-5 catalyst allowed fast mass diffusion, leading to less hydrocracking process and improving the selectivity towards branched hydrocarbons. ${ }^{[33]}$ Similarly, Wang and co-workers reported that introduction of a mesoporous and macroporous system into zeolite Beta-supported Co catalysts induced high selectivity towards branched hydrocarbons and low selectivity towards methane. ${ }^{[34]}$ In addition, the introduction of mesopores into zeolites may also facilitate a high dispersion of Co nanoparticles and consequently increase CO conversion. ${ }^{[35]}$ Nanosized zeolites with shortened diffusion path lengths were also found to be effective in suppressing over-cracking of hydrocarbons. Decreased selectivity towards undesired light hydrocarbons and increased selectivity towards the target gasoline were achieved using nanosized ZSM-5 zeolite catalysts. ${ }^{[36]}$ More recently, hollow ZSM-5 zeolites were combined with $\mathrm{Fe}_{3} \mathrm{O}_{4} @ \mathrm{MnO}_{2}$ catalysts. The resulting materials exhibited high selectivity towards heavy hydrocarbons such as aromatics and gasoline during syngas conversion; the hollow structure reduced overcracking and enhanced catalyst stability via suppression of carbon deposition on active sites. $^{[37]}$

\subsubsection{Effects of the Zeolite Hydrophobicity and Hydrophilicity}

Typically, syngas conversion to hydrocarbons over zeolite-based catalysts suffers from high $\mathrm{CO}_{2}$ selectivity. This is driven primarily by the water-gas shift reaction (WGS, $\mathrm{CO}+$ $\mathrm{H}_{2} \mathrm{O} \rightarrow \mathrm{CO}_{2}+\mathrm{H}_{2}$ ). Both zeolite silanol groups and metallic species are active sites for the WGS reaction. The presence of $\mathrm{H}_{2} \mathrm{O}$ not only drives the reaction towards undesired $\mathrm{CO}_{2}$ but also poisons the metallic active sites. Transitioning from hydrophilic to hydrophobic zeolites can substantially suppress the WGS and $\mathrm{H}_{2} \mathrm{O}$ diffusion. Zeolites with enhanced hydrophobicity can be prepared by increasing the framework $\mathrm{Si} / \mathrm{Al}$ ratios and decreasing the 
number of defects (silanols). For instance, aluminum-containing ZSM-5 (MFI) zeolites exhibit hydrophilic character, but purely siliceous silicalite-1 (MFI) zeolites exhibit highly hydrophobic property. In this case, encapsulation of a Co/ZSM-5 catalyst with silicalite-1 shells was used to decrease selectivity towards $\mathrm{CO}_{2}$ and enhance selectivity towards gasoline. ${ }^{[38]}$ In this work, a high CO conversion of $68.9 \%$, gasoline selectivity of $74.7 \%$, and low $\mathrm{CO}_{2}$ selectivity of $2.8 \%$ were achieved using Co/ZSM-5@ silicalite-1 catalysts. The hydrophobic silicalite-1 shells resisted retention of water molecules on the metallic catalyst surface, favored the reverse WGS reaction, and consequently decreased $\mathrm{CO}_{2}$ production. Similarly, the $\mathrm{CO}_{2}$ selectivity was reduced by encapsulating a Fe-zeolite catalyst with hydrophobic silicalite-1 shells during syngas conversion. ${ }^{[39]}$

\subsection{Syngas Conversion to Higher Alcohols}

Higher alcohols containing two or more carbon atoms $\left(\mathrm{C}_{2+} \mathrm{OH}\right)$, such as ethanol, propanol, and butanol have attracted enormous interest because of their broad application to the chemical, pharmaceutical, and polymer industries. ${ }^{[40]}$ In particular, ethanol is an important platform feedstock that is widely used as a clean fuel, solvent, detergent, and disinfectant in industrial production and households. Currently, ethanol, propanol, and butanol production rely heavily on fermentation of cellulosic biomass. This approach suffers from competition with the human food supply and low production efficiency, as well as limited ethanol, propanol, and butanol selectivities. As an alternative sustainable route, catalytic syngas conversion to higher alcohols has attracted growing attention because syngas can be obtained from non-petroleum resources. ${ }^{[40]}$ Although substantial success has been achieved in catalytic syngas conversion to hydrocarbons, as discussed in Section 2.1, efficient, high-selectivity production of higher alcohols from syngas remains a major challenge. Recently, zeolitesupported metals have been regarded as promising catalysts for syngas conversion to higher alcohols. ${ }^{[41]}$ For instance, utilization of zeolites in combination with metallic active species enables efficient production of ethanol via direct or indirect routes. The indirect routes include 
DME- and methanol-mediated pathways. In the DME-mediated pathway, ethanol can be produced via a tandem reaction process that includes syngas conversion to DME intermediates, carbonylation of DME to generate methyl acetate, and finally hydrogenation of methyl acetate to form ethanol and methanol products. In the methanol-mediated pathway, methanol intermediates are formed from syngas from the beginning. This is followed by carbonylation of methanol to acetic acid, and finally hydrogenation of acetic acid to ethanol. In both DME- and methanol-mediated pathways, zeolite Brønsted acid sites are the active sites for carbonylation of DME or methanol intermediates, ${ }^{[42]}$ which is the key step in ensuring efficient ethanol production from syngas. ${ }^{[43]}$

\subsubsection{Effect of the Zeolite Brønsted Acidity}

In a recent work, a tri-functional catalyst system that combined CuZnAl/HZSM-5, HMOR zeolite, and CuZnAl catalysts enabled a tandem reaction, leading to an enhanced ethanol selectivity of 50.1\%. ${ }^{[41 \mathrm{~b}]}$ The Brønsted acidity of the HMOR zeolite played an important role in determining the ethanol production performance during syngas conversion. Modifying the HMOR zeolite with $\mathrm{Zn}$ cations to form $\mathrm{Zn}-\mathrm{HMOR}$ decreased the acid strength, thus helping to increase the ethanol selectivity to $69.5 \%$ with an increased CO conversion of $7.4 \%$. However, this tri-functional catalyst system suffered from low catalytic stability due to rapid deactivation of Zn-HMOR. Deactivation was ascribed to formation of bulkier hydrocarbons and coke on the Brønsted acid sites located in the 12-MR channels of HMOR. ${ }^{[44]}$ Pyridine modification to neutralize the Brønsted acid sites within these channels was proved to be an efficient method of enhancing catalyst stability during the DME carbonylation reaction. ${ }^{[44-45]}$ Thus, introduction of pyridine into Zn-HMOR effectively inhibited carbon deposition and further enhanced the catalytic stability of the zeolite-based catalyst system. ${ }^{[41 b]}$ Like the acid strength, the density of Brønsted acid sites also significantly affected catalytic performance and ethanol selectivity during syngas conversion. DME conversion and ethanol selectivity are claimed to have been enhanced by increasing the number of Brønsted acid sites. ${ }^{[46]}$ 
Furthermore, propanol could also be produced from syngas using this zeolite-based multifunctional catalyst system. Syngas was initially converted to methanol over a $\mathrm{Cu} / \mathrm{Zn} / \mathrm{Al}$-based catalyst and the methanol was then converted to propylene over an acidic ZSM-5 zeolite. Finally hydration of propylene into propanol occurred over sulfuric or phosphoric acids. ${ }^{[47]}$

\subsubsection{Stabilization Effect of Metallic Active Sites within Zeolites}

Metallic Rh- and Mo-based nanocatalysts are typically used for direct syngas conversion to ethanol. However, substantial decreases in activity and productivity typically occur during the reaction due to severe sintering of metallic species. Purely siliceous zeolites were recently found to be good supports for confinement synthesis of sinter-resistant metallic nanocatalysts. ${ }^{[48]}$ In addition to their nano-confinement effects, purely siliceous zeolite supports could stabilize unique catalytic sites for a specific reaction route inside a microenvironment. Based on this, Xiao and co-workers successfully encapsulated RhMn within silicalite-1 zeolites to form watermelon-like RhMn@silicalite-1 catalysts (Figure 5A-C). The resulting RhMn@silicalite-1 catalysts exhibited excellent performance during syngas conversion to ethanol, including a high selectivity of $88.3 \%$ in the total oxygenates with $\mathrm{CO}$ conversion of $42.4 \%$ (Figure 5D and E). ${ }^{[41 \mathrm{c}]}$ The $\mathrm{Mn}-\mathrm{O}-\mathrm{Rh}^{\delta+}$ structure was found to be the active sites that facilitate $\mathrm{C}-\mathrm{C}$ coupling needed for ethanol formation. The silicalite- 1 zeolite support maintained the oxidation states of Rh species even under reductive atmospheres, thus enabling good stabilization of the desired $\mathrm{Mn}-\mathrm{O}-\mathrm{Rh}^{\delta+}$ structure. During long-term catalytic processes, the RhMn@silicalite-1 catalyst exhibited excellent catalytic stability because the silicalite-1 zeolite framework effectively hindered $\mathrm{Rh}$ sintering and stabilized active Mn-O$\mathrm{Rh}^{\delta+}$ centers (Figure 5F).

\subsubsection{Effect of the Proximity between Brønsted Acid Sites and Metallic Species}

Careful design of each active site, including compatibility and proximity, is vital to directing the formation of target intermediates and enhancing the final ethanol selectivity. In this respect, a tri-functional catalyst system comprising potassium-modified $\mathrm{ZnO}-\mathrm{ZrO}_{2}, \mathrm{H}-$ 
MOR zeolite, and $\mathrm{Pt}-\mathrm{Sn} / \mathrm{SiC}$ separated by quartz wool accomplished efficient syngas conversion to produce ethanol with a selectivity as high as $90 \% .{ }^{[42 c]}$ In this tandem reaction, $\mathrm{K}^{+}-\mathrm{ZnO}-\mathrm{ZrO}_{2}$ was responsible for the initial syngas conversion into methanol intermediates, the H-MOR zeolite catalyzed methanol carbonylation to form acetic acid, and finally acetic acid was hydrogenated to ethanol at the $\mathrm{Pt}-\mathrm{Sn} / \mathrm{SiC}$ sites (Figure 6). When decreasing the amount of quartz wool such that it did not completely separate the catalyst layers and led to direct contact between granulated catalysts, the selectivity towards ethanol decreased and that towards ethylene increased. The ethanol formed over $\mathrm{Pt}-\mathrm{Sn} / \mathrm{SiC}$ sites can undergo dehydration to generate ethylene over H-MOR zeolite sites. This can be attributed to the increased proximity between the two active sites. Upon completely removing the quartz wool and mixing the three granular catalysts instead of maintaining a layered configuration, ethanol disappeared and $\mathrm{C}_{2}-\mathrm{C}_{4}$ olefins (particularly ethylene) were the major products; the $\mathrm{C}_{2}-\mathrm{C}_{4}$ selectivity was $80 \%$ and the ethylene selectivity was $55 \%$. Upon mixing these three powdered catalysts to achieve closer proximity, the selectivity towards ethylene reached $68 \%$. In this study, complete separation of the three catalytic sites was crucial to achieving efficient ethanol formation from syngas.

\section{3. $\mathrm{CO}_{2}$ Conversion over Zeolite-Based Catalysts}

The increasing amount of atmospheric $\mathrm{CO}_{2}$ originating from anthropogenic emissions is a serious concern worldwide, as it causes global warming and increased ocean acidity. However, $\mathrm{CO}_{2}$ can act as a non-traditional, renewable carbon source for production of value-added chemicals and fuels. Efficient $\mathrm{CO}_{2}$ conversion is crucial to alleviating the greenhouse effect and maintaining a sustainable environment, energy supply, and economy. While this is feasible using concentrated $\mathrm{CO}_{2}$ streams, it is more problematic when low-concentration $\mathrm{CO}_{2}$ is captured from the atmosphere.

Although $\mathrm{CO}_{2}$ is quite thermodynamically and chemically stable, its reactions are thermodynamically easier when $\mathrm{H}_{2}$ is introduced as a co-reactant. $\mathrm{CO}_{2}$ hydrogenation to 
hydrocarbons and oxygenates has recently attracted substantial attention and achieved significant success. ${ }^{[1,3 \mathrm{~b}, 49]}$ However, low $\mathrm{CO}_{2}$ conversion and selectivity toward target products remain challenges. In this section, we focus on recent progress in thermocatalytic and photocatalytic $\mathrm{CO}_{2}$ conversion over zeolite-based catalysts, with an emphasis on the influences of zeolite descriptors and proximity between active sites on catalytic performance. The properties of some representative zeolite-based catalysts and corresponding catalytic performances during production of hydrocarbons and oxygenates from $\mathrm{CO}_{2}$ are summarized in Table 3.

\section{1. $\mathrm{CO}_{2}$ Conversion to Hydrocarbons}

Thermolcatalytic $\mathrm{CO}_{2}$ conversion to hydrocarbons typically involves two pathways: the modified FT and methanol- and DME-mediated synthesis routes, which are distinguished by their intermediates. The modified FT synthesis comprises $\mathrm{CO}_{2}$ hydrogenation to $\mathrm{CO}$ intermediates via the reverse water-gas shift (RWGS) reaction [Equation (1)], ${ }^{[50]}$ followed by CO hydrogenation to hydrocarbons via FT synthesis [Equation (2)]. ${ }^{[1,51]}$ The methanol and DME-mediated synthesis routes are composed of $\mathrm{CO}_{2}$ conversion to methanol and DME intermediates that further undergo methanol- and DME-to-hydrocarbon processes. ${ }^{[52]}$

$$
\begin{aligned}
& \mathrm{CO}_{2}+\mathrm{H}_{2} \rightleftharpoons \mathrm{CO}+\mathrm{H}_{2} \mathrm{O}, \Delta \mathrm{H}_{25^{\circ} \mathrm{C}}=41.2 \mathrm{~kJ} \mathrm{~mol}^{-1} \\
& \mathrm{n} \mathrm{CO}+2 \mathrm{n} \mathrm{H}_{2} \rightleftharpoons \mathrm{C}_{\mathrm{n}} \mathrm{H}_{2 \mathrm{n}}+\mathrm{n} \mathrm{H}_{2} \mathrm{O}
\end{aligned}
$$

In this section, we focus primarily on the modified FT synthesis. The RWGS and FT reaction processes in modified FT synthesis can be achieved either via an indirect route in two separate reactors or via a direct route using a single reactor. The direct $\mathrm{CO}_{2}$ conversion route that occurs in one single reactor is more cost- and energy-efficient than the indirect route in which two different catalyst systems and specific reaction conditions are optimized independently. Therefore, we focus on recent advances in $\mathrm{CO}_{2}$ conversion over zeolite-based multi-functional catalysts via direct routes. These multi-functional catalysts comprise metallic active sites for RWGS reaction followed by FT reaction and zeolite acid sites for 
oligermerization, hydrocracking, and isomerization to improve the selectivity and quality of target hydrocarbons.

\subsubsection{Effect of the Zeolite Brønsted Acidity}

A proper Brønsted acidity helps to maximize the target hydrocarbon yield and improve $\mathrm{CO}_{2}$ conversion. A combination of sodium-modified $\mathrm{ZnFeO}_{\mathrm{x}}$ and hierarchical HZSM-5 zeolites accomplishes direct $\mathrm{CO}_{2}$ conversion to aromatics via $\mathrm{CO}_{2}$ hydrogenation to olefins over $\mathrm{ZnFeO}_{\mathrm{x}}$ sites, followed by olefin aromatization over Brønsted acid sites. ${ }^{[53]}$ Using this catalyst system, it is possible to achieve a high aromatic selectivity (75.6\%) and lower selectivity ( $\leq$ $20 \%$ ) towards $\mathrm{CO}$ and methane at a relatively high $\mathrm{CO}_{2}$ conversion of $41.2 \%$. The Brønsted acidity of the HZSM-5 catalyst determines the aromatic selectivity in such a tandem reaction. When the quantity of Brønsted acid sites increased from $9 \mu \mathrm{mol} \mathrm{g}{ }^{-1}$ to $294 \mu \mathrm{mol} \mathrm{g}{ }^{-1}$, the selectivity towards aromatics increased, while selectivities towards $\mathrm{C}_{2}-\mathrm{C}_{4}$ olefins and $\mathrm{C}_{5+}$ hydrocarbons decreased. However, further increasing the quantity of Brønsted acid sites beyond $294 \mu \mathrm{mol} \mathrm{g}^{-1}$ by decreasing the framework $\mathrm{Si} / \mathrm{Al}$ ratio reduced the aromatic selectivity and increased the selectivities towards $\mathrm{C}_{2}-\mathrm{C}_{4}$ olefins and $\mathrm{C}_{5+}$ hydrocarbons. This was claimed to have occurred because excessive Brønsted acid sites caused coke deposition that blocked the zeolite channels where olefin aromatization occurs. Similarly, controlling the Brønsted acid density of SAPO-34 zeolite allowed $\mathrm{In}_{2} \mathrm{O}_{3}-\mathrm{ZnZrO}_{\mathrm{x}} / \mathrm{SAPO}-34$ bi-functional catalysts to provide excellent $\mathrm{CO}_{2}$ conversion performance with high $\mathrm{C}_{2}-\mathrm{C}_{4}$ olefin selectivity (85\%) and low methane selectivity $(1 \%) .{ }^{[54]}$ Several groups have recently succeeded in increasing the $\mathrm{CO}_{2}$ conversion performance and providing high selectivity for a series of specific hydrocarbon products by tuning the Brønsted acidities of zeolite-based bi-functional catalysts. ${ }^{[54-55]}$

\subsubsection{Effect of the Zeolite Framework Topology}

Selection of a suitable zeolite topology for bi-functional catalysis is a promising method of shifting the $\mathrm{CO}_{2}$ conversion product distribution towards the desired hydrocarbon fractions. ${ }^{[56]}$ 
In a recent work, a bi-functional catalyst system that integrated $\mathrm{Fe}_{2} \mathrm{O}_{3} @ \mathrm{KO}_{2}$ and zeolites (ZSM-5 or mordenite) in a dual-bed configuration was used for $\mathrm{CO}_{2}$ conversion. This enabled a tandem reaction involving RWGS over $\mathrm{Fe}_{2} \mathrm{O}_{3} @ \mathrm{KO}_{2}$, followed by olefin or aromatic formation over zeolites. ${ }^{[56 a]}$ The addition of ZSM-5 (MFI) zeolites increased aromatic formation with high selectivity of $61.4 \%$ in the liquid fraction and decreased the formation of $\mathrm{C}_{2}-\mathrm{C}_{10}$ olefins with isobutane as the main by-product. In contrast, the addition of mordenite (MOR) zeolites dramatically shifted the product distribution towards ethylene and propylene. The different zeolite topologies may account for the difference in product distribution due to their different capabilities with regard to preferential stabilization of various carbenium ions. Compared with the 12-MR channels in MOR zeolite, the 10-MR channels in MFI zeolite afford a much better confinement effect in stabilizing small alkane intermediates. These stabilized alkenes are more easily activated into carbenium ions in MFI than in MOR channels. This allows them to proceed to conversion into aromatics. In addition, zeolite topologies can influence the characteristics of supported metallic species. For example, comparing FAU, MOR, MFI, and *BEA zeolites with the same compensating cations and Ni loading, as well as similar $\mathrm{Si} / \mathrm{Al}$ ratios, *BEA zeolites favor the formation of small $\mathrm{Ni}$ particles and good $\mathrm{Ni}$ dispersion, resulting in better performance with regard to methane production from $\mathrm{CO}_{2} \cdot{ }^{[56 \mathrm{~b}]}$ In general, topologies with constricted or closed regions inside, such as cages, can provide good stabilization and dispersion of metallic species against sintering. ${ }^{[57]}$ Zeolites have recently been regarded as outstanding support materials for loading of various metallic active sites, affording enhanced catalytic performances during $\mathrm{CO}_{2}$ conversion to hydrocarbons. ${ }^{[58]}$ Future efforts should be devoted to unraveling the evolution of active metallic species in nanoporous environments of different topologies. This is particularly important to the design of new, high-efficiency catalysts.

\subsubsection{Effect of the Proximity between Brønsted Acid Sites and Metallic Species}


An appropriate proximity between acid sites and metallic sites of zeolite-based catalysts can provide a synergistic effect when converting $\mathrm{CO}_{2}$ into liquid fuels. Significantly, a high selectivity of $78 \%$ towards gasoline products with only $4 \%$ methane at a $\mathrm{CO}_{2}$ conversion of $22 \%$ was obtained using a multi-functional catalyst system composed of three active components $\left(\mathrm{Fe}_{3} \mathrm{O}_{4}, \mathrm{Fe}_{5} \mathrm{C}_{2}\right.$, and HZSM-5 zeolite). ${ }^{[59]}$ This catalyst allowed a modified FT synthesis with a tandem reaction that involved the RWGS process to occur on $\mathrm{Fe}_{3} \mathrm{O}_{4}$ sites, formation of olefin intermediates took place on $\mathrm{Fe}_{5} \mathrm{C}_{2}$ sites, and finally oligomerization, aromatization, and isomerization of olefins occurred on zeolite Brønsted acid sites (Figure 7A). The proximity between Brønsted acid sites and metallic sites played an important role in this multi-step conversion from $\mathrm{CO}_{2}$ to gasoline. Powder mixing of $\mathrm{Na}-\mathrm{Fe}_{3} \mathrm{O}_{4}$ and $\mathrm{HZSM}-5$ catalysts provided the closest proximity between these two active sites, resulting in low $\mathrm{CO}_{2}$ conversion (13\%) and high selectivity towards undesired methane (60\%) (Figure 7B). This could be because the zeolite acid sites decrease the surface basicity and $\mathrm{Na}-\mathrm{Fe}_{3} \mathrm{O}_{4}$ catalyst carburization degree. Enlarging the distance between metallic and acid sites via granular mixing of $\mathrm{Na}-\mathrm{Fe}_{3} \mathrm{O}_{4}$ and $\mathrm{HZSM}-5$ led to the highest $\mathrm{C}_{5}-\mathrm{C}_{11}$ selectivity of $73 \%$ at a $\mathrm{CO}_{2}$ conversion of $34 \%$ (Figure 7B). In this case, olefin intermediates were formed on the metallic catalytic sites. They then diffused into the zeolite, where oligomerization, isomerization, and aromatization occurred. Upon further enlarging the distance between the active sites by separating $\mathrm{Na}-\mathrm{Fe}_{3} \mathrm{O}_{4}$ and $\mathrm{HZSM}-5$ in a dual-bed configuration, the selectivity towards $\mathrm{C}_{5}-\mathrm{C}_{11}$ decreased slightly (67\%) (Figure 7B). As demonstrated above, appropriate proximity between active catalytic sites is crucial to achieving superior performance during $\mathrm{CO}_{2}$ conversion into hydrocarbons. However, the opposite trend was observed for $\mathrm{CO}_{2}$ conversion via a methanolmediated route. ${ }^{[60]}$ When HZSM-5 catalyst was loaded below $\operatorname{In}_{2} \mathrm{O}_{3}$ and separated by quartz sand in a dual-bed configuration, methanol was formed over $\operatorname{In}_{2} \mathrm{O}_{3}$, diffused into zeolite channels, and converted into hydrocarbons on acid sites. This gave a $\mathrm{C}_{5+}$ hydrocarbon selectivity of $70.4 \%$ and methane selectivity of $4.5 \%$ (Figure 8). Furthermore, closer 
proximity between the two active sites was achieved via granular stacking of HZSM-5 and $\mathrm{In}_{2} \mathrm{O}_{3}$ without addition of quartz sand. This led to an even higher $\mathrm{C}_{5+}$ hydrocarbon selectivity of $78.6 \%$ as well as a particularly low methane selectivity of $1 \%$. It was thought that the closer proximity suppressed undesired RWGS process, resulting in an increased $\mathrm{C}_{5+}$ hydrocarbon selectivity and decreased methane selectivity. The above results demonstrate that the proximity between catalytic active sites significantly affects catalytic performance during $\mathrm{CO}_{2}$ conversion to hydrocarbons. However, this effect may work differently with different catalytic reaction pathways.

\subsubsection{Effects of the Extra-Framework Cations and Atoms}

The compensating cations that balance negative charges of aluminosilicate zeolite frameworks significantly affect the zeolite basicity, $\mathrm{CO}_{2}$ adsorption and activation, and particle sizes of loaded metallic species. Exchanging compensating cations into the zeolite may result in enhanced interaction between $\mathrm{CO}_{2}$ molecules and the zeolite framework, and consequently enhanced $\mathrm{CO}_{2}$ activation. A recent work showed that addition of monovalent $\left(\mathrm{Cs}^{+}, \mathrm{K}^{+}, \mathrm{Na}^{+}, \mathrm{Li}^{+}\right)$and divalent $\left(\mathrm{Ba}^{2+}, \mathrm{Ca}^{2+}, \mathrm{Mg}^{2+}\right)$ cations led to enhanced catalytic

performance during $\mathrm{CO}_{2}$ conversion into methane. The order of activity was $\mathrm{Cs}^{+}>\mathrm{Na}^{+}>\mathrm{Li}^{+}>$ $\mathrm{K}^{+}>\mathrm{H}^{+}$for monovalent cations and $\mathrm{Mg}^{2+}>\mathrm{Ca}^{2+}>\mathrm{Ba}^{2+}$ for divalent cations. ${ }^{[61]}$ Besides the improved $\mathrm{CO}_{2}$ activation, $\mathrm{Mg}^{2+}$ cations also contributed to improving the $\mathrm{Ni}$ dispersion and decreasing the Ni particle size. In addition, modification of zeolites using non-compensating species such as phosphorus can significantly affect aromatic formation during $\mathrm{CO}_{2}$ conversion. ${ }^{[62]}$ The incorporation of phosphorus into a Ga/ZSM-5 zeolite not only modified the zeolite acid strength, but also improved the hydrothermal stability of the Ga/ZSM-5 catalyst, thus increasing long-term stability, reducing coke formation, and enhancing the aromatic yield.

\subsubsection{Effects of the Zeolite Hydrophobicity and Hydrophilicity}


Zeolite hydrophobicity can significantly affect catalytic performance during $\mathrm{CO}_{2}$ conversion, in which water is inevitably involved. During conversion of $\mathrm{CO}_{2}$ into methane $\left(\mathrm{CO}_{2}+4 \mathrm{H}_{2} \rightleftharpoons \mathrm{CH}_{4}+2 \mathrm{H}_{2} \mathrm{O}\right)$, water is generated and results in some inhibitory influences: (1) water adsorbs to metallic sites and framework oxygens, blocking the active sites that are responsible for $\mathrm{CO}_{2}$ activation; ${ }^{[61,63]}$ and (2) water drives the reaction back towards $\mathrm{CO}_{2}$, as $\mathrm{CO}_{2}$ conversion to methane is a reversible reaction of which water is a product. ${ }^{[64]}$ To this end, several groups have proven that employing zeolites with enhanced hydrophobicity significantly contributes to lowering the affinity between zeolites and water. This consequently increases the catalytic performance during $\mathrm{CO}_{2}$ conversion into methane. ${ }^{[56 b, 65]}$

\subsubsection{Photocatalytic $\mathrm{CO}_{2}$ Conversion over Zeolite-Based Catalysts}

To date, most photocatalytic $\mathrm{CO}_{2}$ conversion processes have been based on traditional semiconductor catalysts such as $\mathrm{TiO}_{2}, \mathrm{CsPbBr}_{3}, \mathrm{CdS}$, etc. ${ }^{[66]}$ A new type of zeolite-based photocatalyst for $\mathrm{CO}_{2}$ conversion to methane was recently reported. ${ }^{[67]} \mathrm{Fe}-$ containing ZSM-5 zeolite was found to be photoactive during $\mathrm{CO}_{2}$ conversion to methane. ${ }^{[67 a]}$ Under UV-light irradiation, the $\left[\mathrm{Fe}^{3+}-\mathrm{O}^{2-}\right]$ species in the Fe-ZSM-5 zeolite were excited to $\left[\mathrm{Fe}^{2+}-\mathrm{O}^{-}\right]^{*}$. This photoactive site was responsible for $\mathrm{CO}_{2}$ activation. In addition, SAPO-5 nanosheets (approximately $3.0 \mathrm{~nm}$ in thickness) exhibited greatly enhanced photocatalytic activity during $\mathrm{CO}_{2}$ conversion to methane under $254 \mathrm{~nm}$ light irradiation. ${ }^{[67 \mathrm{~b}]}$ The $\left[\mathrm{Al}^{3+}-\mathrm{O}^{2-}\right]$ units were excited to $\left[\mathrm{Al}^{2+}-\mathrm{O}^{-}\right]^{*}$ under light irradiation, allowing them to act as photoactive sites. Similarly, Ti-containing microporous zeolites and mesoporous silica, such as Ti-MCM-41, TS-1, and Ti-MCM-48, exhibited photocatalytic activity during $\mathrm{CO}_{2}$ conversion into methane. ${ }^{[68]}$ Under UV light, the $\left[\mathrm{Ti}^{4+}-\mathrm{O}^{2-}\right]$ species were excited to $\left[\mathrm{Ti}^{3+}-\mathrm{O}^{-}\right]$, which acted as photoactive sites for $\mathrm{CO}_{2}$ conversion into methane. ${ }^{[68 \mathrm{a}]}$ Zeolite-based catalysts are emerging materials for photocatalytic $\mathrm{CO}_{2}$ conversion into lighter hydrocarbons. Further studies should be devoted to unraveling the mechanisms of such conversion processes. This may help 
researchers to understand the photocatalytic nature of zeolites and stimulate the development of zeolite material design for more efficient $\mathrm{CO}_{2}$ conversion via photocatalytic routes.

\section{2. $\mathrm{CO}_{2}$ Conversion to Oxygenates}

Catalytic hydrogenation of $\mathrm{CO}_{2}$ to high-value $\mathrm{C}_{1}$ and $\mathrm{C}_{2+}$ oxygenates including methanol, formic acid, high alcohols, acetic acid, and DME over zeolite-based catalysts has attracted substantial attention in recent years. In particular, effective catalytic transformation of $\mathrm{CO}_{2}$ into methanol, DME, and their derivates are important to the "methanol economy", and contributes to building a more sustainable world ${ }^{[69]}$ In these catalytic processes, the natures of zeolite catalysts are crucial to enhancing yields and selectivities toward methanol and DME during $\mathrm{CO}_{2}$ conversion. ${ }^{[70]}$

\subsubsection{Effect of the Zeolite Brønsted Acidity}

Catalytic production of DME from $\mathrm{CO}_{2}$ requires a bi-functional catalyst that works with a tandem process of methanol synthesis and methanol dehydration. Methanol dehydration relies heavily on the Brønsted acidity of the zeolite catalysts. Notice that, hydrocarbons can also be formed over Brønsted acid sites during $\mathrm{CO}_{2}$ conversion and the zeolite Brønsted acidity should be designed to shift the production distribution towards DME rather than hydrocarbons. It has been demonstrated that mild Brønsted acidity is responsible for enhancing the DME selectivity during $\mathrm{CO}_{2}$ conversion. In a recent work, the combination of methanol synthesis over a CuZnZr catalyst and methanol dehydration over a HZSM-5 zeolite was employed to produce DME from $\mathrm{CO}_{2}$. This combination provided a high $\mathrm{CO}_{2}$ conversion (24\%) and a high rate of methanol dehydration to DME. ${ }^{[71]}$ Similarly, in the bi-functional CuZnZr/ferrierite catalyst system, the rate of DME production was increased by optimizing the Brønsted acidity of ferrierite zeolite. ${ }^{[72]}$

\subsubsection{Effect of the Zeolite Framework Topology}

Several types of zeolites with various framework topologies have been evaluated for conversion of $\mathrm{CO}_{2}$ into DME and methanol products. ${ }^{[73]}$ In a recent work, CuZnZr catalyst 
(CZZ) was combined with zeolites with three different topologies (MOR, FER, and MFI) for $\mathrm{CO}_{2}$ hydrogenation to DME. ${ }^{[74]}$ The $\mathrm{Cu}$ species metal loading $(48 \%-56 \%)$ and particle sizes $(8 \mathrm{~nm}-9 \mathrm{~nm})$ of these three catalysts were equivalent. When the results were compared, CZZMOR and CZZ-MFI bi-functional catalysts provided DME and methanol selectivities of $62 \%$ and $53.4 \%$, respectively, at a conversion of nearly $20 \%$. Meanwhile, the CZZ-FER catalyst showed a higher selectivity of $70 \%$ toward DME and methanol at $28 \% \mathrm{CO}_{2}$ conversion at $280{ }^{\circ} \mathrm{C}$. This is because the FER zeolite provided a better metallic dispersion and more Lewis base sites for $\mathrm{CO}_{2}$ activation, as well as more available Brønsted acid sites for the methanolto-DME dehydration process.

\subsubsection{Effect of the Proximity between Brønsted Acid Sites and Metallic Species}

During $\mathrm{CO}_{2}$ conversion to DME, the metallic catalysts used for methanol synthesis and zeolites used for methanol dehydration are combined via either physical mixing or integrated fabrication. The proximity between metallic species and zeolite catalysts must be carefully designed to increase the DME production from $\mathrm{CO}_{2}$. This can not only allow fast diffusion of methanol to acid sites for further dehydration, but also prevent metallic sites from being poisoned by generated water. An integrated bi-functional catalyst enables the tandem reaction over distinct catalytic sites sitting in a proper proximity and significantly promotes DME production during $\mathrm{CO}_{2}$ conversion. For instance, a core-shell structure $(\mathrm{CZZr} @ \mathrm{~S}-11)$ with the $\mathrm{CuO}-\mathrm{ZnO}-\mathrm{ZrO}_{2}$ catalyst as the core and the SAPO-11 zeolite as the shell exhibited better performance when producing DME from $\mathrm{CO}_{2}$ than a $\mathrm{CZZr} / \mathrm{S}-11$ catalyst prepared via physical mixing. ${ }^{[73 b]}$ The better performance of the CZZr@S-11 catalyst was attributed to the "separation" of methanol synthesis (on metallic core sites) from methanol dehydration (on zeolite shell sites) in the core-shell structure. This prevented the metallic sites from being poisoned by water formed in the zeolites. Furthermore, methanol dehydration was facilitated in this core-shell structure because of the relatively close proximity between metallic and acid sites. This ensured an efficient methanol-to-DME process. 


\subsubsection{Effects of the Zeolite Hydrophobicity and Hydrophilicity}

In addition to controlling the proximity between acid and metallic active sites, another effective method of reducing water diffusion during $\mathrm{CO}_{2}$ hydrogenation to DME is modulation of zeolite hydrophobic and hydrophilic properties. To this end, designing a suitable zeolite framework $\mathrm{Si} / \mathrm{Al}$ ratio that provides the best compromise between acid catalytic activity for methanol dehydration and resistance to deactivation by water is important to enhancing zeolite-based catalyst performance and stability during $\mathrm{CO}_{2}$ conversion to DME. In a recent work, a ZSM-5 zeolite with increased hydrophobicity was obtained by increasing its $\mathrm{Si} / \mathrm{Al}$ ratio, exhibiting enhanced DME production at a high $\mathrm{CO}_{2}$ conversion of $24 \%$ in a CuZnZr-zeolite catalyst system. ${ }^{[71]}$

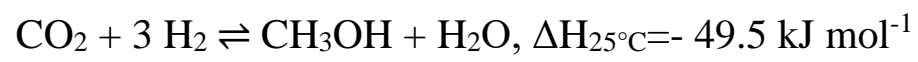

Water is generated as a by-product of $\mathrm{CO}_{2}$ hydrogenation to methanol, as shown in Equation (3). ${ }^{[75]}$ Moreover, the RWGS reaction [Equation (1)] competes with methanol synthesis and also forms water. This water has negative thermodynamic and kinetic effects on $\mathrm{CO}_{2}$ hydrogenation to methanol. ${ }^{[76]}$ Given such background, $\mathrm{Na}^{+}$-gated water-conduction channels were developed by designing a defect-free NaA zeolite separation membrane (Figure 9A-C). In-situ water removal by the water-conduction membrane (WCM) afforded high $\mathrm{CO}_{2}$ conversion and efficient production of methanol from $\mathrm{CO}_{2}{ }^{[77]}$ The hydrophilic zeolite A enabled the facile adsorption of generated water. After the $\mathrm{CO}_{2}, \mathrm{H}_{2}$, water, and methanol molecules entered the zeolite channels, compensating $\mathrm{Na}^{+}$ions facilitated the passage of small, polar water molecules but hindered the passage of molecules that were less polar or larger, such as $\mathrm{H}_{2}$ and $\mathrm{CO}_{2}$, through the zeolitic micro-channels (Figure 9B). Much faster transport of water molecules throughout the zeolitic WCM led to a high $\mathrm{CO}_{2}$ conversion of $61.4 \%$ and methanol yield of $38.9 \%$ over loaded copper-zinc-alumina catalysts. Both of these performances were 3.0 times those achieved without the WCM (Figure 9D-E). Adsorption of water onto metallic sites was substantially inhibited by the presence of a 
zeolitic WCM, affording higher catalyst system stability. Furthermore, a particularly highpurity methanol product ( $\sim 95 \%$ concentration) could be directly gathered due to in-situ water removal by the zeolitic WCM. Such zeolitic WCM-based material designs may boost other C1 chemistry catalytic reactions that are thermodynamically or kinetically restricted by water molecules, such as FT synthesis.

\section{4. $\mathrm{CH}_{4}$ Conversion over Zeolite-Based Catalysts}

$\mathrm{CH}_{4}$, a member of $\mathrm{C} 1$ molecules, is of great importance as a feedstock for energy generation and chemical production. More importantly, $\mathrm{CH}_{4}$ is an earth-abundant gas that can be easily obtained from large reserves of natural gas, shale gas, coalbed methane, and methane hydrate, as shown in Figure 10. ${ }^{[78]}$ However, the use of $\mathrm{CH}_{4}$ suffers from penalties associated with the fact that the reserves tend to be in depopulated areas and must be transported over long distances. Thus, $\mathrm{CH}_{4}$ conversion into transportable, high-value chemicals is particularly important to efficient $\mathrm{CH}_{4}$ utilization. Currently, there are two approaches to produce high-value chemicals from $\mathrm{CH}_{4}$, namely, the indirect and direct routes (Figure 10). The indirect route is a two-step process that involves high-cost production of syngas via $\mathrm{CH}_{4}$ reforming, followed by syngas conversion via FT synthesis or methanol conversion. Reforming of $\mathrm{CH}_{4}$ proceeds at a high temperature (around $800{ }^{\circ} \mathrm{C}$ ) and high pressures (around 300 bar), and is thus energy-intensive. ${ }^{[4 c, 79]}$ Thus, a direct, low-cost system for conversion of $\mathrm{CH}_{4}$ that avoid using a syngas intermediate would help to meet increasing energy and chemical demands. Numerous efforts have been dedicated to developing direct catalytic conversion of $\mathrm{CH}_{4}$ to make olefins, aromatics, methanol, DME, formic acid, and acetic acid. ${ }^{[3 c, 5 f, 79 b, 80]}$ However, the key challenge still lies in control of product selectivity. The difficulty of this challenge is attributed to the fact that all hydrocarbon and oxygenate intermediates and products are more reactive than $\mathrm{CH}_{4}$. Metal-containing zeolites, which combine the advantages of metallic species and zeolites, have proven to be good catalysts with regard to inducing $\mathrm{CH}_{4}$ activation and suppressing over-oxidation and cracking of target 
products. This section will summarize recent advances in the use of zeolite-based catalysts for direct conversion of $\mathrm{CH}_{4}$ into methanol and aromatics. The effects of zeolite descriptors on catalytic performance will be reviewed, with a focus on emphasizing the indispensable role of zeolites in direct $\mathrm{CH}_{4}$ conversion. The properties of some representative zeolite-based catalysts and corresponding catalytic performances during $\mathrm{CH}_{4}$ conversion to methanol and aromatics are summarized in Table 4.

\subsection{Direct $\mathrm{CH}_{4}$ Conversion to Methanol}

Methanol is a significantly important chemical feedstock for hydrogen, DME, formaldehyde, light olefin, and gasoline production. ${ }^{[81]}$ Direct partial oxidation of $\mathrm{CH}_{4}$ to methanol using metal-containing zeolite catalysts at low temperatures and with the aid of oxidants $\left(\mathrm{O}_{2}, \mathrm{~N}_{2} \mathrm{O}\right.$, or $\left.\mathrm{H}_{2} \mathrm{O}_{2}\right)$ is considered to be the most viable pathway towards enhancing the methanol economy. ${ }^{[69]}$ The key challenges for such processes are activation of stable C-H bonds in $\mathrm{CH}_{4}$ and suppression of over-oxidation of methanol product into $\mathrm{CO}_{2}$. This is because methanol possesses weaker $\mathrm{C}-\mathrm{H}$ bonds than $\mathrm{CH}_{4}$ and therefore is easily over-oxidized. Metal-containing zeolites can provide a balance between facilitating $\mathrm{CH}_{4}$ activation and simultaneously inhibiting methanol oxidation, which mimics facile enzyme-catalyzed oxidation of $\mathrm{CH}_{4}$ (Figure 11A). ${ }^{[69,80 b, 82]}$ Among the Fe-, Cu-, Zn-, Ni-, Co-, and Mncontaining zeolite catalysts, $\mathrm{Fe}$ - and $\mathrm{Cu}$-containing zeolites are two typical, commonly reported catalysts used for partial oxidation of $\mathrm{CH}_{4}$ to methanol, and are the focus of these paragraphs. Direct conversion of $\mathrm{CH}_{4}$ to methanol over a metal-containing zeolite catalyst can be achieved via continuous or stepwise processes. The stepwise process is more commonly employed than the continuous process because of its higher methanol yield and selectivity. It has the following three steps: (1) activation of metal-containing zeolite catalysts in an oxidative atmosphere at $200{ }^{\circ} \mathrm{C}-450{ }^{\circ} \mathrm{C}$; (2) $\mathrm{CH}_{4}$ conversion over activated metal-containing zeolite catalysts at $25{ }^{\circ} \mathrm{C}-200{ }^{\circ} \mathrm{C}$, which involves $\mathrm{CH}_{4}$ activation and methanol formation; and 
(3) extraction of methanol from metal-containing zeolite catalysts using a solvent such as water under ambient conditions (Figure 11B). ${ }^{[80 c, d]}$

\subsubsection{Effect of the Zeolite Framework Si/Al Ratio (Brønsted Acidity)}

The activation energy of $\mathrm{C}-\mathrm{H}$ bond dissociation of $\mathrm{CH}_{4}$ is crucial to $\mathrm{CH}_{4}$ conversion. It is affected by zeolite-stabilized active sites, such as mono-, di-, and tri-nuclear metallic species, and even nanosized metal oxide particles. ${ }^{[83]}$ The quantity and location of aluminum in the zeolite framework are of great importance to determine the distributions and sizes of anchored metallic species. Generally, lowering the framework $\mathrm{Si} / \mathrm{Al}$ ratio enhances the ion-exchange capacity. This consequently increases the methanol yield due to an increase in the number of catalytic metallic sites available for $\mathrm{CH}_{4}$ activation. Furthermore, a high framework Si/Al ratio favors generation of mononuclear metal sites, while a low framework $\mathrm{Si} / \mathrm{Al}$ ratio is more likely to stabilize multi-nuclear metallic species or large clusters. ${ }^{[84]}$ Highly dispersed framework $\mathrm{Al}$ atoms in zeolites typically contribute to the generation of highly dispersed metallic sites with monomeric states, while $\mathrm{Al}$ atoms sitting in close proximity favor multinuclear metallic species or even metal oxide particles. A recent work showed that an optimum $\mathrm{Si} / \mathrm{Al}$ ratio that endowed a zeolite with a good dispersion of framework $\mathrm{Al}$ atoms, as well as active di-nuclear $\mathrm{Cu}$ species of $\mathrm{Cu}-\mathrm{MOR}$ zeolite catalysts, gave an ultrahigh methanol yield per $\mathrm{Cu}$ of $0.47 \mathrm{~mol} \mathrm{~mol}^{-1}$ during $\mathrm{CH}_{4}$ conversion. ${ }^{[85]}$ The synthetic strategy significantly affected the locations of $\mathrm{Al}$ sites in aluminosilicate zeolites, and consequently determined the distribution of active metallic sites and their catalytic performance during $\mathrm{CH}_{4}$ conversion to methanol. However, the active species for the $\mathrm{CH}_{4}$ conversion to methanol remain in debates. ${ }^{[86]}$ In addition to anchoring metallic active sites, Brønsted acid sites also contribute to stabilization of the methanol product, thus protecting them from over-oxidation to formate or CO. This finally leads to an enhanced methanol selectivity during $\mathrm{CH}_{4}$ conversion. ${ }^{\text {[87] }}$ In particular, Brønsted acid sites play a significant role when CO molecules are involved during $\mathrm{CH}_{4}$ conversion over a $\mathrm{Cu}$-mordenite zeolite catalyst system. ${ }^{[88]}$ Methanol was generated as 
the main product from $\mathrm{CH}_{4}$ conversion using a $\mathrm{Cu}-\mathrm{Na}$-mordenite catalyst. In contrast, more acetic acid was produced when a $\mathrm{Cu}-\mathrm{H}$-mordenite catalyst with additional Brønsted acid sites was used. The oxidation reaction over metallic sites was coupled with the carbonylation reaction over Brønsted acid sites. The tunable Brønsted acid sites afford a good control with regard to modulating the product selectivity towards methanol or acetic acid. Similarly, the production of methanol and acetic acid could be tuned by modulating the zeolite Brønsted acidity in the Rh@ZSM-5 catalyst system, where single Rh atoms are encapsulated within zeolite micropores. ${ }^{[89]} \mathrm{CH}_{4}$ was initially activated over $\mathrm{Rh}$ sites to form $\mathrm{Rh}-\mathrm{CH}_{3}$ species. Most of these generated $\mathrm{Rh}-\mathrm{CH}_{3}$ then underwent oxygen insertion to form methanol over the Rh@Na-ZSM-5 catalyst or CO insertion to form acetic acid over the Rh@H-ZSM-5 catalyst with additional Brønsted acid sites.

\subsubsection{Effect of the Zeolite Framework Topology}

Selecting a suitable zeolite topology for supporting metallic active sites is crucial to obtaining a high methanol yield during $\mathrm{CH}_{4}$ conversion. Various micro-environments within different topologies are responsible for stabilization of various metallic active sites. Compared to medium- and large-pore zeolites, small-pore zeolites provide good confinement of methane molecules and metallic catalytic species, leading to enhanced catalytic performance during $\mathrm{CH}_{4}$ conversion to methanol. Lobo and co-workers reported that $\mathrm{Cu}$-containing zeolites with small-pore structures, such as SSZ-13 (CHA), SSZ-16 (AFX), and SSZ-39 (AEI), produced more methanol per $\mathrm{Cu}$ atom site (more than $0.05 \mathrm{~mol} \mathrm{~mol}^{-1}$ ) than $\mathrm{Cu}$-containing zeolites with medium-pore ZSM-5 (MFI) and large-pore mordenite (MOR) (less than $\left.0.04 \mathrm{~mol} \mathrm{~mol}^{-1}\right){ }^{[90]}$ Similarly, Bokhoven and co-workers prepared $\mathrm{Cu}$-containing zeolites with 12 different zeolite framework topologies (CHA, MFI, HEU, SZR, FER, MOR, MEI, MAZ, LTL, BPH, EON, and FAU) and studied their catalytic performances during direct $\mathrm{CH}_{4}$ conversion to methanol. ${ }^{[91]}$ Zeolites with 8 -MR pore structures were more effective than 10 - or 12-MR pore systems in increasing catalytic $\mathrm{CH}_{4}$ conversion to methanol. To elucidate the nature of such 
superior catalytic performance, a recent theoretical analysis of $\mathrm{Cu}$-zeolites with small-pore structures such as SSZ-13, SSZ-16, and SSZ-39 during direct conversion of $\mathrm{CH}_{4}$ to methanol was performed (Figure 12A-H). ${ }^{[92]}$ Density functional theory (DFT) calculations indicated that di-nuclear $\left[\mathrm{Cu}_{2}(\mu-\mathrm{O})\right]^{2+}$ sites stabilized inside small-pore zeolites (SSZ-13, SSZ-16, and SSZ-39) afforded lower activation energies for $\mathrm{C}-\mathrm{H}$ bond dissociation of $\mathrm{CH}_{4}$ than $\left[\mathrm{Cu}_{2}(\mu-\right.$ O) $]^{2+}$ stabilized in medium-pore (ZSM-5) and large-pore zeolites (mordenite) (Figure 12IL). ${ }^{[92]}$ Moreover, methanol desorption over the $\left[\mathrm{Cu}_{2}(\mu-\mathrm{O})\right]^{2+}$-AEI zeolite required lower barriers, endowing the $\left[\mathrm{Cu}^{2}(\mu-\mathrm{O})\right]^{2+}$-AEI zeolite catalyst with superior performance during direct $\mathrm{CH}_{4}$ conversion to methanol. In addition, zeolites that featured cage-based structures such as SSZ-13 and SAPO-34 with CHA topology could afford spatial confinement and close contact between substrates and catalytic active sites. They provided better performance than the MFI, FER, and BEA topologies during methanol production from $\mathrm{CH}_{4}{ }^{[93]}$ In recent years, $\mathrm{Fe}-, \mathrm{Cu}-$, and other metal-containing zeolites with various framework topologies including LTL,${ }^{[91]}$ EON,${ }^{[91]}$ MEI,${ }^{[91]}$ BPH,${ }^{[91]}$ HEU,${ }^{[91]}$ SZR,${ }^{[91]}$ FAU,${ }^{[91]}$ AFX,${ }^{[92]}$ MFI,${ }^{[94]}$ MOR,${ }^{[95]}$ FER, ${ }^{[96]}$ BEA,${ }^{[96 a, 97]}$ CHA, ${ }^{[98]}$ MAZ,${ }^{[99]} \mathbf{A E I}^{[100]}$, and ERI ${ }^{[101]}$ have been studied for direct $\mathrm{CH}_{4}$ conversion to methanol. ${ }^{[102]}$ Within these zeolite framework topologies, various active metal sites including mono-, di-, and tri-nuclear metal species and sub-nanometer metal oxide clusters have been proposed and significantly affect the $\mathrm{CH}_{4}$ activation barrier and methanol selectivity. Three key metal-containing zeolite parameters contribute to high methanol yields and superior catalytic stability during direct $\mathrm{CH}_{4}$ oxidation: (1) a high content of active metallic sites with low nuclearity, such as mono-, di-, and tri-nuclear active species; (2) highly dispersed active metallic sites that prevent aggregation of isolated metallic species to form larger clusters; and (3) stabilization of active metallic sites within a constricted region of the zeolite, leading to close contact between substrates and catalytic active sites. Although the active site structures in metal-containing zeolites have been proposed for direct oxidation of $\mathrm{CH}_{4}$ to methanol, the related reaction mechanisms and identification of these active sites 
within zeolites remain controversial. Further computational and experimental verification of active sites and exact reaction mechanisms is highly desired, which can help to improve researchers' understanding of $\mathrm{CH}_{4}$ conversion over metal-containing zeolite catalysts.

\subsubsection{Effect of the Proximity between Brønsted Acid Sites and Metallic Species}

In metal-containing zeolite catalysts, the quantity of zeolite Brønsted acid sites can be controlled easily via the ion-exchange. When the zeolites are not fully exchanged with cations, Brønsted acid sites are retained in close proximity to metallic sites. Recently, the effect of the proximity between Brønsted acid sites and $\mathrm{Zn}$ species in $\mathrm{Zn}$-containing zeolite catalysts on $\mathrm{CH}_{4}$ conversion was studied via ${ }^{1} \mathrm{H}_{-}{ }^{67} \mathrm{Zn}$ double-resonance solid-state NMR spectroscopy. ${ }^{[103]}$ In this study, close proximity between Brønsted acid sites and Zn species was achieved via incipient wetness impregnation of parent H-ZSM-5 (ZSM-5(16)). Decreased proximity was obtained by physically mixing zinc oxide with H-ZSM-5 zeolite (ZSM-5(G2)). In-situ monitoring of the methane H/D exchange reaction via solid-state NMR spectroscopy was performed to evaluate the activities of Zn-containing zeolites. ZSM-5(16) provided closer spatial proximity (distance of $2.70 \AA-3.34 \AA$ ) between Brønsted acidic protons and $\mathrm{Zn}^{2+}$ sites than ZSM-5(G2), generating a synergistic effect that promoted $\mathrm{C}-\mathrm{H}$ bond activation in $\mathrm{CH}_{4}$, This was a decisive factor in achieving an enhanced methanol yield during $\mathrm{CH}_{4}$ conversion.

\subsubsection{Effects of Zeolite Hydrophobicity and Hydrophilicity}

Zeolite modification for enhanced hydrophobicity or hydrophilicity is an efficient method of adjusting the adsorption and desorption behaviors of reactants and products, which is a crucial step in regulating the reaction pathways. $\mathrm{H}_{2} \mathrm{O}_{2}$ is an important oxidizing agent that performs direct partial oxidation of $\mathrm{CH}_{4}$ during its conversion to methanol. Recently, in-situ $\mathrm{H}_{2} \mathrm{O}_{2}$ formation from hydrogen and oxygen over metallic nanocatalysts was found to be a feasible method of performing partial oxidation of $\mathrm{CH}_{4}{ }^{[104]}$ However, these reported work using in-situ formed $\mathrm{H}_{2} \mathrm{O}_{2}$ as an oxidizing agent resulted in lower methanol productivity than the catalytic systems in which $\mathrm{H}_{2} \mathrm{O}_{2}$ was added directly. This may be ascribed to slow in-situ 
generation of $\mathrm{H}_{2} \mathrm{O}_{2}$ from $\mathrm{H}_{2}$ and $\mathrm{O}_{2}$ and fast $\mathrm{H}_{2} \mathrm{O}_{2}$ diffusion away from metallic active sites. Thus, the $\mathrm{H}_{2} \mathrm{O}_{2}$ concentration available for methanol production was relatively low. ${ }^{[105]}$ Given this background, Xiao and co-workers successfully enhanced methanol productivity from $\mathrm{CH}_{4}$ using in-situ formed $\mathrm{H}_{2} \mathrm{O}_{2}$ at $70{ }^{\circ} \mathrm{C}$ in a designed zeolite-based catalyst system (Figure 13). ${ }^{[106]}$ The catalyst was fabricated via encapsulation of AuPd alloy nanoparticles within a ZSM-5 zeolite (denoted as AuPd@ZSM-5), followed by modification of the ZSM-5 zeolite surface with organosilane shells that made the zeolite external surface more hydrophobic (denoted as AuPd@ZSM-5- $\mathrm{C}_{16}$ ). The hydrophobic sheath worked as a molecular fence that allowed hydrophobic $\mathrm{CH}_{4}$ molecules to enter the zeolites but prevented in-situ formed hydrophilic $\mathrm{H}_{2} \mathrm{O}_{2}$ from diffusing away. This led to a high concentration of $\mathrm{H}_{2} \mathrm{O}_{2}$ within the zeolite crystal and consequently enhanced the catalytic performance. The methanol selectivity reached $92 \%$ at $17.3 \%$ conversion of $\mathrm{CH}_{4}$ and methanol productivity was $645.1 \mathrm{mmol} \mathrm{g}_{\mathrm{AuPd}}{ }^{-1}$ $\mathrm{h}^{-1}$. In contrast, the AuPd@ZSM-5 catalyst without hydrophobic shells exhibited a low $\mathrm{CH}_{4}$ conversion of $6.3 \%$ and methanol productivity of $210.9 \mathrm{mmol}_{\mathrm{AuPd}^{-1}} \mathrm{~h}^{-1}$.

\subsubsection{Photocatalytic $\mathrm{CH}_{4}$ Conversion over Zeolite-Based Catalysts}

Incorporation of heteroatoms into the zeolite framework or extra-framework can endow zeolites with photoactivity, making them into photocatalysts that can convert $\mathrm{CH}_{4}$ into hydrocarbons. ${ }^{[67 \mathrm{~b}, 68,107]}$ Recently, several groups reported that $\mathrm{CH}_{4}$ conversion to methanol could be achieved over zeolite-based photocatalysts via a photocatalytic pathway. Upon photoirradiation, both zeolite silanol groups and metallic species were active sites for $\mathrm{CH}_{4}$ conversion. ${ }^{[108]}$ In a pure zeolite photocatalyst system, Beta zeolite (with abundant internal silanol groups) catalyzed the room-temperature transformation of $\mathrm{CH}_{4}$ into methanol under deep UV irradiation $(\lambda<200 \mathrm{~nm}) .{ }^{[108 \mathrm{~b}]}$ When Beta zeolites were subjected to deep UV irradiation, silyloxyl radicals $(\mathrm{Si}-\mathrm{O} \bullet$ ) were formed via homolytic cleavage of silanol $\mathrm{O}-\mathrm{H}$ bonds. This was responsible for $\mathrm{CH}_{4}$ activation that formed methyl radicals. Furthermore, in metal-containing photocatalyst systems such as $\mathrm{Bi}$ - and V-containing Beta zeolites, a 
synergistic effect between the zeolite and metallic species afforded enhanced activity and methanol selectivity during the photocatalytic partial oxidation of $\mathrm{CH}_{4} \cdot{ }^{[108 c]}$

\subsection{Direct $\mathrm{CH}_{4}$ Conversion to Aromatics}

Aromatics are important building block chemicals for the industrial fabrication of cosmetics, detergents, and polymers. ${ }^{[5 f]}$ Direct conversion of $\mathrm{CH}_{4}$ to aromatics using metalcontaining zeolite catalysts is stimulated by the increasing demand for chemicals and large reserves of methane. Non-oxidative methane dehydroaromatization (MDA) over zeolite-based catalysts is a promising route for practical $\mathrm{CH}_{4}$ valorization. In general, MDA catalysts require a combination of metallic sites (mainly Mo species) for non-oxidative $\mathrm{CH}_{4}$ activation and acidic zeolites for aromatic formation. Although the formation mechanism of the first C$\mathrm{C}$ bond has not yet been evidenced experimentally and the active site structure remains unclear, it is generally accepted that oligomerization and cyclization of $\mathrm{C}_{2} \mathrm{H}_{\mathrm{x}}$ intermediates into aromatics occur on zeolite Brønsted acid sites. ${ }^{[109]}$ The zeolite topology, Brønsted acidity, types of metallic species anchored by Brønsted acid sites, and synergies from the combination of Brønsted acid and metallic sites significantly affect the catalytic MDA performance. ${ }^{[110]}$

\subsubsection{Effect of the Zeolite Brønsted Acidity}

In MDA processes over metal-containing zeolite catalysts, the zeolite Brønsted acidity is crucial in affecting both the transition state configuration and the activation barriers of $\mathrm{CH}_{4}$ dehydrogenation process. ${ }^{[11]} \mathrm{CH}_{4}$ activation and conversion are further enhanced upon loading of metallic Mo species into zeolites. However, coke deposition during oligomerization and cyclization of $\mathrm{C}_{2} \mathrm{H}_{\mathrm{x}}$ to aromatics over Brønsted acid sites often occurs, causing rapid deactivation of the Mo-containing zeolite catalysts. ${ }^{[109,112]}$ A proper Brønsted acidity that might endow catalysts with both high activities and coke-resistant properties should be considered for the MDA reaction. Partial exchange of $\mathrm{H}^{+}$within Mo-containing zeolite catalysts with alkali cations such as $\mathrm{Na}^{+}$and $\mathrm{Cs}^{+}$has proven to be an effective way to tune the densities and strengths of zeolite Brønsted acid sites, leading to the formation of Mo- 
containing zeolite catalysts with improved catalytic activities, product selectivities, and longterm stabilities in MDA reaction conditions. ${ }^{[113]}$ On the other hand, since the metallic active species are anchored to the Brønsted acid sites, the acid density strongly influences the distributions and sizes of metallic active species. Increasing the number of Brønsted acid sites (i.e., providing a low framework $\mathrm{Si} / \mathrm{Al}$ ratio) can promote increased dispersion of isolated monomeric Mo species, resulting in enhanced $\mathrm{CH}_{4}$ conversion and aromatic production while suppressing coke deposition. ${ }^{[114]}$ Monomeric Mo species located in zeolite channels have been identified as the most active catalytic sites for MDA process. ${ }^{[115]}$ In contrast, decreasing the number of Brønsted acid sites can cause formation of larger metallic clusters and migration or agglomeration of metallic species onto zeolite surfaces. This generally decreases the catalytic performance during $\mathrm{CH}_{4}$ conversion to aromatics.

\subsubsection{Effect of the Zeolite Framework Topology}

Zeolites with distinct framework topologies such as MCM-22 (MWW), ZSM-5 (MFI), IM-5 (IMF), and ZSM-11 (MEL) have been studied for MDA process. ${ }^{[109 a, 110 b, 116]}$ For instance, MCM-22-supported Mo catalysts outperforms ZSM-5-supported Mo catalysts during MDA in terms of catalytic stability and benzene yield. ${ }^{[16 c]}$ This is attributed to the unique topology of MCM-22 and the homogeneous distribution of the Mo species loaded on the MCM-22 support. Both ZSM-5 and MCM-22 feature 2D 10-MR channel systems, making them good supports for active Mo species during MDA because of the close similarity between their pore diameters and the kinetic diameter of a benzene molecule (approximately $6.0 \AA)^{[109 a]}$ Specially, MCM-22 possesses a unique pore architecture, namely, a 3D 12-MR super-cage system $(7.1 \AA \times 7.1 \AA$ × $18.4 \AA)$ interconnected by 10 -MR windows. Compared to the structure of ZSM-5, such super-cages in MCM-22 afford a large ability to accommodate coke deposition while retaining the ability to catalyze aromatic formation from $\mathrm{CH}_{4}$.

\subsubsection{Effects of the Zeolite Secondary-Pore System and Particle Size}


Besides tuning the Brønsted acidity of zeolites, another strategy for increasing the stabilities of metal-containing zeolite catalysts is to incorporate secondary pore systems into zeolites or decrease zeolite particle sizes. To this end, hierarchical or nanosized zeolites with shortened diffusion path length can effectively reduce coke formation and consequently enhance MDA catalytic performance. Several groups found that fabrication of hollow Mo/HZSM-5 catalysts could facilitate mass transfer, efficiently improving $\mathrm{CH}_{4}$ conversion, aromatic selectivity, and catalytic stability. ${ }^{[117]}$ For instance, Tsubaki and co-workers developed Mo/silicalite-1@ZSM-5 zeolite catalysts with hollow capsule structures. These catalysts exhibited significantly enhanced $\mathrm{CH}_{4}$ conversion and benzene production rates, alongside decreased carbon deposition. ${ }^{[117 a]}$ Similarly, enhanced MDA catalytic performance was noted when using hollow Mo/HZSM-5 catalysts. Such a hollow ZSM-5 structure significantly affected the coke distribution. Coke was favored to deposit on internal, rather than external, zeolites surfaces. External coke caused more severe deactivation than internal coke because the former severely blocked the pore mouths and consequently hindered the reaction. This phenomenon was responsible for the superior catalytic stability of such hollow Mo/HZSM-5 catalysts during MDA process. ${ }^{[117 b]}$

\section{$5 \mathrm{CH}_{3} \mathrm{OH}$ Conversion over Zeolite-Based Catalysts}

\subsection{Industrialization of $\mathrm{CH}_{3} \mathrm{OH}$ Conversion}

$\mathrm{CH}_{3} \mathrm{OH}$, a convenient liquid fuel and raw material, can be easily obtained via conversion of syngas, direct partial oxidation of $\mathrm{CH}_{4}$, or hydrogenation of atmospheric $\mathrm{CO}_{2}$ with hydrogen as described above. $\mathrm{CH}_{3} \mathrm{OH}$ conversion provides a promising strategy for energy storage, to overcome petroleum depletion, and to satisfy growing chemical needs. This makes $\mathrm{CH}_{3} \mathrm{OH}$ a good carbon source for reducing oil and gas utilization and makes a "methanol economy" possible. ${ }^{[69]}$ Furthermore, $\mathrm{CH}_{3} \mathrm{OH}$ conversion to olefins (MTO), aromatics (MTA), gasoline (MTG), and DME over zeolite catalysts are significant $\mathrm{C} 1$ chemistry processes that provide alternative methods of producing high-value chemicals from non-petroleum resources. 
In 2010, the world's first commercial MTO plant on the basis of SAPO-34 catalyst with a production capacity of million tons of light olefins (ethylene and propylene) per year was constructed by the Dalian Institute of Chemical Physics (DICP) (named DMTO technology). ${ }^{[118]}$ DICP subsequently developed DMTO-II and DMTO-III technologies, further improving the olefin yield and production capacity. Simultaneously, UOP and Norsk Hydro used the SAPO-34 zeolite catalyst to develop a low-pressure, fast fluidized-bed reactor for MTO process. The Shanghai Research Institute of Petrochemical Technology also developed fluidized-bed SMTO technology. The Lurgi company developed a fixed-bed MTP process and constructed the first MTP plant based on ZSM-5 zeolite catalyst in 2011. Zeolite catalysts are crucial to the industrialization of MTO and MTP processes. These large-scale industrialization efforts also greatly stimulate the continuous development of highperformance zeolite catalysts preparation methods and mechanistic knowledge needed to enhance production efficiency. ${ }^{[81 b, 119]}$

Notice that, although various types of zeolites have been used for $\mathrm{CH}_{3} \mathrm{OH}$ conversion, SAPO-34 and ZSM-5 are the only two zeolites applied in industrial MTO and MTP processes. From the catalyst viewpoints, successful industrializations of zeolite-catalyzed MTO and MTP technologies need to overcome many scientific and technical difficulties: (1) a deep understanding of reaction and deactivation mechanisms, which is crucial to establishing a selectivity control for these reaction systems; (2) development of an efficient catalyst based on a good study of interplay among synthesis strategies, catalyst characteristics, and reaction performances; and (3) large-scale catalyst production using commercially available raw materials. ${ }^{[18]}$ Initially, intensive studies have been devoted to unravelling the hydrocarbon pool (HCP) mechanism during MTO and MTP reactions based on SAPO-34 and ZSM-5 zeolites. Moreover, SAPO-34 and ZSM-5 zeolites have demonstrated excellent performances in MTO and MTP reactions because of their suitable pore sizes, medium acidities, and high thermal and hydrothermal stabilities. In particular, the cylinder-like cages in SAPO-34 and 
intersecting channels in ZSM-5 have proven to be ideal breeding ground for HCP species, which can explain the reason why SAPO-34 and ZSM-5 perform better than other 8-MR, cage-type SAPOs and 10-MR aluminosilicate zeolites in MTO and MTP processes. ${ }^{[18,120]}$ These insights into reaction mechanism provide an opportunity to adjust SAPO-34 and ZSM5 zeolite properties for maximizing their $\mathrm{CH}_{3} \mathrm{OH}$ conversion efficiency. Furthermore, the interplays among synthesis strategies, catalyst characteristics, and reaction performances of both SAPO-34 and ZSM-5 zeolites have been intensively investigated. ${ }^{[81 \mathrm{~b}]}$ This promises SAPO-34 and ZSM-5 zeolites good candidates in industrial MTO and MTP processes on the basis of a rational approach of catalyst design and synthesis. More importantly, SAPO-34 and ZSM-5 zeolites can be scaled up using commercially available raw materials, and their high solid yields, high crystallization rates, and operational and economical feasibility finally enable commercialization of SAPO-34 and ZSM-5 zeolites in MTO and MTP industries.

Although SAPO-34 and ZSM-5 zeolites are used as commercial catalysts in industrial MTO and MTP processes, it is still important to further enhance their activities, selectivities, and stabilities. In addition to zeolite pore opening sizes, the cages and intersection spaces affect selectivity as well. Thus, finding a zeolite with more suitable cages and intersection spaces is also an ongoing research direction for developing a better MTO or MTP catalyst. In past decades, intense studies on catalyst preparations and mechanisms for zeolite-catalyzed $\mathrm{CH}_{3} \mathrm{OH}$ conversion have been reported..$^{[4 a, 81 b, 119,121]}$ In Section 5.2, we focus on presenting recent academic advances regarding zeolites for MTO and MTP processes, with an emphasis on the effects of the zeolite framework topology, Brønsted acidity, secondary-pore system, and particle size on catalytic performance.

\subsection{Fundamental Research on Zeolite-Catalyzed MTO and MTP Reactions}

It is accepted that MTO and MTP reactions over zeolite catalysts follow a direct mechanism in the initial period and an indirect HCP mechanism in the subsequent highactivity period. ${ }^{[4 a, 120,122]}$ Light olefins are mainly formed through the HCP species in the 
indirect pathway. Based on the type of HCP species, HCP mechanism involves aromatic- and alkene-based HCP mechanisms. ${ }^{[123]}$ For the aromatic-based cycle, the polymethylbenzenes and their protonated counterparts have been identified as active intermediates for olefin formation. Generally, methylbenzene intermediates with less than three methyl groups favor the formation of ethylene, while those with more methyl groups deliver propylene and butylene. For the alkene-based cycle, light olefins are formed via cracking of $\mathrm{C}_{3+}$ alkene intermediates. The zeolite topology and acidity are key factors in controlling the types of active intermediates, reaction pathways, and product distributions. ${ }^{[124]}$

\subsubsection{Effect of the Zeolite Brønsted Acidity}

Brønsted acid sites of zeolites act as catalytic sites for $\mathrm{CH}_{3} \mathrm{OH}$ conversion via $\mathrm{HCP}$ mechanisms. Sufficient Brønsted acid sites ensure successive and efficient reactions. However, excess Brønsted acid sites and high acid strengths cause deactivation by fast coke deposition. In aluminosilicates such as ZSM-5 and Beta zeolites, both aromatic- and alkenebased mechanisms work simultaneously. At lower Brønsted acid densities, the alkene-based mechanism is dominant, resulting in higher selectivity towards light olefins and lower aromatic selectivity. ${ }^{[125]}$ In contrast, when the Brønsted acid density is high, the aromaticbased mechanism can be facilitated efficiently and higher aromatic selectivity is achieved. ${ }^{[126]}$ A similar trend has been identified in the SAPO-18 catalyst system, in which a high acid density favors the aromatic-based mechanism over the alkene-based one. ${ }^{[127]}$ When MTO occurs over other SAPO catalysts, a proper Brønsted acidity with mild acid strength and relatively low acid density favors an improved MTO catalytic performance including enhanced lifetime and high olefin selectivity. The Brønsted acid densities and strengths (bridged $\mathrm{Si}(\mathrm{OH}) \mathrm{Al}$ hydroxyls) can be tuned by varying the quantities and chemical environments of the incorporated Si atoms. The chemical environments of the incorporated $\mathrm{Si}$ atoms vary from single $\mathrm{Si}(4 \mathrm{Al})$ species to $\mathrm{Si}(0 \mathrm{Al})$ islands within the $\mathrm{SAPO}$ catalysts. The $\mathrm{Si}(\mathrm{nAl})$ species $(\mathrm{n}=1,2,3)$ located near $\mathrm{Si}$ islands provide much stronger acidities than single 
$\mathrm{Si}(4 \mathrm{Al})$ species. Thus, decreasing the $\mathrm{Si}$ amount (low acid density) and generating single $\mathrm{Si}(4 \mathrm{Al})$ species (mild acid strength) within SAPO catalysts are useful and effective strategies for improving MTO performance and providing high olefin productivity. Similarly, in aluminosilicate zeolites, varying the locations of aluminum atoms can strongly influence reaction pathways and MTO performance. ${ }^{[128]}$ Substantial efforts have been devoted towards controlling the amounts and chemical environments of Si atoms in silicoaluminophosphates and $\mathrm{Al}$ atoms in aluminosilicate zeolites, but challenges remain with regard to characterization and precise control of the $\mathrm{T}(\mathrm{Si}$ and $\mathrm{Al})$ atom locations.

\subsubsection{Effect of the Zeolite Framework Topology}

Different zeolite topologies can induce various spatial confinement effects, strongly affecting the HCP intermediates and reaction routes, and thus the product selectivity. ${ }^{[129]} \mathrm{A}$ suitable topology is crucial to maximizing the yield of the desired products during MTO reaction. Small-pore zeolites with 8-MR pore openings, such as SAPO-34 (CHA), RUB-13 (RTH), SAPO-18 (AEI), and SAPO-35 (LEV), have apparent superiority for light olefins production in MTO process. ${ }^{[129 a]}$ The narrow 8-MR pore openings hinder the transfer of large HCP intermediate species, making light olefins (especially ethylene and propylene) the main products. ${ }^{[130]}$ In contrast, medium-pore zeolites with 10 -MR pore openings, such as ZSM-5 (MFI) and ZSM-48 (*MRE), offer less stringent space limitation and favor increased selectivity towards propylene. ${ }^{[49 h, 131]}$ Large-pore zeolites with $12-\mathrm{MR}$ pore openings, such as Beta zeolites, generally induce the formation of heavier hydrocarbons. This is mainly because the aromatic-mediated mechanism dominates during the MTO reaction due to the lack of a spatial confinement effect within 12-MR channel systems. ${ }^{[132]}$ Like pore openings, cavity and cage sizes and structures are of great importance in determining the active HCP intermediates due to their spatial confinement effects. In a recent work, a small-pore SAPO-14 zeolite gave the highest record of one-pass propylene selectivity of up to $77.3 \%$ in the MTO process (Figure 14A-F). ${ }^{[133]}$ Unlike in SAPO-18 and SAPO-34 zeolite catalysts, where the aromatic- 
based mechanism generally dominates, leading to formation of heavier hydrocarbons, the SAPO-14 zeolite with AFN topology possesses a unique structure with ultra-small cages and narrower 8-MR pore openings. This suppresses the aromatic-based mechanism and promotes the alkene-based mechanism. The higher proportion of alkene-based mechanism is responsible for the high selectivity towards propylene (Figure 14G-H). The zeolite dimensions are another key factor that influences the MTO performance. For instance, both aromatic- and alkene-based mechanisms occur simultaneously over the ZSM-5 zeolite with 2D 10-MR intersecting channel systems, generally giving $40 \%-50 \%$ propylene selectivity. In contrast, alkene-based mechanism is the dominant route due to the lack of intermediates interactions in the 1D 10-MR ZSM-22 (TON) zeolite. ${ }^{[134]}$ However, the 1D zeolite suffers from rapid deactivation by diffusion problem.

Recently, Corma and co-workers proposed a novel synthetic strategy for zeolites using organic structure-directing agents (OSDAs) that mimic the transition states of pre-established chemical reactions to be catalyzed. ${ }^{[135]}$ Following this strategy, cage-based small-pore SSZ-13 (CHA), SAPO-18 (AEI), and RUB-13 (RTH) zeolites were synthesized by using the mimics of HCP intermediates as OSDAs (Figure 15). ${ }^{[136]}$ For MTO reaction process, the RUB-13 zeolite showed higher propylene-to-ethylene ratios than CHA- and AEI-type zeolites (3.07 vs. 0.86-2.00). This may be due to that the RTH cavity provided better stabilization of pentaMCP ${ }^{+}$intermediates than other cage-based small-pore zeolites, and thus directed the reaction go through the paring route that favored the propylene formation. This novel zeolite synthesis strategy based on the design of HCP intermediate mimics of MTO reactions as OSDAs indicates the strong relationship between zeolite topology and HCPs in MTO processes.

\subsubsection{Effects of the Zeolite Secondary-Pore System and Particle Size}

In addition to optimizing the zeolite topology and Brønsted Acidity, incorporating secondary pores and decreasing zeolite particle sizes can affect MTO performance 
significantly. This is because the shortened path lengths within hierarchical and nanosized zeolites effectively alleviate the mass transport limitations of micropores, thus reducing unwanted secondary reactions and the rapid deactivation caused by coke deposition. Extensive efforts have been devoted to developing new synthetic strategies for fabrication of hierarchical and nanosized zeolites. ${ }^{[30 b, 137]}$ These high-quality hierarchical and nanosized zeolites that feature single-crystalline, interconnected mesopores, micro-meso-macro systems, ultrasmall sizes, or nanosheet morphologies have been utilized to increase MTO performance, investigate reaction mechanisms, and improve industrial olefin production capacities. ${ }^{[138]}$

\section{HCOOH Conversion to Hydrogen over Zeolite-Based Catalysts}

\subsection{HCOOH Conversion to Hydrogen}

Hydrogen has drawn ever-increasing attention as a clean, efficient fuel due to its renewability and high energy density. ${ }^{[139]}$ However, there are significant limitations related to the safe, efficient storage and delivery of hydrogen that must be overcome for the implementation of a hydrogen economy. Production of hydrogen from so-called liquid organic hydrogen carriers (LOHCs) is an effective strategy for overcoming these limitations. $\mathrm{HCOOH}$ features a high hydrogen content of $4.4 \mathrm{wt} \%$, sustainability, nontoxicity, and easy storage and transportation. Thus, it is an outstanding LOHC candidate. ${ }^{[140]}$ Currently, $\mathrm{HCOOH}$ is regarded as a promising hydrogen carrier and a new type of $\mathrm{C} 1$ resource. Hydrogen can be released via a dehydrogenation pathway $\left(\mathrm{HCOOH} \rightarrow \mathrm{H}_{2}+\mathrm{CO}_{2}\right)$, but there is an undesired dehydration pathway $\left(\mathrm{HCOOH} \rightarrow \mathrm{H}_{2} \mathrm{O}+\mathrm{CO}\right)$ that should be avoided due to the poisonous effect of $\mathrm{CO}^{[141]}$ Thus, a suitable catalyst system that facilitates the dehydrogenation of $\mathrm{HCOOH}$ while suppressing dehydration is needed.

\subsection{HCOOH Dehydrogenation over Zeolite-Based Catalysts}

To date, both homogeneous and heterogeneous catalysts have been studied intensively for gas- and liquid-phase dehydrogenation of $\mathrm{HCOOH}$ molecules. Compared to homogeneous catalysts, the heterogeneous catalysts have attracted enormous interest due to their facile 
separation, superior recovery capabilities, and low reaction temperatures. Of the various heterogeneous catalysts, ultrasmall metal nanoparticles (NPs) exhibit excellent catalytic $\mathrm{HCOOH}$ dehydrogenation performance because of their high surface-to-volume ratios. However, these metal NPs are thermodynamically unstable and suffer from severe aggregation, which substantially decrease both their catalytic activities and product selectivities. Several support materials have been used to immobilize metal NPs for $\mathrm{HCOOH}$ decomposition reactions, including metal-organic frameworks (MOFs), ${ }^{[141 \mathrm{~b}, 142]}$ metal oxides, ${ }^{[143]}$ graphene, ${ }^{[144]}$ porous carbon, ${ }^{[145]}$ and zeolites. ${ }^{[146]}$ In particular, zeolite materials with ordered micropores $(<2 \mathrm{~nm})$, good crystallinity, and high thermal, hydrothermal, and chemical stabilities have attracted increasing attention as excellent supports for immobilization of metal NPs. They effectively protect the NPs from aggregation and improve their catalytic activities and stabilities during $\mathrm{HCOOH}$ decomposition. The zeolite Brønsted acidity, framework defects, and nano-confinement effects play key roles in determining the yield and selectivity for hydrogen during $\mathrm{HCOOH}$ dehydrogenation.

\subsubsection{Effects of the Zeolite Brønsted Acidity and Framework Defects}

Zeolites with tunable acidities and basicities can participate in reactions and affect the $\mathrm{HCOOH}$ decomposition reaction pathway. Pure zeolites with Brønsted acidities have been demonstrated to be active in gas-phase $\mathrm{HCOOH}$ decomposition reactions, including dehydrogenation and dehydration. ${ }^{[147]}$ Both computational and experimental results indicate that the H-ZSM-5 zeolite favores dehydration over dehydrogenation of $\mathrm{HCOOH}$ molecules, leading to a low hydrogen selectivity of $21 \%$. According to computational investigations, the barriers of dehydrogenation and dehydration of $\mathrm{HCOOH}$ in H-ZSM-5 zeolites are $199.0 \mathrm{~kJ}$ $\mathrm{mol}^{-1}$ and $158.6 \mathrm{~kJ} \mathrm{~mol}^{-1}$, respectively. The dehydration barrier is $40.4 \mathrm{~kJ} \mathrm{~mol}^{-1}$ lower than the dehydrogenation barrier, and thus dehydration occurs preferentially over the H-ZSM-5 zeolite. In addition, silanol defects ( $\mathrm{SiOH}$ groups) in purely siliceous silicalite-1 zeolite were computationally and experimentally demonstrated to be active in $\mathrm{HCOOH}$ dehydration, ${ }^{[147]}$ 
leading to formation of undesired CO. A similar work found that Brønsted acid sites were active in $\mathrm{HCOOH}$ dehydration, causing decreased hydrogen production performance ${ }^{[148]}$ Both the Brønsted acidity and silanol defects inhibit $\mathrm{HCOOH}$ dehydrogenation to hydrogen. Thus, purely siliceous, defect-free zeolites are considered to be superior supports for hydrogen production via $\mathrm{HCOOH}$ dehydrogenation.

\subsubsection{Nano-Confinement Effect from Metallic Sites within Zeolites}

Zeolites that feature nano-confinement can provide good stabilization of metallic species, ensuring good thermal stability even under harsh conditions such as high temperatures and oxidation-reduction atmospheres. Recently, $\mathrm{Yu}$ and co-workers developed in-situ encapsulation ultrasmall of $\mathrm{Pd}$ clusters within the purely siliceous potassium-containing silicalite-1 zeolite $\left(\mathrm{Pd} / \mathrm{S}-1\right.$-in-K) via hydrothermal synthesis using $\left[\mathrm{Pd}\left(\mathrm{NH}_{2} \mathrm{CH}_{2} \mathrm{CH}_{2} \mathrm{NH}_{2}\right)_{2}\right] \mathrm{Cl}_{2}$ as a precursor (Figure 16A) ${ }^{[48 a]}$ Pd clusters appeared to be confined in the intersectional void spaces of the MFI structure as indicated by high-resolution scanning transmission electron microscopy (STEM) (Figure 16B-E). The as-synthesized Pd/S-1-in-K catalyst exhibited excellent hydrogen production activity during liquid-phase $\mathrm{HCOOH}$ dehydrogenation, with turnover frequency (TOF) values of up to $856 \mathrm{~h}^{-1}$ at $25^{\circ} \mathrm{C}$ and $3027 \mathrm{~h}^{-1}$ at $50{ }^{\circ} \mathrm{C}$ (Figure $16 \mathrm{~F}$ H). Notably, the addition of potassium to the S-1 zeolite matrix significantly increased its basicity, which aided in cleavage of $\mathrm{O}-\mathrm{H}$ bonds of $\mathrm{HCOOH}$ molecules and subsequent hydrogen production. Significantly, Pd/S-1-in-K exhibited excellent recyclability as well as high thermal stability because of the good nano-confinement effect of Pd clusters within the zeolite matrix. Afterwards, Yu and co-workers further in-situ encapsulated subnanometric Pd$\mathrm{Ni}(\mathrm{OH})_{2}$ bimetallic clusters within the $\mathrm{S}-1$ zeolite $\left(\mathrm{Pd}-\mathrm{Ni}(\mathrm{OH})_{2} @ \mathrm{~S}-1\right)$ by using $\left[\mathrm{Pd}\left(\mathrm{NH}_{2} \mathrm{CH}_{2} \mathrm{CH}_{2} \mathrm{NH}_{2}\right)_{2}\right] \mathrm{Cl}_{2}$ and $\left[\mathrm{Ni}\left(\mathrm{NH}_{2} \mathrm{CH}_{2} \mathrm{CH}_{2} \mathrm{NH}_{2}\right)_{3}\right]\left(\mathrm{NO}_{3}\right)_{2}$ as simultaneous precursors (Figure 16I and J). ${ }^{[149]}$ Synergy between ultrasmall Pd clusters and $\mathrm{Ni}(\mathrm{OH})_{2}$ was observed and contributed to decreasing the $\mathrm{HCOOH}$ decomposition activation barrier, thus affording the initial and total TOF values as high as $5803 \mathrm{~h}^{-1}$ and $1879 \mathrm{~h}^{-1}$ at $60{ }^{\circ} \mathrm{C}$ (Figure $16 \mathrm{~K}$ ). Due to 
the good nano-confinement effect of active bimetallic hybrid clusters within the S-1 zeolite matrix, the Pd-Ni(OH) $@$ S-1 catalyst exhibited excellent stability under various industrial oxidation reduction conditions at $600{ }^{\circ} \mathrm{C}-700^{\circ} \mathrm{C}$.

\section{Conclusion and Outlook}

Over the past decade, the development of zeolite-based catalysts has boosted the $\mathrm{C} 1$ chemistry substantially, triggering its industrialization in order to decrease oil consumption and satisfy growing demands for energy and chemicals. This area of study benefits from unique zeolite characteristics such as ordered micropores, distinct topologies, varied spatial confinement effects, tunable acidities, controllable hydrophobic and hydrophilic properties, and specific anchoring sites for metallic active species. This review has attempted to give a comprehensive and timely overview of developments in $\mathrm{C} 1$ chemistry over recent years, with an emphasis on addressing the effects of zeolites on value-added hydrocarbon (e.g., methane, light olefins, aromatics, and liquid fuels) and oxygenate (e.g., methanol, DME, and higher alcohols) production from $\mathrm{C} 1$ resources $\left(\mathrm{CO}, \mathrm{CO}_{2}, \mathrm{CH}_{4}, \mathrm{CH}_{3} \mathrm{OH}\right.$, and $\left.\mathrm{HCOOH}\right)$. Selection of a suitable zeolite catalyst or support is crucial to efficient production of target chemicals from a specific $\mathrm{C} 1$ molecule. The diversity and tunability of zeolites provide great opportunities and challenges for $\mathrm{C} 1$ chemistry as discussed below.

High catalytic activity, selectivity, and stability based on current zeolite-based catalyst systems. In order to make catalytic transformation of $\mathrm{C} 1$ molecules more economically viable for industrialization, high catalytic activity, selectivity, and stability of zeolite-based catalysts are development long-term goals to pursue. Based on existing mature zeolite catalyst systems in which reaction mechanisms and synthesis strategies are well-established, precise tailoring and control of zeolite topologies, $\mathrm{T}$ atom ( $\mathrm{Si}, \mathrm{Al}$, and other heteroatoms) locations, pore connectivities in hierarchical structures, size and dispersion of metallic species (single atoms, clusters, and nanoparticles), and proximity between active catalytic sites are effective approaches to achieving high $\mathrm{C} 1$ molecule conversion performance. For instance, although 
SAPO-34 zeolites have been extensively applied as commercial catalysts in industrial MTO process, one can further enhance their activities, selectivities, and stabilities by using nanosized or hierarchical SAPO-34 zeolites, by tuning the Si content and location in the zeolite framework, or by coupling another functional component for a synergistic effect. These possibilities should be investigated further. This situation is the same with application of ZSM-5 zeolites to MTP industrialization. ${ }^{[2 \mathrm{~b}]}$ However, there remains a lack of rational synthetic strategies that provide precise control of the desired zeolite characteristics at the molecular level to meet the high demand for $\mathrm{C} 1$ molecule-derived chemicals and energy. In addition, the conversion of $\mathrm{CH}_{4}$ and $\mathrm{CO}_{2}$ to high-value chemicals over zeolite-based bi- and multi-functional catalysts is low (typically $<30 \%$ ) because of the high thermodynamical and chemical stabilities of $\mathrm{CH}_{4}$ and $\mathrm{CO}_{2}$, thus hindering their practical utilization. Therefore, developing desired catalysts with precisely controllable active sites (e.g., acid sites, metallic active sites, and combinations of active sites with synergistic effects) is of great importance to improving $\mathrm{C} 1$ molecule conversion. This will be an increasingly important $\mathrm{C} 1$ chemistry research topic in the future.

\section{Mechanism investigation via in-situ characterization, DFT calculations, and machine}

learning. In-depth understanding of the reaction mechanisms behind catalytic production of value-added chemicals from $\mathrm{C} 1$ resources, especially zeolite evolution and interactions between zeolites and metallic sites during catalysis, is crucial to facilitating the rational design of more efficient catalysts. ${ }^{[150]}$ For instance, active sites in metal-containing zeolite catalysts used for direct $\mathrm{CH}_{4}$ conversion to methanol or aromatics have been proposed for a long time, but the details of $\mathrm{CH}_{4}$ conversion and identification of active sites within zeolites remain in debate. Experimental verification of the active sites and exact reaction mechanisms is highly needed, which requires in-situ investigation of $\mathrm{C} 1$ molecule activation, intermediate evolution, and catalyst structure transformation. To this end, in-situ spectroscopic and microscopic techniques, such as aberration-corrected scanning transmission electron microscopy $\left(\mathrm{C}_{\mathrm{s}^{-}}\right.$ 
corrected STEM) and the recently reported combination of high-resolution high-angle annular dark-field STEM and integrated differential phase contrast imaging techniques, X-ray absorption spectroscopy, electron spin resonance spectroscopy, laser-induced fluorescence, solid-state NMR spectroscopies, and molecule beam time-of-flight mass spectrometry equipped with a soft ionization technique are feasible approaches to unraveling the truth of what occurs within zeolite micropores in $\mathrm{C} 1$ chemistry. Furthermore, theoretical calculations should be coupled to illustrate the energy barriers of bond breaking and formation of some single events, and provide deep insight into the catalytic conversion of $\mathrm{C} 1$ molecules. Currently, increasing development of computing power and machine learning should allow more complex and realistic catalytic systems to be modeled successfully, and thus more solid illustrations of reaction mechanisms to be proposed. ${ }^{[151]}$

Modification of zeolites: modulating zeolite wettabilities and pore openings. $\mathrm{H}_{2} \mathrm{O}$ molecules are inevitably involved as reactants and by-products in catalytic processes such as the WGS reaction and conversion of $\mathrm{CO}_{2}$ to methane, methanol, and DME. $\mathrm{H}_{2} \mathrm{O}$ not only drives the reaction toward undesired products but also poisons metallic active sites, thus inhibiting their catalytic performance during $\mathrm{C} 1$ resource conversion. Designing zeolite catalysts with appropriate hydrophobicities, hydrophilicities, or pore openings helps to avoid undesired WGS and influence the kinetic diffusion of $\mathrm{H}_{2} \mathrm{O}$ molecules, consequently improving $\mathrm{CO}$ and $\mathrm{CO}_{2}$ conversions as well as selectivity towards value-added products. Modification of zeolites with cations or functional shells has proven to be an effective method of tuning the zeolite pore openings and wettabilities. The hydrophobicities and hydrophilicities of zeolites depend on the proximity between metallic and acid sites. When the metallic active sites and acid sites are in close proximity, hydrophobic zeolites are desired to weaken the adsorption and diffusion of poisonous $\mathrm{H}_{2} \mathrm{O}$ to metallic sites. When these two active sites are in decreased proximity, hydrophilic zeolites are desired because they provide water-conduction channels that remove the water from the catalyst system. Further studies 
should be focused on modulating zeolite pore openings and wettabilities, especially when relevant molecules exhibit significant polarity or kinetic radius differences, or $\mathrm{H}_{2} \mathrm{O}$ is involved during reactions. Such advances could significantly influence the adsorption and desorption behaviors of reactants and products, as well as reaction pathways, and consequently product distributions.

Design and screening of high-performance zeolite-based catalysts. The pursuit of new types of high-performance zeolite catalysts with desired framework topologies has never stopped. A desired zeolite topology (e.g., pore opening and cavity) and acidity might afford enormous opportunities to maximize production toward a specific product. Producing a new zeolite topology requires one to test many variables and conditions (e.g., OSDAs, Si/Al ratios, crystallization temperatures, $\mathrm{pH}$ values, additives, etc.) during synthesis. This makes the synthesis of new types of zeolites labor-intensive. Thus, predicting the relationships between catalytic performance, zeolite structure, and zeolite synthesis based on available experimental data and computations is both essential and of great significance in accelerating the discovery of high-performance zeolite topologies and achieving synthesis targets. ${ }^{[152]}$ To this end, "a priori" synthesized zeolites and machine learning are emerging as promising, powerful tools that can help to establish relationships and help to predict topologies and synthesis routes. ${ }^{[153]}$ For instance, the hydrocarbon selectivities in DME conversion have been predicted via an artificial intelligence model that uses the temperature, weight hourly space velocity, DME concentration, and zeolite catalyst acidity as input variables. Its predictions are consistent with corresponding experimental results. ${ }^{[154]}$ Furthermore, more than 100 already-discovered and undiscovered intermetallic-based electrocatalysts for $\mathrm{CO}_{2}$ reduction reaction and hydrogen evolution reactions have been identified from 1499 candidates via machine learning. ${ }^{[155]}$ On the other hand, the rational design of OSDAs is key to discovering new types of zeolite catalysts. In particular, the novel "a priori" strategy that mimics the transition states of preestablished chemical reactions to be catalyzed could provide inspiration for rational design of 
OSDAs towards new types of zeolites. ${ }^{[156]}$ In already industrialized catalyst systems, such as the SAPO-34 zeolite used for MTO process, discovery of a new type of high-performance catalyst that can further improve catalytic performance and production efficiency is highly desired and may go on for a long time. In addition, high-throughput (HT) design and synthesis of catalysts can afford efficient development of new types of zeolites, and also aid in screening and industrial exploration of zeolite-based catalysts in a large scale. Such HT method features robotic multi-reactors that operate under the automation, parallelization, and miniaturization tenets, which can automatically explore many synthetic variables and conditions while dramatically reducing time- and labor-cost. ${ }^{[152 \mathrm{a}]}$ In the future, a fully automated system for HT catalyst synthesis that integrates robotics, engineering, and data analyses will be an important area of research, which may facilitate industrial exploration of zeolite-based catalysts.

Material design based on new technologies. The morphologies, sizes, and spatial distributions of active sites in zeolite-based bi- and multi-functional catalysts strongly affect C1 molecule conversion. Compared to lab-based preparation of bi-functional catalysts, 3D printing, a new technology, may provide a facile alternative approach to synthesizing multifunctional catalysts with precise control of porosity, size, shape, and active site spatial arrangements. ${ }^{[157]}$ This 3D printing technology endows zeolite-based multi-functional catalysts with designable configurations and can aid in large-scale catalyst preparation.

In conclusion, zeolites as important catalysts and supports for metallic species play crucial roles in $\mathrm{C} 1$ chemistry. Recent advances in controlling guest active sites, framework topologies, nano-confinement effects, Brønsted acidities (Si/Al ratios), secondary-pore systems, particle sizes, extra-framework cations and atoms, hydrophobicity and hydrophilicity, and proximity between active sites have provided important guidance for the development of novel highperformance zeolite-based catalysts and expanded the application of zeolites to $\mathrm{C} 1$ chemistry. Because of ceaseless researcher efforts towards meeting current challenges in precisely 
controlling zeolite characteristics, deep understanding zeolite-catalyzed reaction mechanisms, and developing efficient synthetic strategies, applications of zeolites to $\mathrm{C} 1$ chemistry are expected to achieve still more success in both academia and industry in the future.

\section{Acknowledgements}

The authors thank the National Natural Science Foundation of China (Grants 21920102005, 21835002, and 21621001), the National Key Research and Development Program of China (Grant 2016YFB0701100), the 111 Project of China (B17020), and the Spanish Government through "Severo Ochoa" (SEV-2016-0683, MINECO) and PGC2018-101247-B-I00 for supporting this work.

Received: ((will be filled in by the editorial staff))

Revised: ((will be filled in by the editorial staff)) Published online: ((will be filled in by the editorial staff)) 


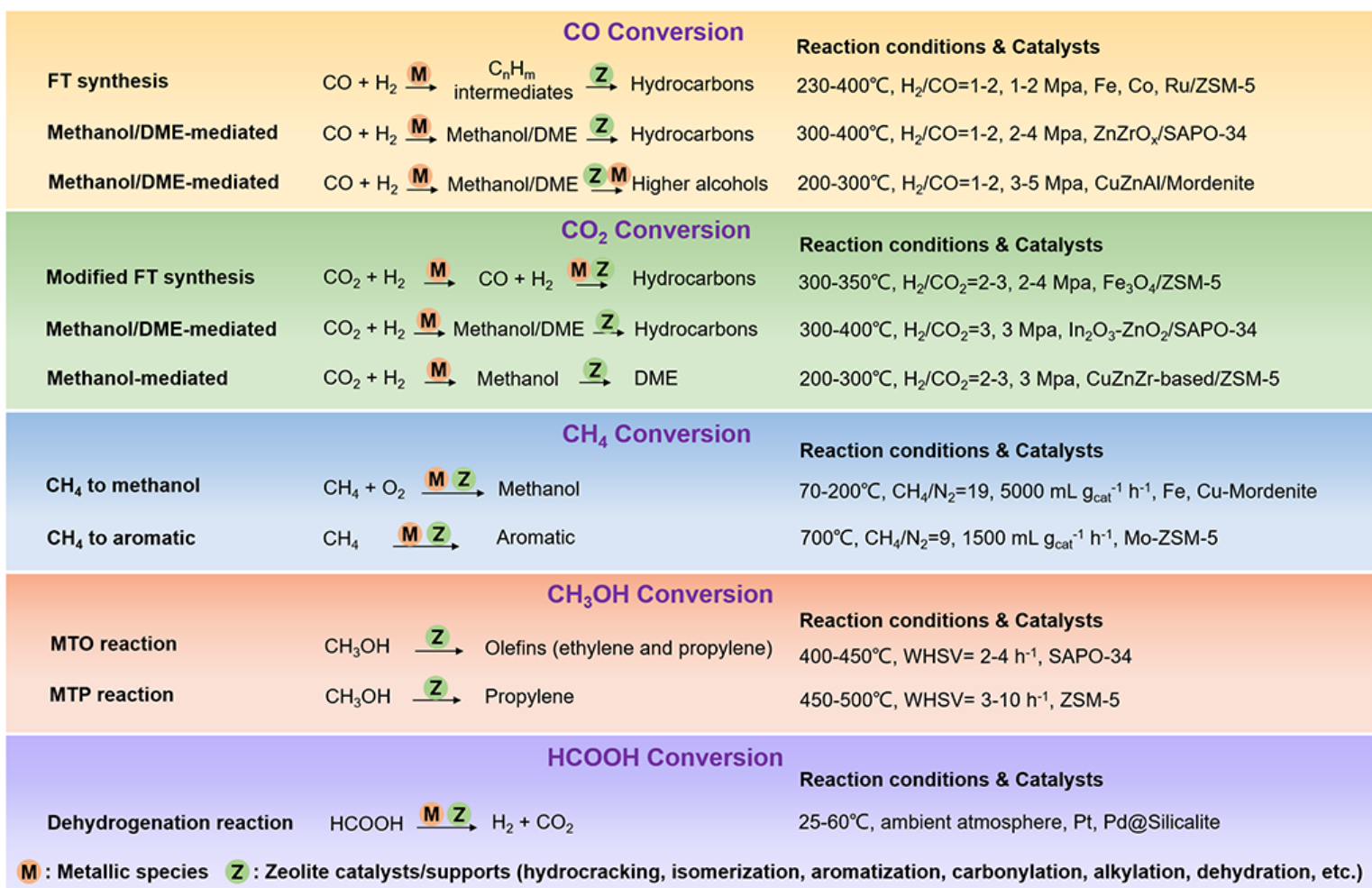

Figure 1. Summary of some representative routes from $\mathrm{C} 1$ molecules to value-added chemicals and corresponding most-studied catalysts and reaction conditions. 


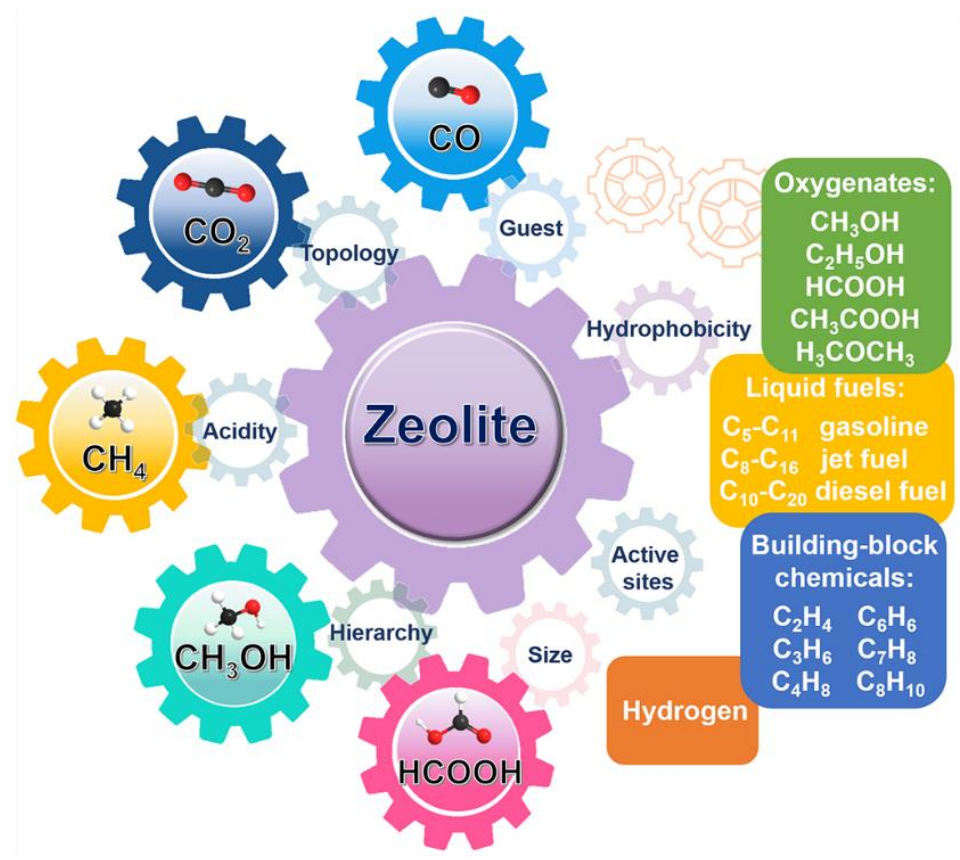

Figure 2. Schematic of zeolite utilization to $\mathrm{C} 1$ chemistry: zeolite descriptors and valueadded chemicals over zeolite-based catalysts. 


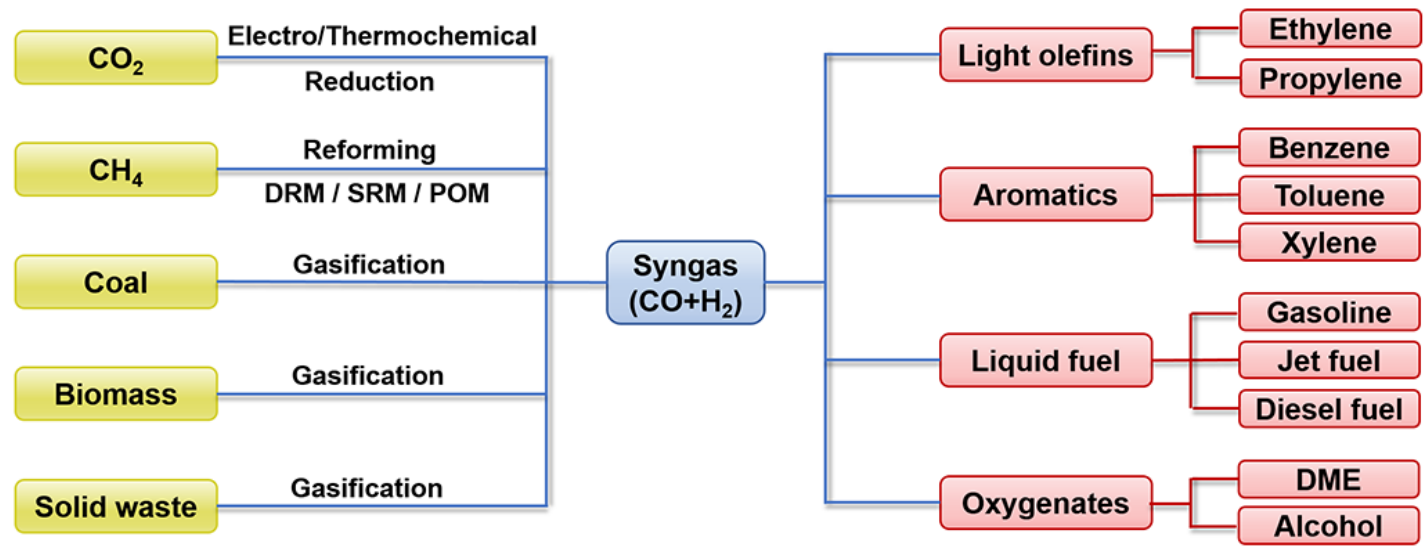

Figure 3. Flow scheme showing processes of producing syngas and some value-added syngas-derived chemicals. 

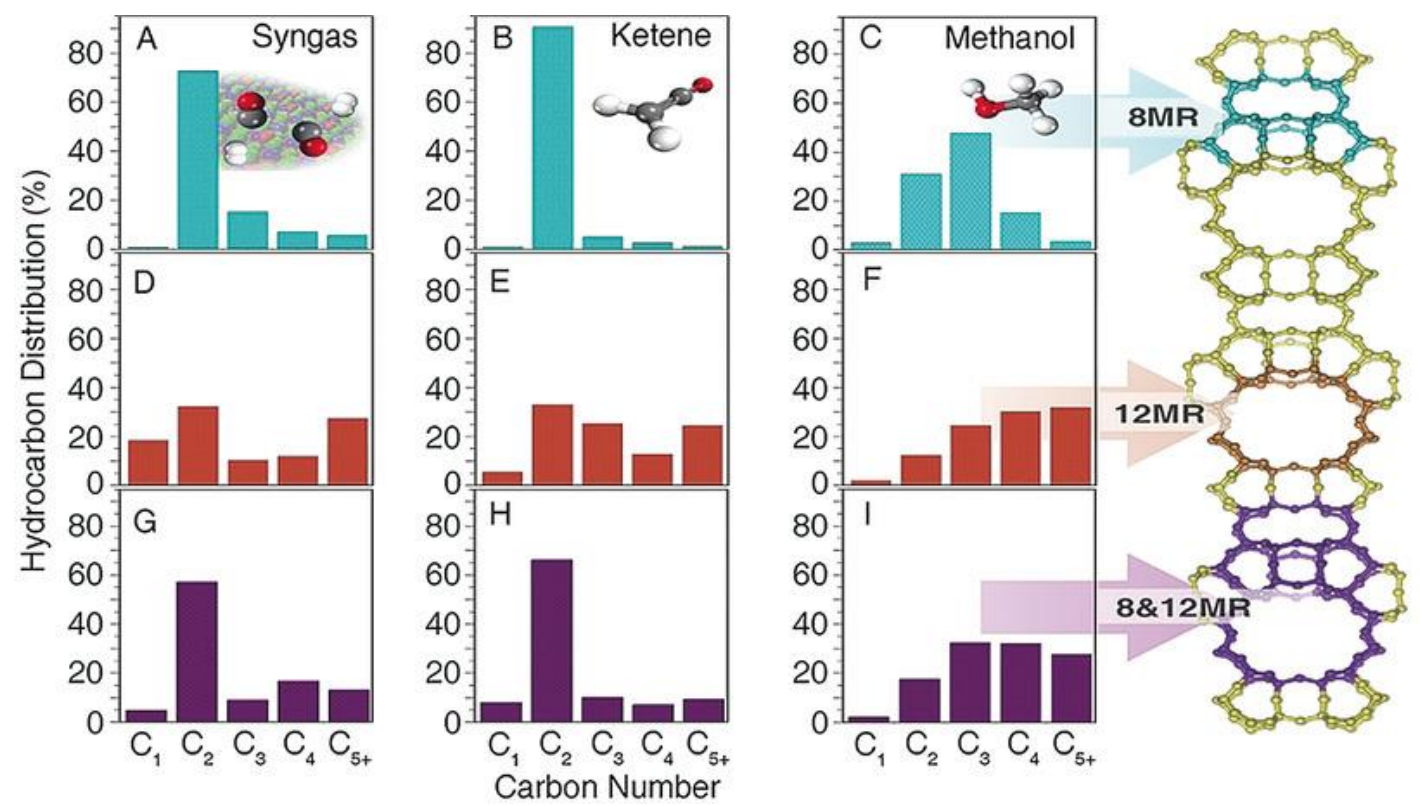

Figure 4. Hydrocarbon distributions in the conversion of syngas, ketene, and methanol over different sites of MOR zeolites at $375{ }^{\circ} \mathrm{C}$. A-C) MOR\#2-py with only the 8-MR acid sites accessible. D-F) MOR\#14 with only the 12-MR acid sites accessible. G-I) MOR\#3 with both the 8-MR and 12-MR acid sites available. A), D), and G) Syngas over $\mathrm{ZnCrO}_{\mathrm{x}}-\mathrm{MOR}$. B), E), and H) Ketene conversion over MOR. C), F), and I) Methanol conversion over MOR. A-I) Reproduced with permission. ${ }^{[20]}$ Copyright 2018, John Wiley and Sons. 

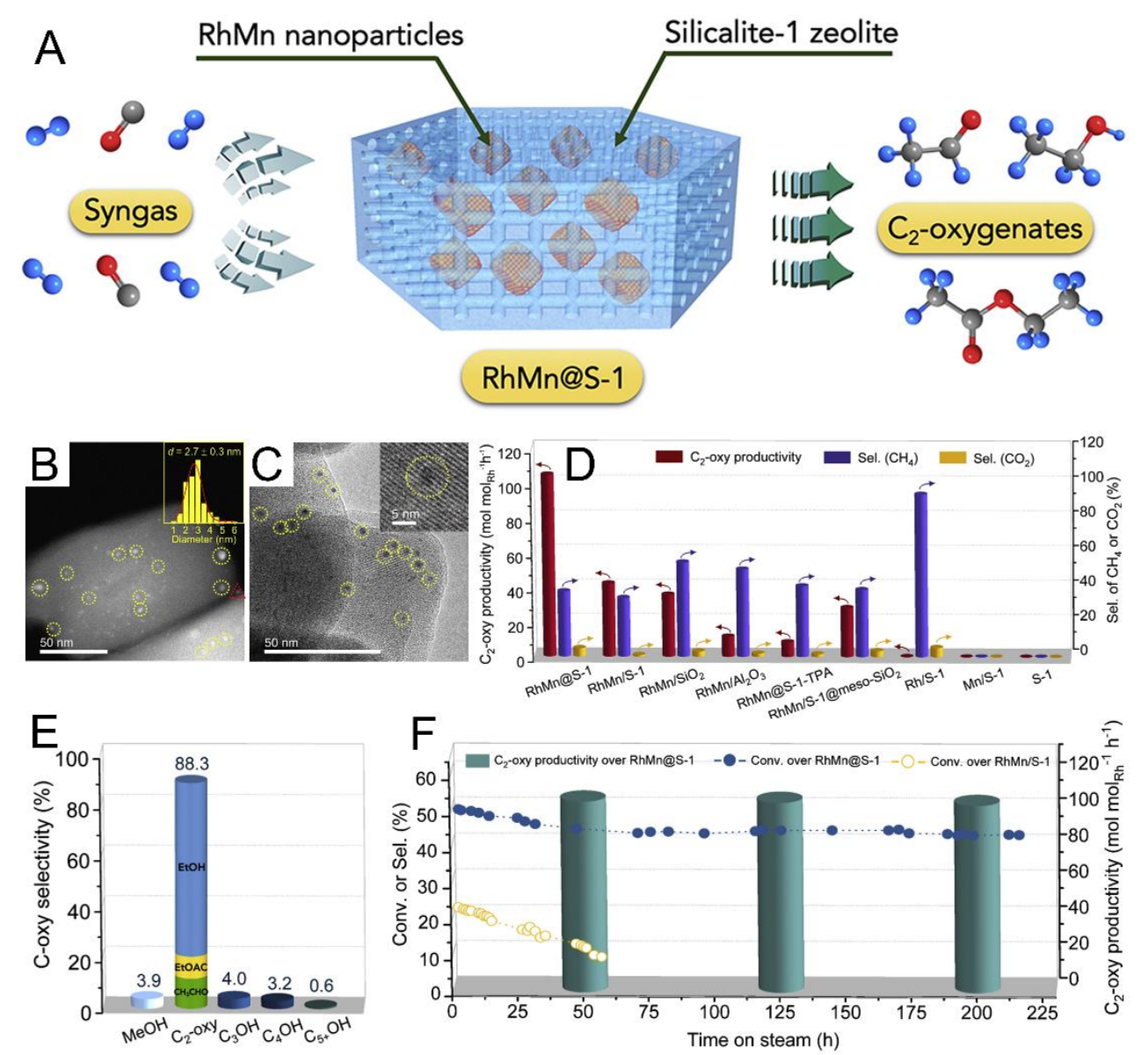

Figure 5. A) The direct conversion of syngas to $\mathrm{C}_{2}$-oxygenates over RhMn@ $\mathrm{S}-1$ catalyst. B, C) Tomographic-section (B) STEM and (C) tomographic TEM images of RhMn@S-1. The inset in (B) shows metal nanoparticle size distributions. The inset in (C) shows an enlarged view of nanoparticle within zeolite crystal. The yellow circles and red triangle highlight the metal nanoparticles inside and out of the zeolite crystals, respectively. D) Average productivities of $\mathrm{C}_{2}$-oxygenates and selectivities of methane and $\mathrm{CO}_{2}$ over various $\mathrm{RhMn}$ based catalysts. E) The selectivities of various oxygenate products in the total oxygenates over RhMn@S-1 catalyst. F) Data characterizing the durability of the RhMn@S-1 catalyst in syngas transformation. The dotted lines: dependence of CO conversions on RhMn@S-1 and $\mathrm{RhMn} / \mathrm{S}-1$ catalysts on time. The columns: average $\mathrm{C}_{2}$-oxy productivities in the randomly selected periods $(20 \mathrm{~h})$ during the long-term tests over RhMn@S-1 catalyst. Reaction conditions: $0.5 \mathrm{~g}$ of catalyst; $3 \mathrm{MPa}, \mathrm{H}_{2} / \mathrm{CO}$ molar ratio at 2; flow rate at $30 \mathrm{~mL} \mathrm{~min}^{-1}$, gas hourly space velocity at $3600 \mathrm{~mL} \mathrm{gcat}^{-1} \mathrm{~h}^{-1}, 320{ }^{\circ} \mathrm{C}$. A-F) Reproduced with permission. [41c] Copyright 2020, Elsevier. 

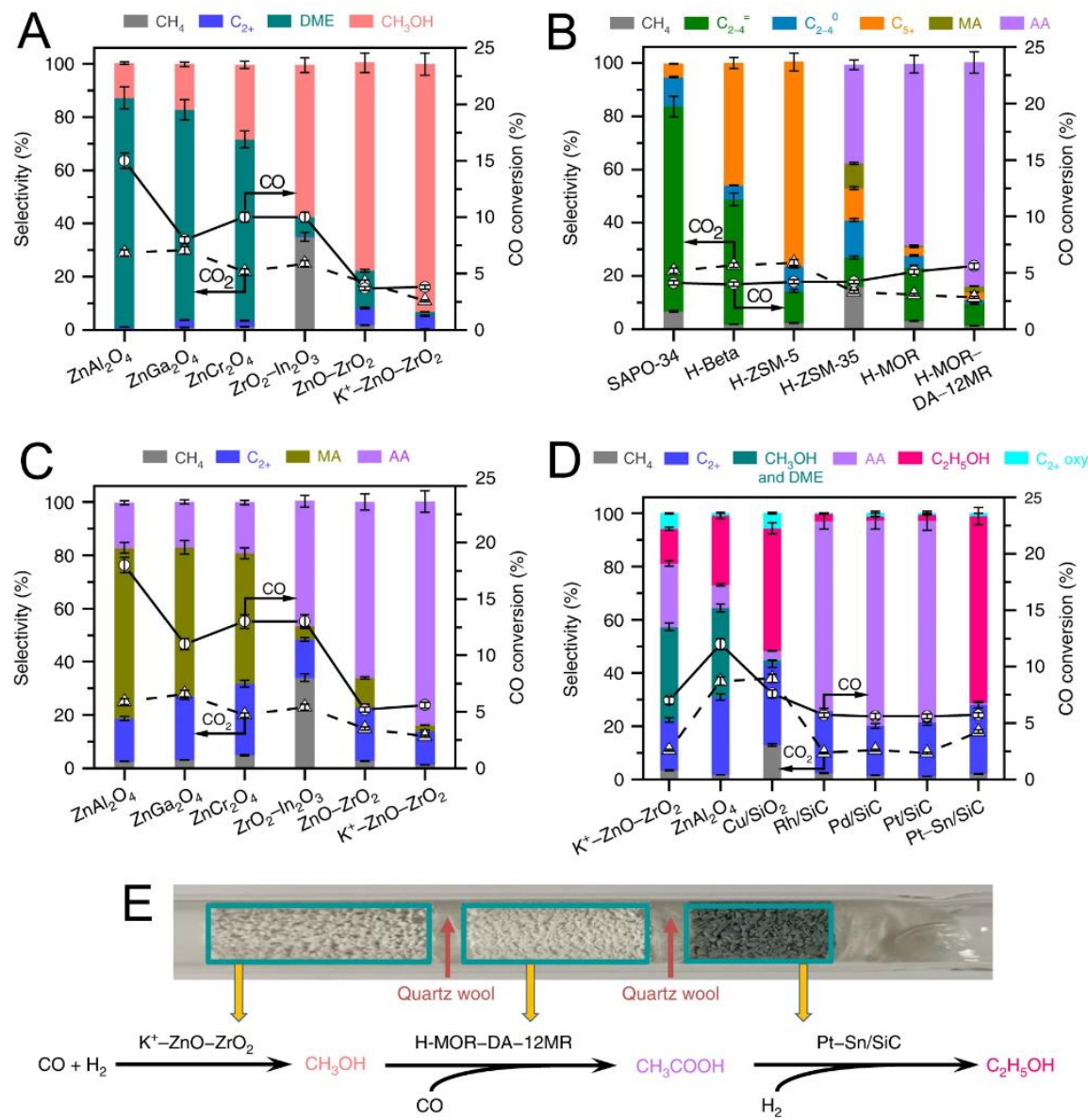

Figure 6. Catalytic behaviours and reaction pathways. A) Metal oxides alone. B) Combinations of $\mathrm{K}^{+}-\mathrm{ZnO}-\mathrm{ZrO}_{2}$ and zeolites. C) Combinations of metal oxides and H-MORDA-12MR. D) Combinations of $\mathrm{K}^{+}-\mathrm{ZnO}-\mathrm{ZrO}_{2}, \mathrm{H}-\mathrm{MOR}-\mathrm{DA}-12 \mathrm{MR}$ and hydrogenation catalysts. E) Reaction pathways for direct synthesis of ethanol from syngas. $\mathrm{C}_{2+}: \mathrm{C}_{2+}$ hydrocarbons; DME: dimethyl ether; $\mathrm{C}_{2-4}=\mathrm{C}_{2}-\mathrm{C}_{4}$ olefins; $\mathrm{C}_{2-4}{ }^{0}: \mathrm{C}_{2}-\mathrm{C}_{4}$ paraffins; $\mathrm{C}_{5+}: \mathrm{C}_{5+}$ hydrocarbons; MA: methyl acetate; AA: acetic acid; $\mathrm{C}_{2+}$ oxy.: ethyl acetate and methyl acetate. Reaction conditions: weights of metal oxide, zeolite and hydrogenation catalyst = $0.66,0.66$, and $0.66 \mathrm{~g} ; \mathrm{H}_{2} / \mathrm{CO}=1: 1 ; \mathrm{P}=5.0 \mathrm{MPa} ; \mathrm{T}=583 \mathrm{~K} ; \mathrm{F}=25 \mathrm{~mL} \mathrm{~min}^{-1}$; time on stream, $20 \mathrm{~h}$. The selectivity was calculated on a molar carbon basis. Carbon balances were 95-99 \%. The experiments in each case were performed for three times. The error bar represents the relative deviation, which is within $5 \%$. A-E) Reproduced with permission. ${ }^{[2 \mathrm{c}]}$ Copyright 2020, Springer Nature. 

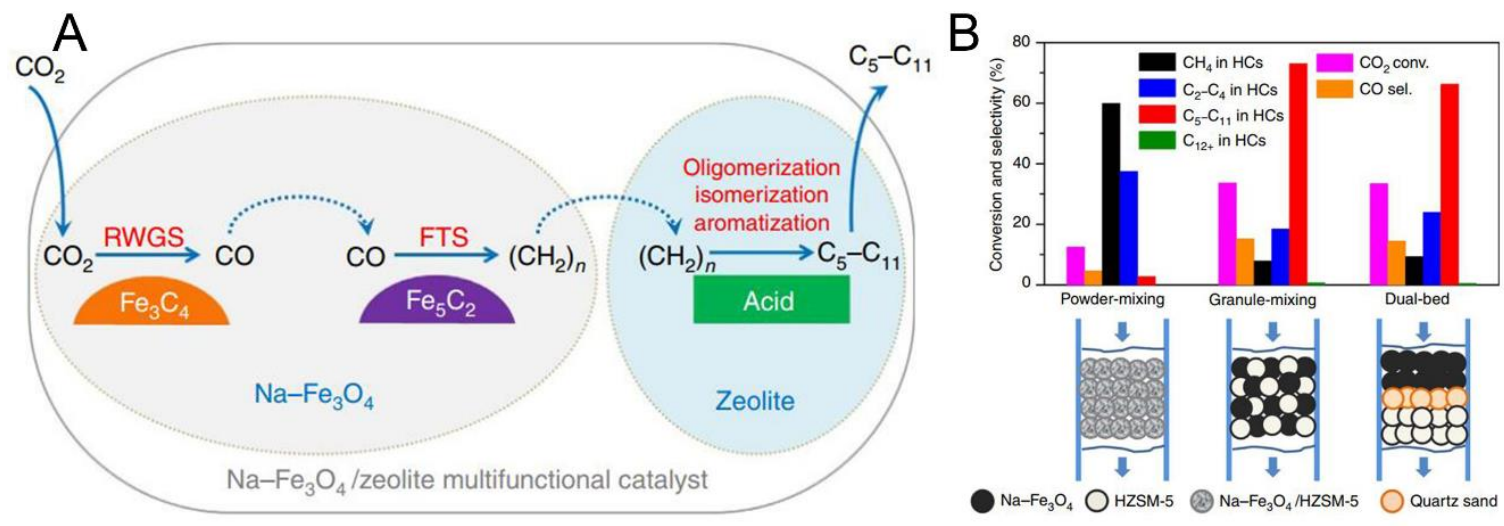

Figure 7. A) Reaction scheme for $\mathrm{CO}_{2}$ hydrogenation to gasoline-range hydrocarbons. The $\mathrm{CO}_{2}$ hydrogenation reaction over $\mathrm{Na}-\mathrm{Fe}_{3} \mathrm{O}_{4} /$ Zeolite multi-functional catalyst takes place in three steps: (1) an initially reduced to CO intermediate via RWGS; (2) a subsequent hydrogenation of $\mathrm{CO}$ to $\alpha$-olefin intermediate via FTS; and (3) the formation of gasolinerange hydrocarbons via the acid-catalyzed oligomerization, isomerization, and aromatization reactions. B) $\mathrm{CO}_{2}$ conversion and product selectivity over different combinations of $\mathrm{Na}^{-\mathrm{Fe}_{3} \mathrm{O}_{4}}$ and HZSM-5 catalysts, HCs: hydrocarbons, reaction conditions: $\mathrm{H}_{2} / \mathrm{CO}_{2}=3,320{ }^{\circ} \mathrm{C}, 3 \mathrm{MPa}$, and $4000 \mathrm{~mL} \mathrm{~g}_{\mathrm{cat}}{ }^{-1} \mathrm{~h}^{-1}$. A, B) Reproduced with permission. ${ }^{[59]}$ Copyright 2017, Springer Nature. 


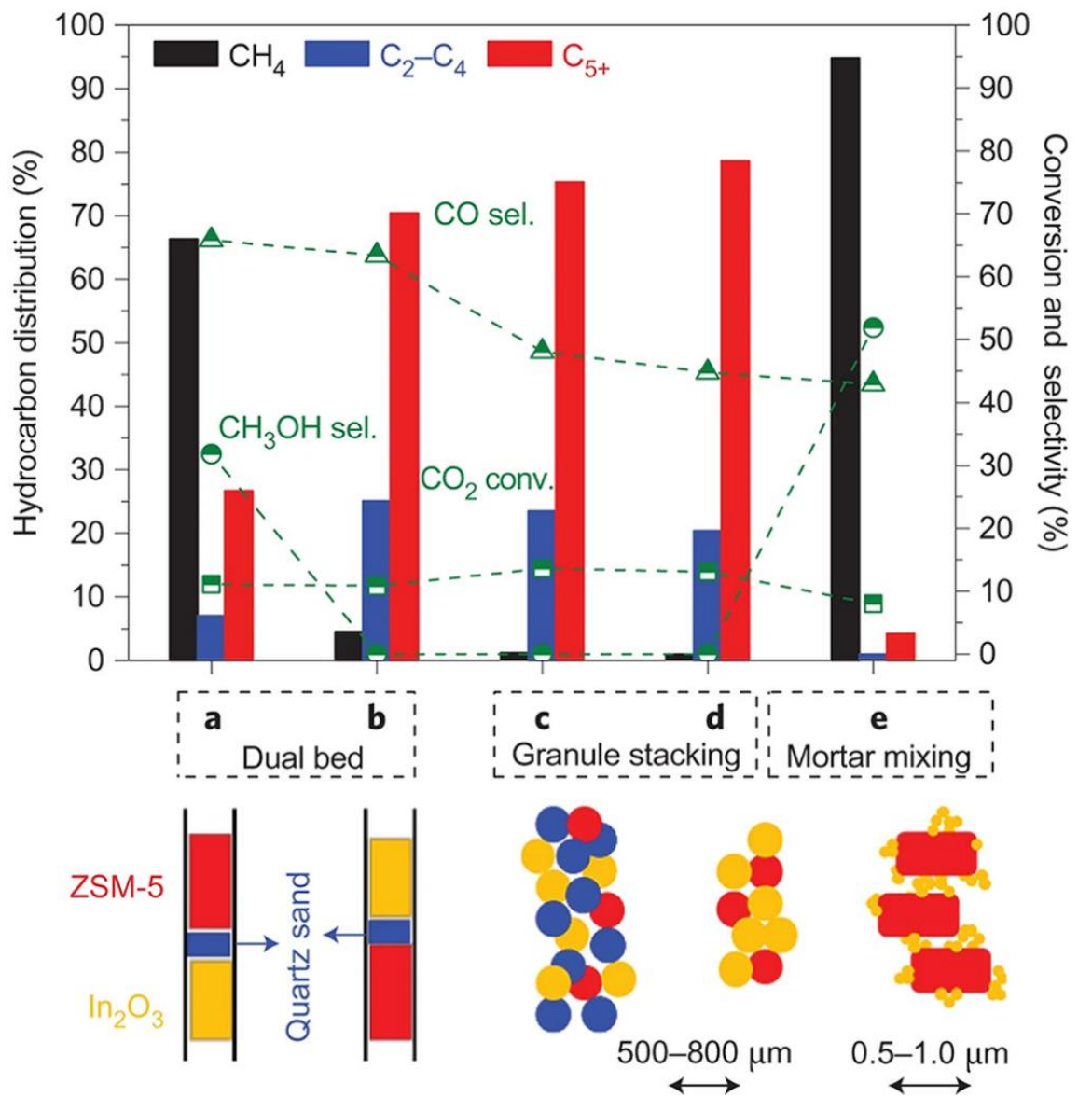

Figure 8. Influence of the integration manner of the active components $\left(\operatorname{In}_{2} \mathrm{O}_{3} / \mathrm{HZSM}-5\right.$ mass ratio $=2: 1$ ) on catalytic behaviors under the same conditions. a, Dual-bed configuration with $\mathrm{In}_{2} \mathrm{O}_{3}$ packed below HZSM-5 and separated by a layer of quartz sand. b, HZSM-5 packed below $\mathrm{In}_{2} \mathrm{O}_{3}$ and separated by quartz sand. c, Stacking of granules with the $\operatorname{In}_{2} \mathrm{O}_{3}, \mathrm{HZSM}-5$, and quartz sand particle sizes of $250-380 \mu \mathrm{m}$. d, $\mathrm{In}_{2} \mathrm{O}_{3}$ and HZSM-5 particles well mixed without quartz sand. e, $\operatorname{In}_{2} \mathrm{O}_{3}$ and HZSM-5 mixed with an agate mortar. The catalytic performance is improved significantly by moving the two components to a closer proximity, whereas the $\mathrm{C}_{5+}$ hydrocarbon selectivity decreases remarkably with a further increase in the proximity by grinding the powder mixture of the two active components in an agate mortar. Reproduced with permission. ${ }^{[60]}$ Copyright 2017, Springer Nature 

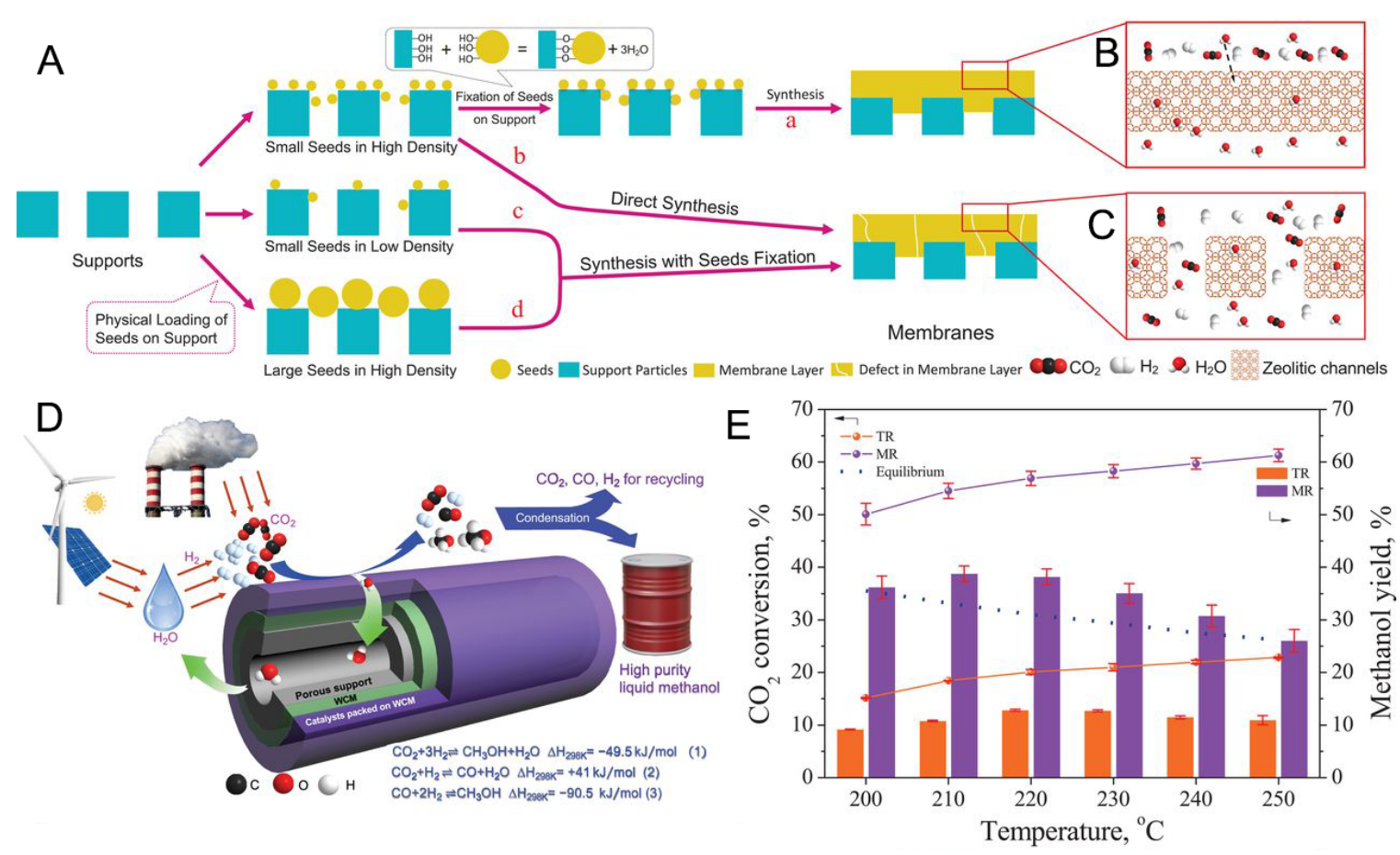

Figure 9. A) Schematics of different preparation routes. In route a, 50- to 200-nm seeds are fixed at high loading density onto and into the support through dehydration of surface hydroxyl groups as illustrated, for growth of WCM-a with defects largely suppressed, whereas in route $b$, these seeds are used directly for growth of membrane (M-b) with defects. In route $\mathrm{c}$, the seeds are diluted by a factor of 2 or 10 relative to route a for growth of M-c-02 and M-c-10, respectively. In route d, larger seeds (300 to $400 \mathrm{~nm}$ and 400 to $700 \mathrm{~nm}$ ) are fixed onto and into the support through dehydration for growth of M-d-300 and M-d-400, respectively. B, C) Molecular transport pathway through WCM-a (B) and through membranes prepared by routes $b$ to $d(C)$. D) Schematics of WCM-incorporated dehydration membrane reactor (MR) for high-purity methanol direct synthesis from renewable resources. E) Catalytic $\mathrm{CO}_{2}$ conversion (points) and methanol yield (columns) obtained in the traditional reactor (TR; orange) and in the MR (purple) as a function of temperature at 35 bar and feed $\left(\mathrm{CO}_{2} / \mathrm{H}_{2}=1 / 3\right)$ gas hourly space velocity of $5100 \mathrm{ml} \mathrm{g}_{\mathrm{cat}}{ }^{-1}$ hour $^{-1}$. A-E) Reproduced with permission. ${ }^{\text {[77] }}$ Copyright 2020, Science. 


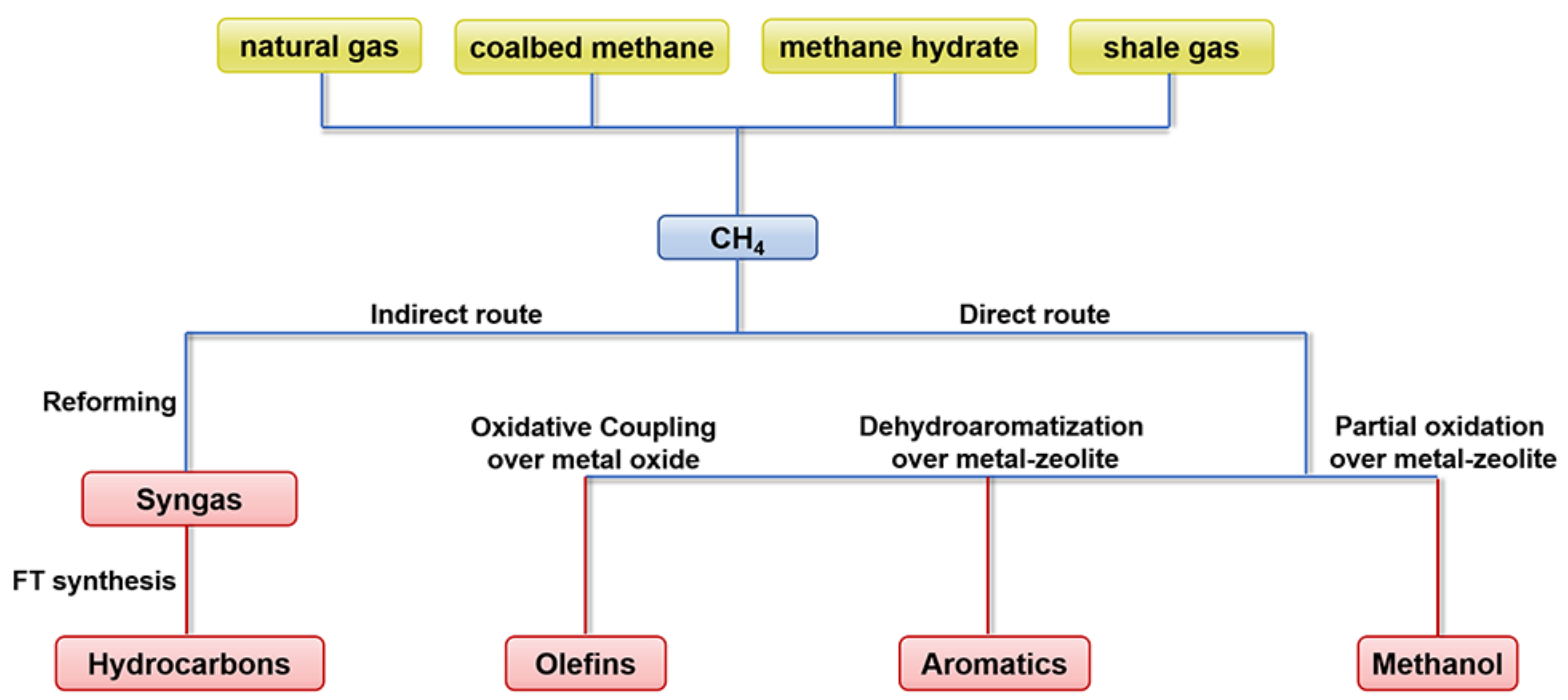

Figure 10. Flow scheme showing processes of producing $\mathrm{CH}_{4}$ and some value-added chemicals formed from $\mathrm{CH}_{4}$ through indirect and direct routes. 

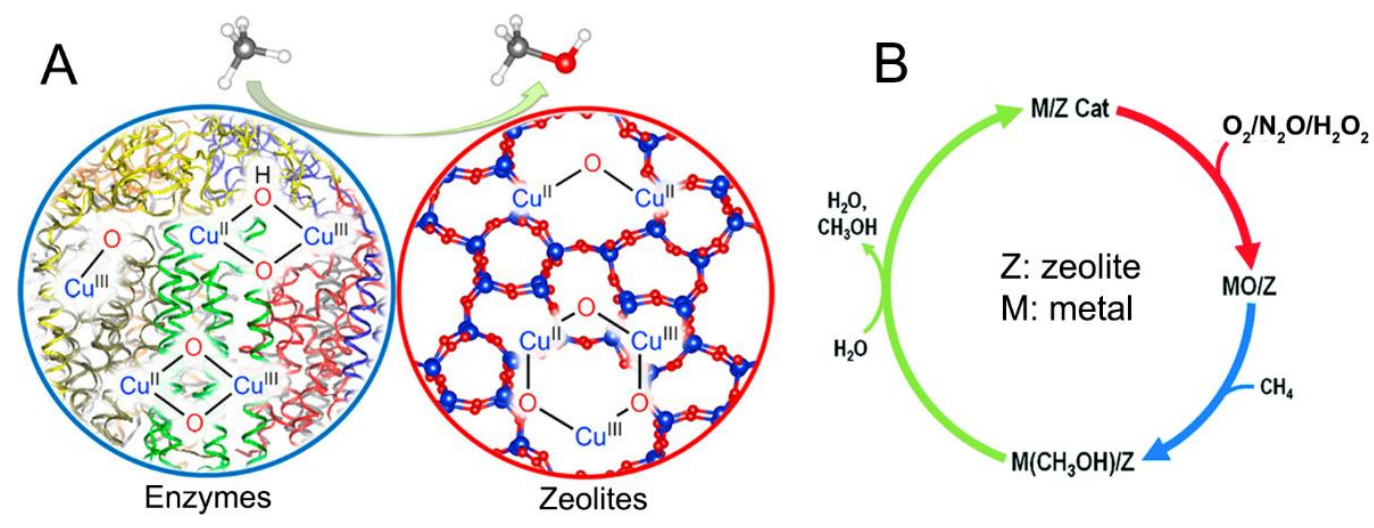

Figure 11. A) Schematic of metal-containing zeolites in methane conversion which mimics facile enzyme-catalyzed oxidation of methane. A) Reproduced with permission. ${ }^{[80 \mathrm{~b}]}$ Copyright 2018, American Chemical Society. B) Schematic representation of stepwise process of methane conversion to methanol by metal-containing zeolite catalysts (M/Z Cat). B) Reproduced with permission. ${ }^{[80 \mathrm{c}]}$ Copyright 2019, Royal Society of Chemistry. 

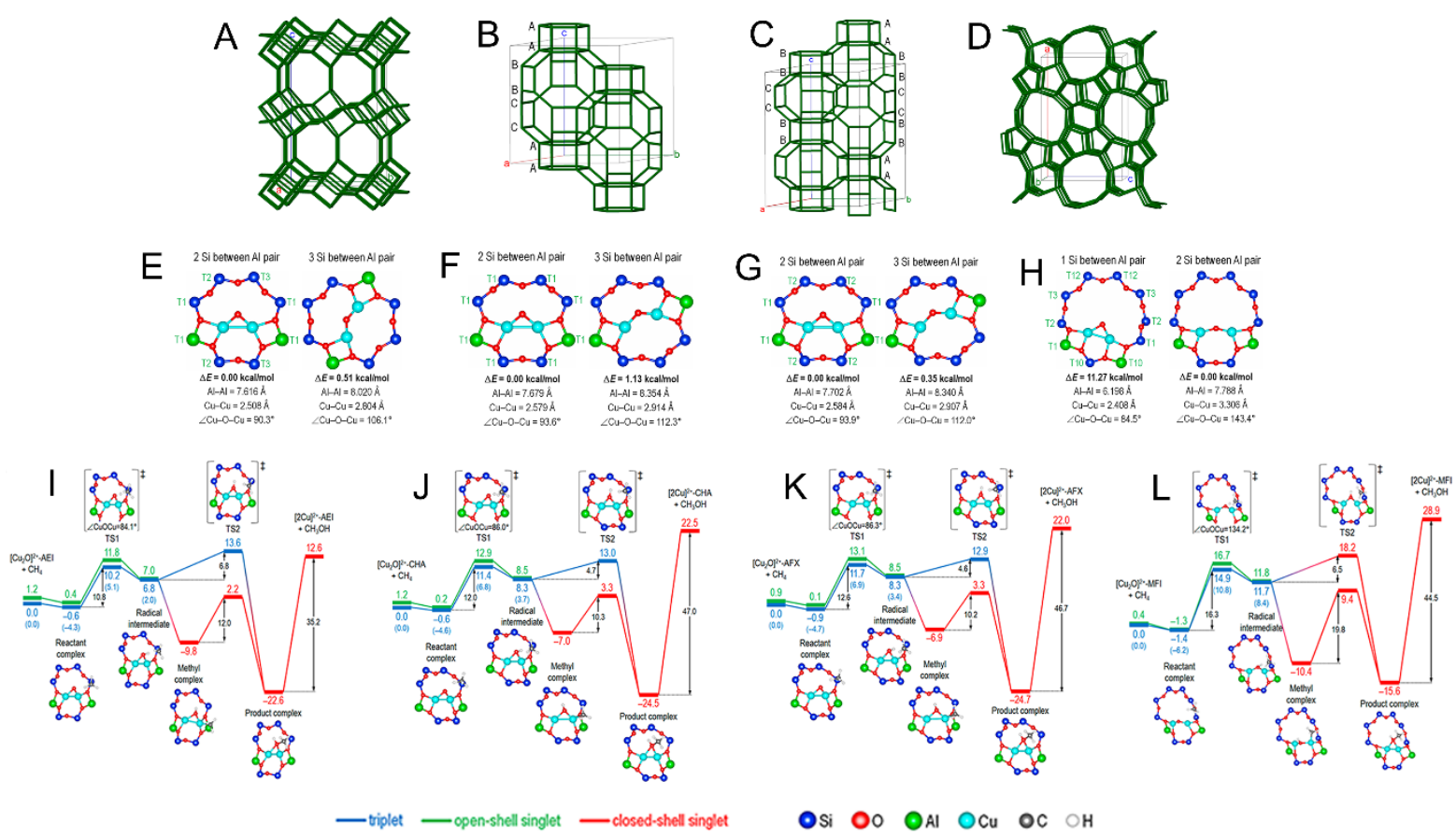

Figure 12. A-D) Zeolite framework types (A) AEI, (B) CHA, (C) AFX, and (D) MFI retrieved from the zeolite database. Lines and corners represent $\mathrm{O}$ and $\mathrm{T}$ ( $\mathrm{Si}$ or $\mathrm{Al}$ ) atoms, respectively. One unit cell of each (depicted as a cube) is used for the calculations with periodic structures. E-H) Optimized structures for $\left[\mathrm{Cu}_{2}(\mu-\mathrm{O})\right]^{2+}$ in the 8-MRs of (E) AEI, (F) CHA, and (G) AFX and (H) in the zigzag 10-MR of MFI zeolites calculated in the triplet ground state. For each, different $\mathrm{Al} \cdots \mathrm{Al}$ arrangements are considered. Only the active sites and the zeolite rings are shown, while the remaining atoms of the zeolites are omitted for clarity. I-L) Reaction energy diagrams and optimized structures of intermediates and transition states for the conversion of methane to methanol by (I) $\left[\mathrm{Cu}_{2}(\mu-\mathrm{O})\right]^{2+}-\mathrm{AEI},(\mathrm{J})-\mathrm{CHA}$, (K) -AFX, and (L) -MFI zeolites with two Si atoms separating the Al pair located at T1/T1 site. All energies are given in $\mathrm{kcal} \mathrm{mol}^{-1}$. Values in parentheses are relative energies that include dispersion correction. The ground-state and TS2 (direct) structures are shown. Only the active sites and the zeolite rings are shown, while the remaining atoms of the zeolites are

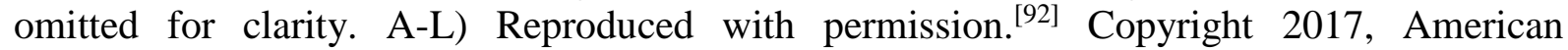
Chemical Society. 

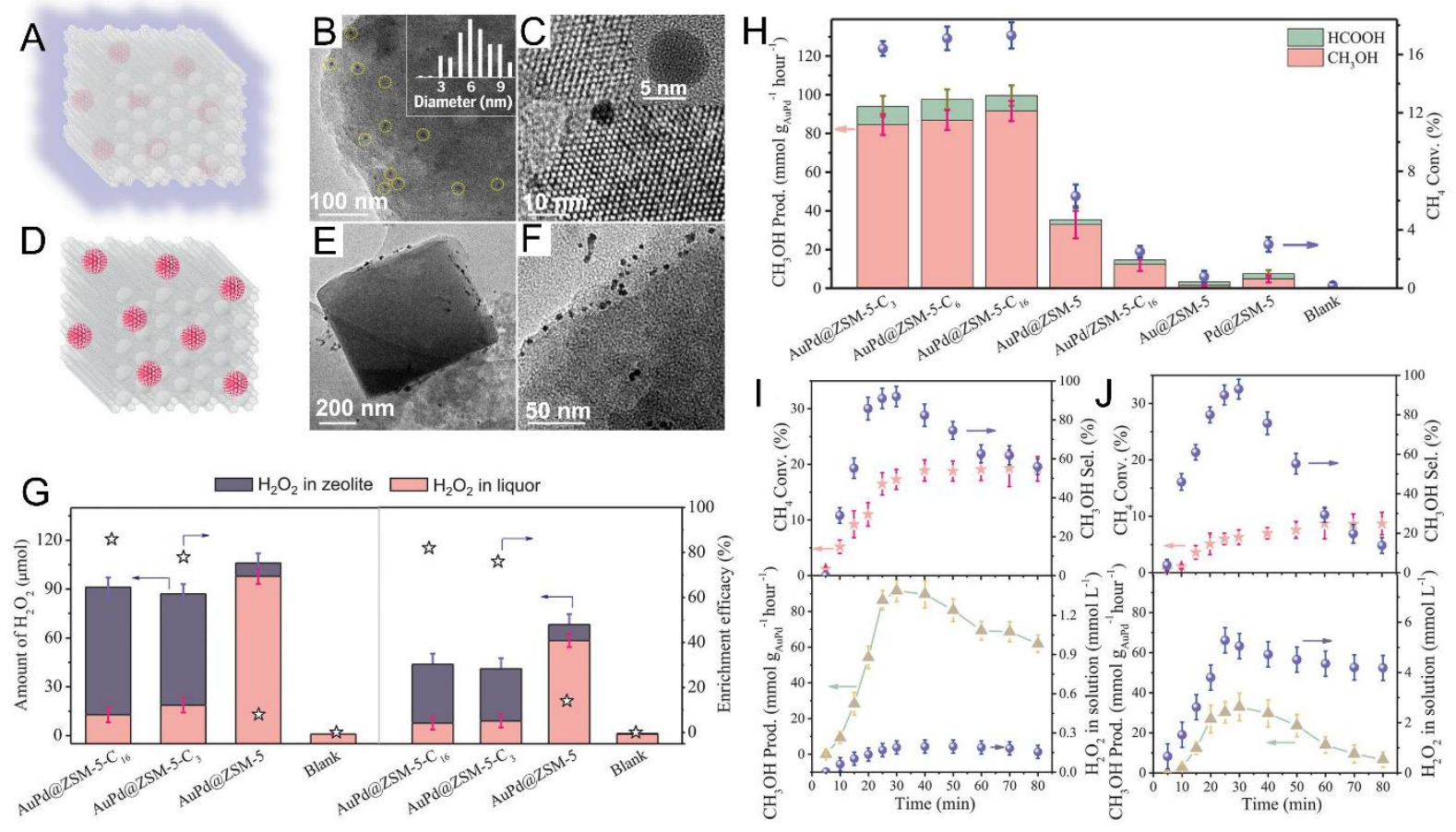

Figure 13. A-F) Models and tomographic section TEM images of (A-C) AuPd@ZSM-5-C 16 and (D-F) AuPd/ZSM-5. Scale bars: (B) $100 \mathrm{~nm}$; (C) $10 \mathrm{~nm}$ (5 nm in inset); (E) $200 \mathrm{~nm}$; (F) $50 \mathrm{~nm} . \mathrm{G}$ ) Data showing the amount of $\mathrm{H}_{2} \mathrm{O}_{2}$ in the (left) $\mathrm{H}_{2} \mathrm{O}_{2}$ synthesis and (right) methane oxidation process. The enrichment efficacy is the percentage of $\mathrm{H}_{2} \mathrm{O}_{2}$ in zeolite crystals to the total amount of $\mathrm{H}_{2} \mathrm{O}_{2}$ in the reactor. $\mathrm{H}$ ) Data characterizing the oxidation of methane with $\mathrm{H}_{2}$ and $\mathrm{O}_{2}$ over various catalysts. I, J) Dependences of the methane conversion (Conv.), methanol selectivity (Sel.), methanol productivity (Prod.), and $\mathrm{H}_{2} \mathrm{O}_{2}$ concentration in water solution on reaction time over (I) AuPd@ZSM-5-C 16 and (J) AuPd@ZSM-5 catalysts. Reaction conditions for $\mathrm{H}_{2} \mathrm{O}_{2}$ synthesis: $5.6 \mathrm{~g}$ of $\mathrm{MeOH}, 4.4 \mathrm{~g}$ of $\mathrm{H}_{2} \mathrm{O}, 30 \mathrm{~min}, 0{ }^{\circ} \mathrm{C}, 10 \mathrm{mg}$ of catalyst, 4.0 $\mathrm{MPa}$ of feed gas with $5 \% \mathrm{H}_{2} / 10 \% \quad \mathrm{O}_{2} / 45 \% \mathrm{Ar} / 40 \% \mathrm{He}$, and $1200 \mathrm{rpm}$. Reaction conditions for methane oxidation: $10 \mathrm{~mL}$ of water, $30 \mathrm{~min}, 70{ }^{\circ} \mathrm{C}, 27 \mathrm{mg}$ of catalyst, $3.0 \mathrm{MPa}$ of feed gas with $3.3 \% \mathrm{H}_{2} / 6.6 \% \mathrm{O}_{2} / 1.6 \% \mathrm{CH}_{4} / 61.7 \% \mathrm{Ar} / 26.8 \% \mathrm{He}, 15 \mathrm{~min}$, and $1200 \mathrm{rpm}$. Each reaction was tested eight times to obtain the error bars. A-J) Reproduced with permission. ${ }^{[106]}$ Copyright 2020, Science. 

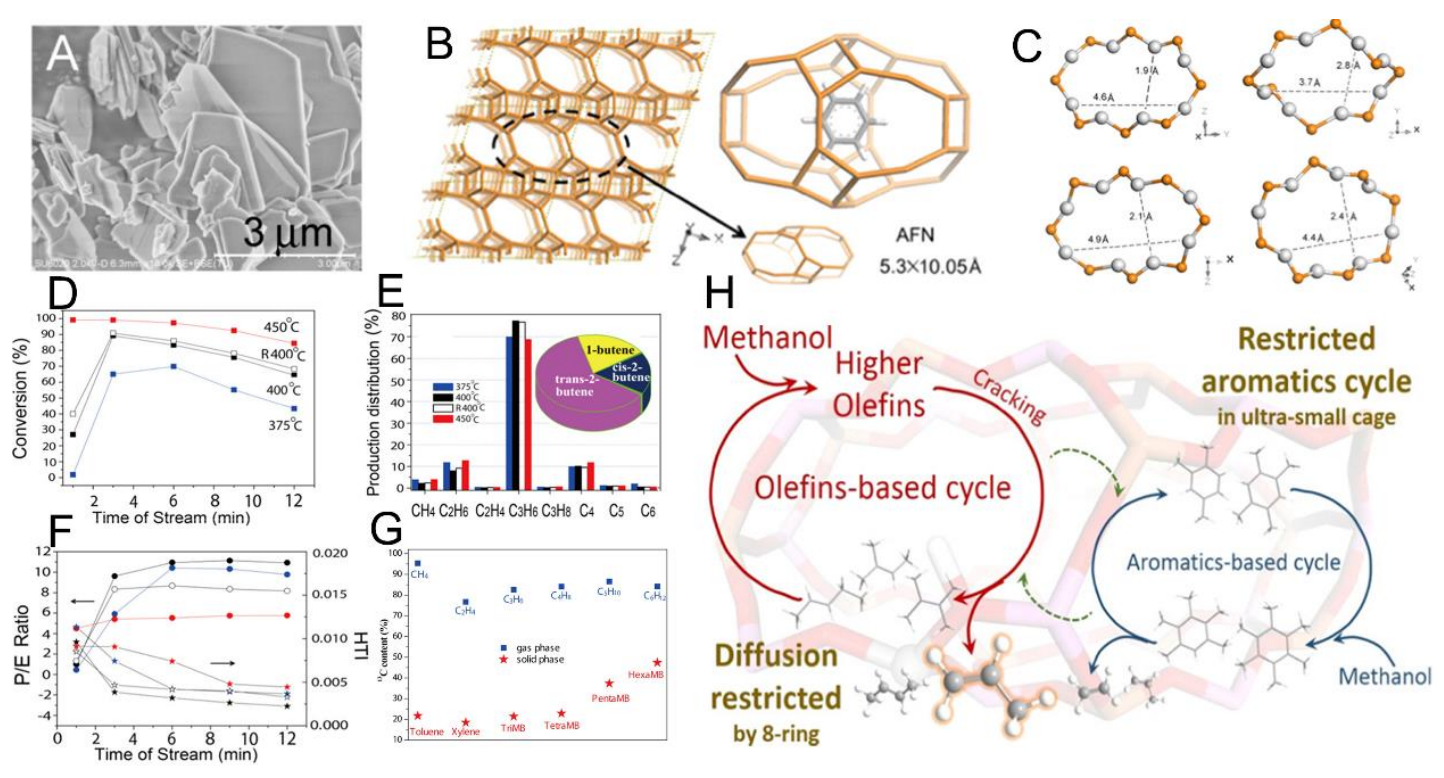

Figure 14. A) SEM images of the calcined SAPO-14. B) AFN structure viewed along the [010] direction and $4^{6} 8^{8}$ AFN cage with a hexamethylbenzene located in (C) 8-MR pore openings of SAPO-14 in four directions. D) Methanol conversion as a function of time of stream. E) Product distribution at TOS of 3 min. The inset of (E) is the detail of $\mathrm{C}_{4}$ product distribution at $400{ }^{\circ} \mathrm{C}$, TOS $=3 \mathrm{~min}$. F) P/E Ratio and HTI as a function of time of stream over the SAPO-14 catalyst at various temperatures. Intermittent sampling was taken. Blue: $375{ }^{\circ} \mathrm{C}$, black: $400{ }^{\circ} \mathrm{C}$, red: $450{ }^{\circ} \mathrm{C}$, $\mathrm{R}$ and hollow symbol refer to the regenerated sample. Methanol space velocity WHSV is $2.0 \mathrm{~h}^{-1}$ with methanol partial pressure of $\left.16.8 \mathrm{kPa} . \mathrm{G}\right){ }^{13} \mathrm{C}$ content in effluent and retained hydrocarbons in SAPO- 14 at $400{ }^{\circ} \mathrm{C}$ after 2 min ${ }^{12} \mathrm{C}$-methanol reaction, followed by $1 \mathrm{~min}{ }^{13} \mathrm{C}$-methanol reaction, WHSV $=2 \mathrm{~h}^{-1}$. H) Supposed reaction mechanism of high propylene selectivity in methanol conversion over the SAPO-14 catalyst. A-H) Reproduced with permission. ${ }^{[133]}$ Copyright 2020, American Chemical Society. 

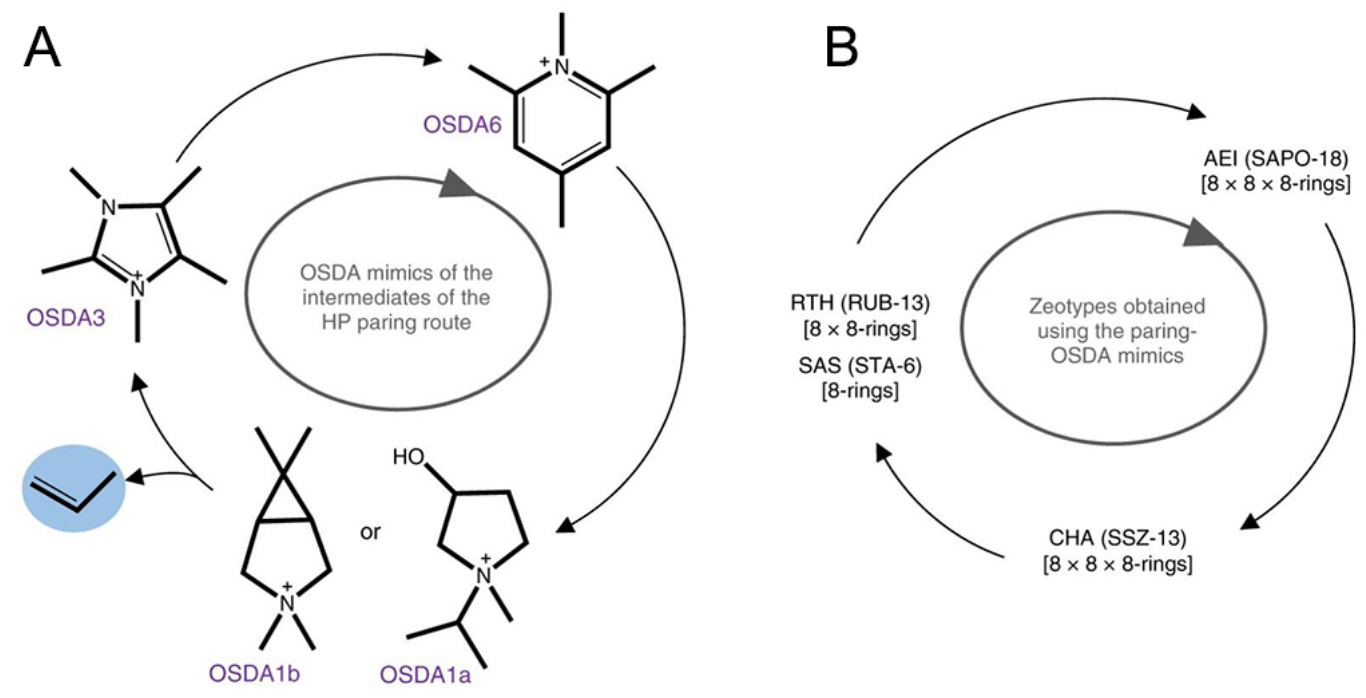

Figure 15. OSDA mimics and zeolites. A) Proposed OSDA mimics of the different intermediates present in the HP paring route. B) Zeotypes obtained using these OSDA mimics. A, B) Reproduced with permission. ${ }^{[136]}$ Copyright 2018, Springer Nature. 

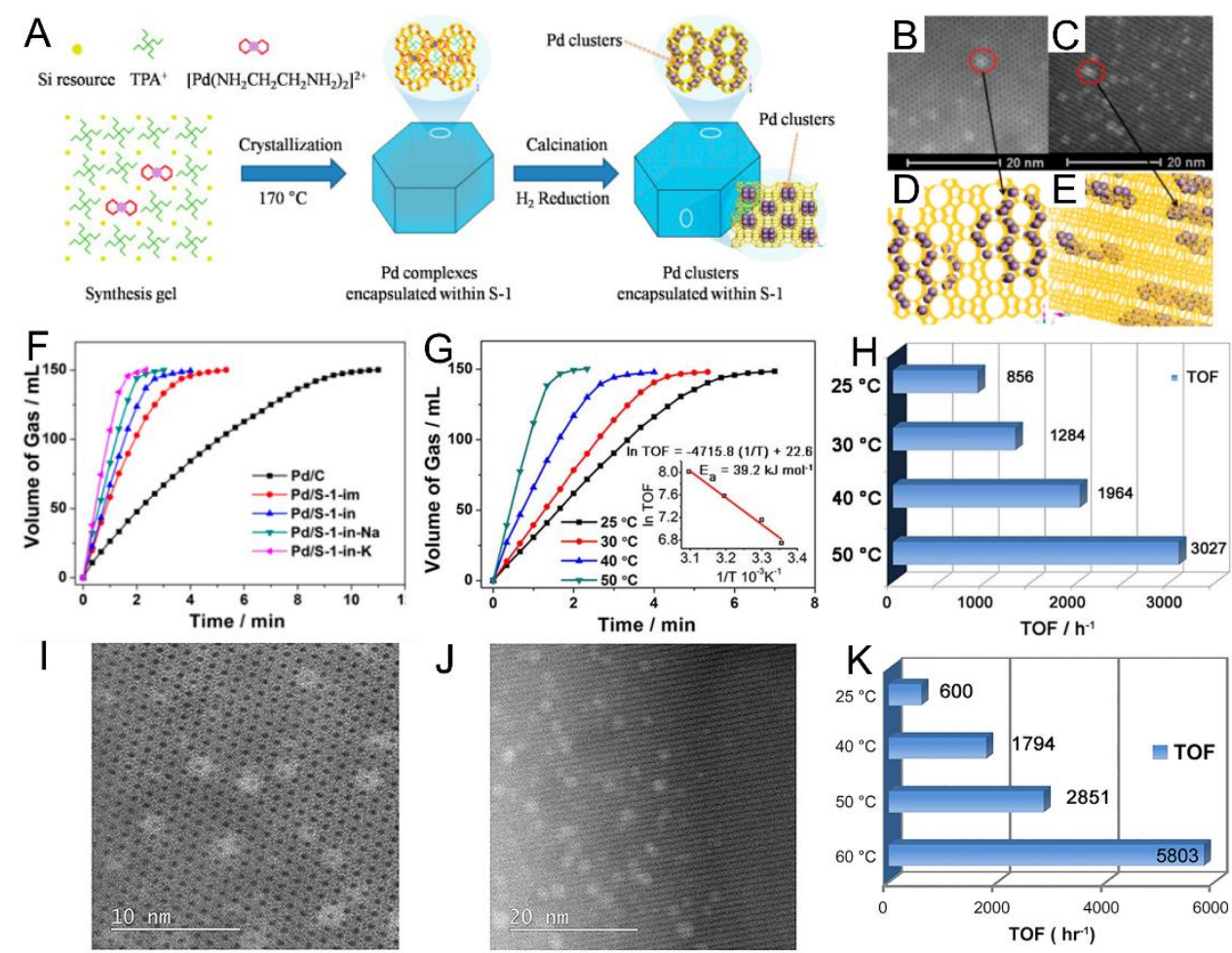

Figure 16. A) Schematic of confinement synthesis of Pd clusters within nanosized silicalite-1 zeolite. B-E) High-resolution STEM images (B, C) of Pd/S-1-K sample and corresponding schematic crystallographic projections (D, E) of MFI viewed from different orientations. F) Volume of the generated gas $\left(\mathrm{CO}_{2}+\mathrm{H}_{2}\right)$ versus time for the dehydrogenation of FA-SF $(1: 1)$ solution over $\mathrm{Pd} / \mathrm{C}$ and $\mathrm{Pd} / \mathrm{S}-1$ catalysts at $\left.50{ }^{\circ} \mathrm{C}\left(\mathrm{n}_{\mathrm{Pd}} / \mathrm{n}_{\mathrm{FA}}=0.01\right) . \mathrm{G}, \mathrm{H}\right)$ Volume of the generated gas $\left(\mathrm{CO}_{2}+\mathrm{H}_{2}\right)$ versus time $(\mathrm{G})$ and corresponding TOF values of $\mathrm{H}_{2}$ generation (H) for the dehydrogenation of FA-SF (1:1) solution at different temperatures over Pd/S-1-in$\mathrm{k}$ catalyst. Inset of $(\mathrm{G})$ : Arrhenius plot (ln TOF vs. 1/T). A-H) Reproduced with permission. ${ }^{[48 a]}$ Copyright 2016, American Chemical Society. I, J) $\mathrm{C}_{\mathrm{s}}$-corrected STEM images of $0.8 \mathrm{Pd} 0.2 \mathrm{Ni}(\mathrm{OH})_{2} @ \mathrm{~S}-1$ catalyst viewed along the b-axis orientation with high magnification (I) and viewed along other orientation (J). K) initial TOF values of $\mathrm{H}_{2}$ generation for the decomposition of $2 \mathrm{M}$ FA solution at different temperatures over 0.8Pd0.2Ni(OH) $)_{2} @ \mathrm{~S}-1$ catalyst. I-K) Reproduced with permission. ${ }^{[149]}$ Copyright 2017, Elsevier. 
Table 1. Structural information of several commercialized zeolite catalysts utilized in $\mathrm{C} 1$ chemistry. ${ }^{\mathrm{a}}$

\begin{tabular}{|c|c|c|c|c|c|}
\hline Topology & $\begin{array}{l}\text { Type } \\
\text { Material }\end{array}$ & $\begin{array}{l}\text { Lattice } \\
\text { parameters }\end{array}$ & Channel size (ring size) & $\begin{array}{c}\text { Channel } \\
\text { dimensionality }^{c}\end{array}$ & Framework image $^{d}$ \\
\hline CHA & $\begin{array}{l}\text { SAPO-34 } \\
\text { SSZ-13 }\end{array}$ & $\begin{array}{l}a=13.6750 \AA \\
b=13.6750 \AA \\
c=14.7670 \AA \\
\alpha=90.000^{\circ} \\
\beta=90.000^{\circ} \\
V=90.000^{\circ}\end{array}$ & [001] 3.8 × $3.8 \AA$ (8-MR) & $\begin{array}{l}\text { Sorption: 3D } \\
\text { Topological: 3D }\end{array}$ & Along [001] direction \\
\hline MFI & $\begin{array}{l}\text { ZSM-5 } \\
\text { Silicalite-1 }\end{array}$ & $\begin{array}{l}a=20.0900 \AA \\
b=19.7380 \AA \\
c=13.1420 \AA \\
\alpha=90.000^{\circ} \\
\beta=90.000^{\circ} \\
\gamma=90.000^{\circ}\end{array}$ & $\begin{array}{l}{[100] 5.1 \times 5.5 \AA(10-M R)} \\
{[010] 5.3 \times 5.6 \AA(10-M R)}\end{array}$ & $\begin{array}{l}\text { Sorption: 3D } \\
\text { Topological: 3D }\end{array}$ & Along [010] direction \\
\hline${ }^{*}$ BEA & Beta & $\begin{array}{l}a=12.6320 \AA \\
b=12.6320 \AA \\
c=26.1860 \AA \\
\alpha=90.000^{\circ} \\
\beta=90.000^{\circ} \\
y=90.000^{\circ}\end{array}$ & $\begin{array}{l}{[100] 6.6 \times 6.7 \AA(12-\mathrm{MR})} \\
{[001] 5.6 \times 5.6 \AA(12-\mathrm{MR})}\end{array}$ & $\begin{array}{l}\text { Sorption: 3D } \\
\text { Topological: 3D }\end{array}$ & Along [100] directior \\
\hline MOR & Mordenite & $\begin{array}{l}a=18.2560 \AA \\
b=20.5340 \AA \\
c=7.54200 \AA \\
\alpha=90.000^{\circ} \\
\beta=90.000^{\circ} \\
V=90.000^{\circ}\end{array}$ & $\begin{array}{l}{[001] 6.5 \times 7.0 \AA(12-M R)} \\
{[001] 2.6 \times 5.7 \AA(8-M R)}\end{array}$ & $\begin{array}{l}\text { Sorption: 1D } \\
\text { Topological: } 2 \mathrm{D}\end{array}$ & Along [001] direction \\
\hline AEI & $\begin{array}{l}\text { SSZ-39 } \\
\text { SAPO-18 }\end{array}$ & $\begin{array}{l}a=13.6770 \AA \\
b=12.6070 \AA \\
c=18.4970 \AA \\
\alpha=90.000^{\circ} \\
\beta=90.000^{\circ} \\
\gamma=90.000^{\circ}\end{array}$ & $\begin{array}{l}{[001] 3.8 \times 3.8 \AA(8-M R)} \\
{[100] 3.8 \times 3.8 \AA(8-M R)} \\
{[110] 3.8 \times 3.8 \AA(8-M R)}\end{array}$ & $\begin{array}{l}\text { Sorption: 3D } \\
\text { Topological: } 3 \mathrm{D}\end{array}$ & \\
\hline
\end{tabular}

${ }^{\text {a) }}$ Data collected from the zeolite database $;{ }^{[7]}$ b) Idealized framework data obtained from a DLS-refinement, which was carried out assuming a (sometimes hypothetical) $\mathrm{SiO}_{2}$ composition. ${ }^{\text {c) }}$ Sorption and topological channel dimensionalities correspond to a pore opening larger than $3.4 \AA$ and a pore opening larger than a 6-MR, respectively. d) Red rectangle/rhombus represents the unit cell of corresponding zeolite topology. 
Table 2. Representative zeolite-based catalysts and their performance in syngas conversion to ethanol and hydrocarbons. ${ }^{a}$

\begin{tabular}{|c|c|c|c|c|c|c|c|c|c|c|c|}
\hline \multirow{2}{*}{ Catalyst } & \multicolumn{2}{|c|}{ Zeolite character } & \multicolumn{2}{|c|}{ Metallic species } & \multirow[b]{2}{*}{$\begin{array}{l}\text { CO } \\
\text { conv } \\
.[\%]\end{array}$} & \multicolumn{5}{|c|}{ Product selectivity [\%] } & \multirow[b]{2}{*}{ Ref. } \\
\hline & Topology & $\begin{array}{c}\mathrm{Si} / \mathrm{Al} \\
(\mathrm{B} \text { sites } \\
\left.\left[\mu \mathrm{mol} \mathrm{g}^{-1}\right]\right)^{\mathrm{b}}\end{array}$ & $\begin{array}{c}\text { Metal } \\
\text { (loading) }^{c} \\
{[w t \%]}\end{array}$ & $\begin{array}{l}\text { Metal } \\
\text { size } \\
{[\mathrm{nm}]}\end{array}$ & & $\begin{array}{l}\text { Light } \\
\text { olefins }\end{array}$ & Aromatics & Gasoline & $\begin{array}{l}\text { Diesel } \\
\text { fuel }\end{array}$ & Ethanol & \\
\hline $\begin{array}{l}\mathrm{ZnCrO} / \mathrm{SAPO} \\
-34\end{array}$ & CHA & - & $\begin{array}{l}\mathrm{ZnCrO}_{x} \\
(58)\end{array}$ & $>5$ & 17 & 80 & - & - & - & - & [12a] \\
\hline $\begin{array}{l}\mathrm{ZnCrO}_{x^{-}} \\
\text {Mordenite }\end{array}$ & MOR & $(0.98)$ & $\begin{array}{l}\mathrm{ZnCrO}_{x} \\
(50)\end{array}$ & - & 26 & $\begin{array}{l}\text { Ethylene } \\
=73\end{array}$ & - & - & - & - & [20] \\
\hline $\begin{array}{l}\mathrm{ZnCrO}_{x} / \mathrm{AlPO}- \\
18\end{array}$ & AEI & 0 & $\begin{array}{l}\mathrm{ZnCrO}_{x} \\
(50)\end{array}$ & - & 16.6 & $84.4^{d}$ & - & - & - & - & [23] \\
\hline $\begin{array}{l}\mathrm{ZnCrO}_{\mathrm{x}} / \mathrm{low}- \\
\text { Si-AIPO-18 }\end{array}$ & AEI & 0.013 & $\begin{array}{l}\mathrm{ZnCrO}_{x} \\
(50)\end{array}$ & - & 25.2 & $86.7^{d}$ & - & - & - & - & [23] \\
\hline $\begin{array}{l}\mathrm{Fe} / \mathrm{C} @ \mathrm{SAPO}- \\
34\end{array}$ & CHA & 0.247 & $\mathrm{Fe}(35)$ & $>10$ & - & 36.2 & - & - & - & - & [25b] \\
\hline $\begin{array}{l}\mathrm{FeZnNa/ZSM-} \\
5\end{array}$ & MFI & $\begin{array}{l}22.8 \\
(0.2)\end{array}$ & $\begin{array}{l}\mathrm{FeZnNa} \\
(16.7)\end{array}$ & $>10$ & 88.8 & - & 50.6 & - & - & - & {$[16]$} \\
\hline $\begin{array}{l}\mathrm{ZnCrO}_{x} / \mathrm{ZSM}- \\
5\end{array}$ & MFI & 266.5 & $\begin{array}{l}\mathrm{ZnCrO}_{x} \\
(50)\end{array}$ & $20-50$ & 16 & - & 73.9 & - & - & - & [25a] \\
\hline Fe/ZSM-5 & MFI & $\begin{array}{l}85 \\
(0.67)\end{array}$ & $\mathrm{Fe}(5.43)$ & $1.5-3.9$ & 56.3 & - & 23.2 & - & - & - & {$[30 \mathrm{c}]$} \\
\hline $\begin{array}{l}\mathrm{Fe}_{3} \mathrm{O}_{4} @ \mathrm{MnO}_{2} \\
\text { /ZSM-5 }\end{array}$ & MFI & 13.5 & $\begin{array}{l}\mathrm{Fe}_{3} \mathrm{O}_{4} @ \mathrm{M} \\
\mathrm{nO}_{2}(50)\end{array}$ & $>20$ & 83.4 & - & 33.83 & - & - & - & {$[37 \mathrm{a}]$} \\
\hline $\mathrm{Co} / \mathrm{Ce}-\mathrm{Y}$ & FAU & 2.8 & Co (15) & 16 & 34 & - & - & 74 & - & - & {$[18 b]$} \\
\hline Co/ZSM-5 & MFI & $\begin{array}{l}13 \\
(0.507)\end{array}$ & Co (20) & $>10$ & 26.8 & - & - & 22.9 & - & - & [19] \\
\hline Co/Mordenite & MOR & $\begin{array}{l}8 \\
(0.345)\end{array}$ & Co (20) & $>10$ & 40.1 & - & - & 19.2 & - & - & [19] \\
\hline Co/Beta & BEA & $\begin{array}{l}9 \\
(0.088)\end{array}$ & Co (20) & $>10$ & 17.5 & - & - & 19.4 & - & - & [19] \\
\hline $\begin{array}{l}\text { ZSM- } \\
\text { 5/Ru/Silicalite } \\
-1\end{array}$ & MFI & $\begin{array}{l}168 \\
(0.049)\end{array}$ & $\mathrm{Ru}(6.7)$ & $3-20$ & 20.9 & - & - & 50.6 & - & - & [27] \\
\hline $\begin{array}{l}\text { ZSM- } \\
\text { 5/Ru/ZSM-5 }\end{array}$ & MFI & $\begin{array}{l}27 \\
(0.465)\end{array}$ & $\mathrm{Ru}(7.8)$ & $3-20$ & 36.8 & - & - & 60.6 & - & - & {$[27]$} \\
\hline Co/ZSM-5 & MFI & 14 & Co (8) & $\begin{array}{l}8.4 \pm \\
1.8\end{array}$ & 45 & - & - & 70 & - & - & [31] \\
\hline Co/ZSM-5 & MFI & 15 & Co (4.3) & $>10$ & 55.6 & - & - & 72.7 & - & - & [38] \\
\hline $\begin{array}{l}\text { Co/ZSM- } \\
5 @ \text { Silicalite-1 }\end{array}$ & MFI@MFI & 35.7 & Co (2.6) & $>10$ & 68.9 & - & - & 74.7 & - & - & [38] \\
\hline Fe/ZSM-5 & MFI & 19 & $\mathrm{Fe}(20)$ & $>20$ & 53.1 & - & - & 60.1 & - & - & [39] \\
\hline Co/K-Y & FAU & 2.8 & Co (15) & 14 & 30 & - & - & - & 58 & - & [18b] \\
\hline Co/Y & FAU & 2.6 & Co (15) & 8.4 & 40 & - & - & - & 60 & - & [32] \\
\hline $\begin{array}{l}\mathrm{ZnO}- \\
\mathrm{ZrO}_{2} / \mathrm{Mordenit} \\
\mathrm{e} / \mathrm{Pt}-\mathrm{Sn} / \mathrm{SiC}\end{array}$ & MOR & 19 & $\begin{array}{l}\mathrm{ZnO}-\mathrm{ZrO}_{2} \\
(33.3)\end{array}$ & $5-10$ & 4.0 & - & - & - & - & 81 & {$[42 \mathrm{c}]$} \\
\hline
\end{tabular}




\begin{tabular}{|c|c|c|c|c|c|c|c|c|c|c|c|}
\hline $\begin{array}{l}\text { CuZnAl/HZS } \\
\text { M- } \\
\text { 5/Mordenite }\end{array}$ & MFI/MOR & 20 & $\begin{array}{l}\text { CuZnAl } \\
(25-50)\end{array}$ & - & 6.4 & - & - & - & - & 50.1 & [41b] \\
\hline $\begin{array}{l}\text { CuZnAl/HZS } \\
\text { M-5/Zn- } \\
\text { Mordenite }\end{array}$ & MFI/MOR & 20 & $\begin{array}{l}\text { CuZnAl } \\
(25-50)\end{array}$ & - & 7.4 & - & - & - & - & 69.5 & [41b] \\
\hline $\begin{array}{l}\text { RhMn@Silical } \\
\text { ite-1 }\end{array}$ & MFI & infinite & $\begin{array}{l}\operatorname{Rh}(0.76) \\
\operatorname{Mn}(0.85\end{array}$ & 2.4-3.0 & 42.4 & - & - & - & - & $88.3^{e}$ & {$[41 \mathrm{c}]$} \\
\hline
\end{tabular}

a) This table focuses on presenting the zeolite characteristics, metallic species, and corresponding catalytic performance in syngas conversion, and the reaction conditions mentioned here are a bit different when producing various target products from syngas, which mainly falls in the following range: $230-400{ }^{\circ} \mathrm{C}, 1.0-5.0 \mathrm{MPa}, 1500-7714 \mathrm{~mL} \mathrm{~h}^{-1} \mathrm{gcat}^{-1}, \mathrm{H}_{2} / \mathrm{CO}$ $=1-3 ;{ }^{\text {b) }}$ Brønsted sites per gram of zeolites were determined by ${ }^{1} \mathrm{H}$ MAS NMR or FT-IR

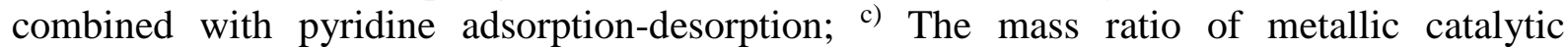
components in zeolite-based bi- and multi-functional catalyst systems; d) Selectivity was calculated based on carbon molar amount of hydrocarbons without other products such as $\mathrm{CO}_{2}$ and oxygenates (note: the hydrocarbon selectivity in all the products is $50.6 \%$ and $51.6 \%$ for $\mathrm{ZnCrO}_{\mathrm{x}} / \mathrm{AlPO}-18$ and $\mathrm{ZnCrO}_{\mathrm{x}} /$ low-Si AlPO-18, respectively); ${ }^{\text {e) Selectivity of }}$ ethanol in total oxygenates (note: selectivity of oxygenates in all the products is $40.3 \%$ ). 
Table 3 Representative zeolite-based catalysts and their performance in $\mathrm{CO}_{2}$ conversion into hydrocarbons and oxygenates. ${ }^{\mathrm{a}}$

\begin{tabular}{|c|c|c|c|c|c|c|c|c|c|c|}
\hline \multirow{2}{*}{ Catalyst } & \multicolumn{2}{|c|}{ Zeolite character } & \multicolumn{2}{|c|}{ Metallic species } & \multirow[b]{2}{*}{$\begin{array}{l}\mathrm{CO}_{2} \\
\text { conv } \\
.[\%]\end{array}$} & \multicolumn{4}{|c|}{ Product selectivity [\%] } & \multirow[b]{2}{*}{ Ref. } \\
\hline & Topology & Si/Al. & $\begin{array}{c}\text { Metal } \\
\text { (loading) }^{\mathrm{b}} \\
\text { [wt\%] }^{\text {a }}\end{array}$ & $\begin{array}{l}\text { Metal } \\
\text { size } \\
{[\mathrm{nm}]}\end{array}$ & & Methane & Aromatics & Methanol & DME & \\
\hline Rh@Silicalite-1 & MFI & infinite & $\operatorname{Rh}(0.45)$ & $4.3 \pm 0.5$ & 17.9 & 8.5 & - & - & - & [55g] \\
\hline Rh@ZSM-5 & MFI & 28.1 & $\operatorname{Rh}(0.42)$ & $5.0 \pm 0.6$ & 59.1 & 99.6 & - & - & - & [55g] \\
\hline $\mathrm{Ni} / \mathrm{ZSM}-5$ & MFI & 39.1 & $\mathrm{Ni}(10.29)$ & 10.2 & 68.4 & 94.8 & - & - & & [55h] \\
\hline Ni@ZSM-5 & MFI & 37.4 & $\mathrm{Ni}(10.59)$ & 7.6 & 66.2 & 99.8 & - & - & & [55h] \\
\hline $\mathrm{Ni} /$ Beta & BEA & 11.9 & $\mathrm{Ni}(9.5)$ & 20.1 & 33 & 88 & - & - & - & [58d] \\
\hline $\mathrm{Ni} / \mathrm{La}_{2} \mathrm{O}_{3} /$ Beta & BEA & 12.7 & $\begin{array}{l}\mathrm{Ni}(7.8) \\
\mathrm{La}_{2} \mathrm{O}_{3}(7.4)\end{array}$ & $\mathrm{Ni}(8.7)$ & 65 & 99 & - & - & - & [58d] \\
\hline $\mathrm{Ni} / \mathrm{La}_{2} \mathrm{O}_{3} /$ Beta & BEA & 25 & $\begin{array}{l}\mathrm{Ni}(11.04) \\
\mathrm{La}(15.51)\end{array}$ & - & 84 & 97 & - & - & - & [58e] \\
\hline $\mathrm{ZnFeO} / \mathrm{ZSM}-5$ & MFI & 12.5 & $\begin{array}{l}\mathrm{Fe}(49.78) \\
\mathrm{Na}(4.25)\end{array}$ & $\begin{array}{l}\mathrm{ZnFeO} x \\
(>5)\end{array}$ & 41.2 & - & 75.6 & - & - & [53] \\
\hline $\mathrm{Cr}_{2} \mathrm{O}_{3} / \mathrm{ZSM}-5$ & MFI & 40.5 & $\mathrm{Cr}_{2} \mathrm{O}_{3}(50)$ & $>50$ & 34.5 & - & 75.9 & - & - & [55c] \\
\hline ZnZrO/ZSM-5 & MFI & 100 & $\begin{array}{l}\text { ZnZrO } \\
(50)\end{array}$ & $20-30$ & 14 & - & 73 & - & - & [55j] \\
\hline PdZn/ZSM-5, & MFI & 15 & $\begin{array}{l}\mathrm{Pd}(5) \\
\mathrm{Zn}(15)\end{array}$ & $\begin{array}{l}\mathrm{PdZn} \\
(5.5)\end{array}$ & 14 & - & - & 4.2 & 30.4 & [70a] \\
\hline CuZnZr/Mordenite & MOR & 21 & $\begin{array}{l}\text { CuZnZr } \\
(66.6)\end{array}$ & $\mathrm{Cu}(8)$ & 23.2 & - & - & 11.2 & 50.8 & [74] \\
\hline CuZnZr/Ferrierite & FER & 6 & $\begin{array}{l}\text { CuZnZr } \\
(66.6)\end{array}$ & $\mathrm{Cu}(8)$ & 26.0 & - & - & 12.8 & 55.7 & [74] \\
\hline CuZnZr/ZSM-5 & MFI & 36 & $\begin{array}{l}\text { CuZnZr } \\
(66.6)\end{array}$ & $\mathrm{Cu}(9)$ & 21.3 & - & - & 12.9 & 40.5 & [74] \\
\hline
\end{tabular}

a) This table focuses on presenting the zeolite characteristics, metallic species, and corresponding catalytic performance in $\mathrm{CO}_{2}$ conversion, and the reaction conditions mentioned here are a bit different when producing various target products from $\mathrm{CO}_{2}$, which mainly falls in the following range: $250-400{ }^{\circ} \mathrm{C}, 0.1-5.0 \mathrm{MPa}, 1200-25000 \mathrm{~h}^{-1}, \mathrm{CO}_{2} / \mathrm{H}_{2} / \mathrm{N}_{2}(\mathrm{Ar})$ $\left.=1 /(1-4) /(0.12-1.5) ;{ }^{b}\right)$ The mass ratio of metallic catalytic components in zeolite-based biand multi-functional catalyst systems. 
Table 4 Representative zeolite-based catalysts and their performance in $\mathrm{CH}_{4}$ conversion into methanol and aromatics. ${ }^{\mathrm{a}}$

\begin{tabular}{|c|c|c|c|c|c|c|c|c|}
\hline \multirow{2}{*}{ Catalyst } & \multicolumn{2}{|c|}{ Zeolite character } & \multicolumn{2}{|c|}{ Metallic species } & \multirow[b]{2}{*}{$\begin{array}{c}\mathrm{CH}_{4} \\
\text { conv. } \\
{[\%]}\end{array}$} & \multicolumn{2}{|c|}{ Product selectivity [\%] } & \multirow[b]{2}{*}{ Ref. } \\
\hline & Topology & $\begin{array}{c}\mathrm{Si} / \mathrm{Al} \\
(\mathrm{B} \text { sites } \\
\left.\left[\mathrm{mmol} \mathrm{g}^{-1}\right]\right)^{\mathrm{b}}\end{array}$ & $\begin{array}{c}\text { Metal } \\
\text { (loading) } \\
\text { [wt\%] }\end{array}$ & $\begin{array}{l}\text { Metal size } \\
{[\mathrm{nm}]}\end{array}$ & & $\begin{array}{c}\text { Methanol } \\
\text { selectivity (yield or } \\
\text { productivity) }\end{array}$ & $\begin{array}{c}\text { Aromatics } \\
\text { selectivity } \\
\text { (Formation } \\
\text { rate) }\end{array}$ & \\
\hline Cu-Mordenite & MOR & 7 & $\mathrm{Cu}(2.33)$ & dinuclear & - & $\left(170 \mu \mathrm{mol} \mathrm{g}{ }^{-1}\right)$ & - & [85] \\
\hline Cu-Mordenite & MOR & 6.5 & $\mathrm{Cu}(4.18)$ & - & - & $95\left(118.5 \mu \mathrm{mol} \mathrm{g}^{-1}\right)$ & - & [87] \\
\hline Cu-Mordenite & MOR & 10 & $\mathrm{Cu}(2.58)$ & trinuclear & - & $\left(55.3 \mu \mathrm{mol} \mathrm{g}^{-1}\right)$ & - & [95t] \\
\hline Cu-Mordenite & MOR & 6 & $\mathrm{Cu}(4.7)$ & $\mathrm{Cu}<5$ & - & $\left(56.2 \mu \mathrm{mol} \mathrm{g}^{-1}\right)$ & - & [95h] \\
\hline Cu-Na-SSZ-13 & CHA & 12 & $\mathrm{Cu}(3.6)$ & dinuclear & - & $\left(28.1 \mu \mathrm{mol} \mathrm{g}^{-1}\right)$ & - & {$[100]$} \\
\hline Cu-Na-SSZ-39 & AEI & 10 & $\mathrm{Cu}(4.4)$ & dinuclear & - & $\left(22.7 \mu \mathrm{mol} \mathrm{g}^{-1}\right)$ & - & [100] \\
\hline Cu-Erionite & ERI & 5.6 & $\mathrm{Cu}(4.2)$ & - & - & $\left(147 \mu \mathrm{mol} \mathrm{g}{ }^{-1}\right)$ & - & [101] \\
\hline $\begin{array}{l}\text { AuPd@ZSM- } \\
5 @ \text { silane }\end{array}$ & MFI & 30 & $\begin{array}{l}\mathrm{Au}(3.24) \\
\mathrm{Pd}(1.76)\end{array}$ & AuPd $<10$ & 17.3 & $\begin{array}{l}92 \\
\left(91.6 \mathrm{mmol} \mathrm{g}_{\mathrm{AuPd}}{ }^{-1} \mathrm{~h}^{-1}\right)\end{array}$ & - & [106] \\
\hline Fe-ZSM-5 & MFI & 24 & $\mathrm{Fe}(2)$ & - & $<10$ & - & 67.7 & [110d] \\
\hline Mo-ZSM-5 & MFI & 24 & Mo (3.37) & - & $<15$ & - & 82.4 & [110d] \\
\hline Mo-ZSM-5 & MFI & $16.5(0.076)$ & Mo (3.1) & - & 5.2 & - & 47 & [113] \\
\hline Mo/Na-ZSM-5 & MFI & $16.5(0.040)$ & Mo (3.1) & - & 3.5 & - & 72.7 & [113] \\
\hline Mo/Cs-ZSM-5 & MFI & $16.5(0.043)$ & Mo (3.2) & - & 3.6 & - & 65 & [113] \\
\hline Mo/Ca-ZSM-5 & MFI & $16.5(0.052)$ & Mo (3.0) & - & 2.5 & - & 56.6 & [113] \\
\hline Mo/MCM-22 & MWW & $10.5(0.606)$ & $\begin{array}{l}\mathrm{Mo} /(\mathrm{Si}+\mathrm{Al}) \\
=0.0254\end{array}$ & - & $<10$ & - & $<60$ & [114a] \\
\hline Mo/MCM-22 & MWW & $45.5(0.168)$ & $\begin{array}{l}\mathrm{Mo} /(\mathrm{Si}+\mathrm{Al}) \\
=0.0327\end{array}$ & - & $<7$ & - & $<40$ & [114a] \\
\hline
\end{tabular}

a) This table focuses on presenting the zeolite characteristics, metallic species, and corresponding catalytic performance in $\mathrm{CH}_{4}$ conversion, and the reaction conditions mentioned here are a bit different when producing various target products from $\mathrm{CH}_{4}$, which mainly falls in the following range: oxidation of metal-containing zeolite catalysts at 300$550{ }^{\circ} \mathrm{C}, \mathrm{CH}_{4}$ conversion at $70-300{ }^{\circ} \mathrm{C}, 80-95 \% \mathrm{CH}_{4}$ in helium, nitrogen, or argon with a flow rate of $10-70 \mathrm{~mL} \mathrm{~min}^{-1}$; b) Brønsted sites per gram of zeolites were determined by ${ }^{1} \mathrm{H}$ MAS NMR or FT-IR combined with pyridine adsorption-desorption; ${ }^{c)}$ The mass ratio of metallic catalytic components in zeolite-based bi- and multi-functional catalyst systems. 


\section{References}

[1] W. Zhou, K. Cheng, J. Kang, C. Zhou, V. Subramanian, Q. Zhang, Y. Wang. Chem. Soc. Rev. 2019, 48, 3193.

[2] D. X. Martínez-Vargas, L. Sandoval-Rangel, O. Campuzano-Calderon, M. RomeroFlores, F. J. Lozano, K. D. P. Nigam, A. Mendoza, A. Montesinos-Castellanos. Ind. Eng. Chem. Res 2019, 58, 15872.

[3] a) C. Du, P. Lu, N. Tsubaki. ACS Omega 2020, 5, 49; b) X. Jiang, X. Nie, X. Guo, C. Song, J. G. Chen. Chem. Rev. 2020, DOI:10.1021/acs.chemrev.9b00723; c) P. Tomkins, M. Ranocchiari, J. A. van Bokhoven. Acc. Chem. Res. 2017, 50, 418; d) W. Dai, X. Wang, G. Wu, N. Guan, M. Hunger, L. Li. ACS Catal. 2011, 1, 292; e) A. Galadima, O. Muraza. Ind. Eng. Chem. Res 2015, 54, 4891; f) P. Preuster, J. Albert. Energy Technol. 2018, 6, 501; g) N. Onishi, M. Iguchi, X. Yang, R. Kanega, H. Kawanami, Q. Xu, Y. Himeda. Adv. Energy Mater. 2019, 9, 1801275.

[4] a) I. Yarulina, A. D. Chowdhury, F. Meirer, B. M. Weckhuysen, J. Gascon. Nat. Catal. 2018, 1, 398; b) F. Valentini, V. Kozell, C. Petrucci, A. Marrocchi, Y. Gu, D. Gelman, L. Vaccaro. Energy Environ. Sci. 2019, 12, 2646; c) L. Sun, Y. Wang, N. Guan, L. Li. Energy Technol. 2020, 8, 1900826.

[5] a) J. Liu, Y. He, L. Yan, C. Ma, C. Zhang, H. Xiang, X. Wen, Y. Li. Fuel 2020, 263, 116803; b) W. Li, Y. He, H. Li, D. Shen, C. Xing, R. Yang. Catal. Commun. 2017, 98, 98; c) Q. Lin, Q. Zhang, G. Yang, Q. Chen, J. Li, Q. Wei, Y. Tan, H. Wan, N. Tsubaki. J. Catal. 2016, 344, 378; d) J. Kang, X. Wang, X. Peng, Y. Yang, K. Cheng, Q. Zhang, Y. Wang. Ind. Eng. Chem. Res 2016, 55, 13008; e) M. Cai, A. Palčić, V. Subramanian, S. Moldovan, O. Ersen, V. Valtchev, V. V. Ordomsky, A. Y. Khodakov. J. Catal. 2016, 338, 227; f) P. Schwach, X. Pan, X. Bao. Chem. Rev. 2017, 117, 8497; g) Z. Li, Q. Xu. Acc. Chem. Res. 2017, 50, 1449. 
[6] a) A. Corma. Chem. Rev. 1995, 95, 559; b) C. Martínez, A. Corma. Coord. Chem. Rev. 2011, 255, 1558; c) Y. Li, L. Li, J. Yu. Chem 2017, 3, 928.

[7] http://www.iza-structure.org/databases/.

[8] a) S. Kasipandi, J. W. Bae. Adv. Mater. 2019, 31, 1803390; b) A. Masudi, N. W. C. Jusoh, M. Oki. Catal. Sci. Technol. 2020, DOI:10.1039/C9CY01875A.

[9] a) K. Saravanan, H. Ham, N. Tsubaki, J. W. Bae. Appl. Catal. B Environ. 2017, 217, 494; b) Y. Sun, X. Han, Z. Zhao. Catal. Sci. Technol. 2019, 9, 3763; c) C. Liu, S. Liu, H. Zhou, J. Su, W. Jiao, L. Zhang, Y. Wang, H. He, Z. Xie. Appl. Catal. A 2019, 585, 117206.

[10] a) R. A. Friedel, R. B. Anderson. J. Am. Chem. Soc. 1950, 72, 1212; b) I. Puskas, R. S. Hurlbut. Catal. Today 2003, 84, 99; c) D. Leckel. Energy Fuels 2009, 23, 2342; d) H. M. Torres Galvis, K. P. de Jong. ACS Catal. 2013, 3, 2130.

[11] a) Y. Zhu, X. Pan, F. Jiao, J. Li, J. Yang, M. Ding, Y. Han, Z. Liu, X. Bao. ACS Catal. 2017, 7, 2800; b) Y. Xu, D. Liu, X. Liu. Appl. Catal. A 2018, 552, 168; c) G. Yang, J. He, Y. Zhang, Y. Yoneyama, Y. Tan, Y. Han, T. Vitidsant, N. Tsubaki. Energy Fuels 2008, 22, 1463; d) N. Duyckaerts, I.-T. Trotuş, A.-C. Swertz, F. Schüth, G. Prieto. ACS Catal. 2016, 6, 4229.

[12] a) F. Jiao, J. Li, X. Pan, J. Xiao, H. Li, H. Ma, M. Wei, Y. Pan, Z. Zhou, M. Li, S. Miao, J. Li, Y. Zhu, D. Xiao, T. He, J. Yang, F. Qi, Q. Fu, X. Bao. Science 2016, 351, 1065; b) B. Mazonde, S. Cheng, G. Zhang, M. Javed, W. Gao, Y. Zhang, M. Tao, C. Lu, C. Xing. Catal. Sci. Technol. 2018, 8, 2802; c) R. L. Varma, N. N. Bakhshi, J. F. Mathews. Ind. Eng. Chem. Res 1990, 29, 1753.

[13] N. Wang, Q. Sun, J. Yu. Adv. Mater. 2019, 31, 1803966.

[14] a) D. L. S. Nieskens, J. D. Lunn, A. Malek. ACS Catal. 2019, 9, 691; b) Y. Ni, Y. Liu, Z. Chen, M. Yang, H. Liu, Y. He, Y. Fu, W. Zhu, Z. Liu. ACS Catal. 2019, 9, 1026; c) S. Wang, P. Wang, D. Shi, S. He, L. Zhang, W. Yan, Z. Qin, J. Li, M. Dong, J. Wang, 
U. Olsbye, W. Fan. ACS Catal. 2020, 10, 2046; d) T. Liu, T. Lu, M. Yang, L. Zhou, X. Yang, B. Gao, Y. Su. Catal. Lett. 2019, 149, 3338; e) N. Li, F. Jiao, X. Pan, Y. Ding, J. Feng, X. Bao. ACS Catal. 2019, 9, 960; f) M. T. Arslan, B. A. Qureshi, S. Z. A. Gilani, D. Cai, Y. Ma, M. Usman, X. Chen, Y. Wang, F. Wei. ACS Catal. 2019, 9, 2203; g) J. Su, D. Wang, Y. Wang, H. Zhou, C. Liu, S. Liu, C. Wang, W. Yang, Z. Xie, M. He. ChemCatChem 2018, 10, 1536; h) X. Liu, W. Zhou, Y. Yang, K. Cheng, J. Kang, L. Zhang, G. Zhang, X. Min, Q. Zhang, Y. Wang. Chem. Sci 2018, 9, 4708; i) K. Cheng, W. Zhou, J. Kang, S. He, S. Shi, Q. Zhang, Y. Pan, W. Wen, Y. Wang. Chem 2017, 3, 334.

[15] J. Plana-Pallejà, S. Abelló, C. Berrueco, D. Montané. Appl. Catal. A 2016, 515, 126.

[16] B. Zhao, P. Zhai, P. Wang, J. Li, T. Li, M. Peng, M. Zhao, G. Hu, Y. Yang, Y.-W. Li, Q. Zhang, W. Fan, D. Ma. Chem 2017, 3, 323.

[17] X. Yang, R. Wang, J. Yang, W. Qian, Y. Zhang, X. Li, Y. Huang, T. Zhang, D. Chen. ACS Catal. 2020, 10, 3797.

[18] a) J. Huang, W. Wang, Z. Fei, Q. Liu, X. Chen, Z. Zhang, J. Tang, M. Cui, X. Qiao. Ind. Eng. Chem. Res 2019, 58, 5131; b) J. Li, Y. He, L. Tan, P. Zhang, X. Peng, A. Oruganti, G. Yang, H. Abe, Y. Wang, N. Tsubaki. Nat. Catal. 2018, 1, 787.

[19] V. Subramanian, V. L. Zholobenko, K. Cheng, C. Lancelot, S. Heyte, J. Thuriot, S. Paul, V. V. Ordomsky, A. Y. Khodakov. ChemCatChem 2016, 8, 380.

[20] F. Jiao, X. Pan, K. Gong, Y. Chen, G. Li, X. Bao. Angew. Chem. Int. Ed. 2018, 57, 4692.

[21] N. Li, F. Jiao, X. Pan, Y. Chen, J. Feng, G. Li, X. Bao. Angew. Chem. Int. Ed. 2019, $58,7400$.

[22] a) M. Boronat, A. Corma. ACS Catal. 2019, 9, 1539; b) C. Li, A. Vidal-Moya, P. J. Miguel, J. Dedecek, M. Boronat, A. Corma. ACS Catal. 2018, 8, 7688. 
[23] J. Su, H. Zhou, S. Liu, C. Wang, W. Jiao, Y. Wang, C. Liu, Y. Ye, L. Zhang, Y. Zhao, H. Liu, D. Wang, W. Yang, Z. Xie, M. He. Nat. Commun. 2019, 10, 1297.

[24] a) G. Noh, Z. Shi, S. I. Zones, E. Iglesia. J. Catal. 2018, 368, 389; b) G. Noh, S. I. Zones, E. Iglesia. J. Phys. Chem. C 2018, 122, 25475.

[25] a) J. Yang, X. Pan, F. Jiao, J. Li, X. Bao. Chem. Commun. 2017, 53, 11146; b) T. Qiu, L. Wang, S. Lv, B. Sun, Y. Zhang, Z. Liu, W. Yang, J. Li. Fuel 2017, 203, 811.

[26] Z. Di, T. Zhao, X. Feng, M. Luo. Catal. Lett. 2019, 149, 441.

[27] J. Přech, D. R. Strossi Pedrolo, N. R. Marcilio, B. Gu, A. S. Peregudova, M. Mazur, V. V. Ordomsky, V. Valtchev, A. Y. Khodakov. ACS Catal. 2020, 10, 2544.

[28] J. L. Weber, N. A. Krans, J. P. Hofmann, E. J. M. Hensen, J. Zecevic, P. E. de Jongh, K. P. de Jong. Catal. Today 2020, 342, 161.

[29] T. Wang, Y. Xu, C. Shi, F. Jiang, B. Liu, X. Liu. Catal. Sci. Technol. 2019, 9, 3933.

[30] a) Q. Zhang, G. Chen, Y. Wang, M. Chen, G. Guo, J. Shi, J. Luo, J. Yu. Chem. Mater. 2018, 30, 2750; b) Q. Zhang, A. Mayoral, O. Terasaki, Q. Zhang, B. Ma, C. Zhao, G. Yang, J. Yu. J. Am. Chem. Soc. 2019, 141, 3772; c) C. Wen, C. Wang, L. Chen, X. Zhang, Q. Liu, L. Ma. Fuel 2019, 244, 492.

[31] K. Cheng, L. Zhang, J. Kang, X. Peng, Q. Zhang, Y. Wang. Chem. -Eur. J. 2015, 21, 1928.

[32] X. Peng, K. Cheng, J. Kang, B. Gu, X. Yu, Q. Zhang, Y. Wang. Angew. Chem. Int. Ed. 2015, 54, 4553.

[33] C. Flores, N. Batalha, V. V. Ordomsky, V. L. Zholobenko, W. Baaziz, N. R. Marcilio, A. Y. Khodakov. ChemCatChem 2018, 10, 2291.

[34] H. Li, B. Hou, J. Wang, C. Qin, M. Zhong, X. Huang, L. Jia, D. Li. Mol. Catal. 2018, 459, 106.

[35] J.-E. Min, S. Kim, G. Kwak, Y. T. Kim, S. J. Han, Y. Lee, K.-W. Jun, S. K. Kim. Catal. Sci. Technol. 2018, 8, 6346. 
[36] Y. Wang, W. Gao, S. Kazumi, Y. Fang, L. Shi, Y. Yoneyama, G. Yang, N. Tsubaki. Fuel 2019, 253, 249.

[37] a) Y. Xu, J. Liu, J. Wang, G. Ma, J. Lin, Y. Yang, Y. Li, C. Zhang, M. Ding. ACS Catal. 2019, 9, 5147; b) Y. Xu, J. Wang, G. Ma, J. Lin, M. Ding. ACS Sustainable Chem. Eng. 2019, 7, 18125.

[38] M. Javed, S. Cheng, G. Zhang, P. Dai, Y. Cao, C. Lu, R. Yang, C. Xing, S. Shan. Fuel 2018, 215, 226.

[39] M. Javed, G. Zhang, W. Gao, Y. Cao, P. Dai, X. Ji, C. Lu, R. Yang, C. Xing, J. Sun. Catal. Today 2019, 330, 39.

[40] H. T. Luk, C. Mondelli, D. C. Ferré, J. A. Stewart, J. Pérez-Ramírez. Chem. Soc. Rev. 2017, 46, 1358.

[41] a) W. Zhou, J. Kang, K. Cheng, S. He, J. Shi, C. Zhou, Q. Zhang, J. Chen, L. Peng, M. Chen, Y. Wang. Angew. Chem. Int. Ed. 2018, 57, 12012; b) Z. Cao, T. Hu, J. Guo, J. Xie, N. Zhang, J. Zheng, L. Che, B. H. Chen. Fuel 2019, 254, 115542; c) C. Wang, J. Zhang, G. Qin, L. Wang, E. Zuidema, Q. Yang, S. Dang, C. Yang, J. Xiao, X. Meng, C. Mesters, F.-S. Xiao. Chem 2020, 6, 646.

[42] a) H. Zhou, W. Zhu, L. Shi, H. Liu, S. Liu, Y. Ni, Y. Liu, Y. He, S. Xu, L. Li, Z. Liu. J. Mol. Catal. A: Chem. 2016, 417, 1; b) A. A. C. Reule, J. A. Sawada, N. Semagina. J. Catal. 2017, 349, 98; c) J. Kang, S. He, W. Zhou, Z. Shen, Y. Li, M. Chen, Q. Zhang, Y. Wang. Nat. Commun. 2020, 11, 827.

[43] a) M. Boronat, C. Martínez-Sánchez, D. Law, A. Corma. J. Am. Chem. Soc. 2008, 130, 16316; b) P. Cheung, A. Bhan, G. J. Sunley, D. J. Law, E. Iglesia. J. Catal. 2007, 245, 110; c) T. Blasco, M. Boronat, P. Concepción, A. Corma, D. Law, J. A. Vidal-Moya. Angew. Chem. Int. Ed. 2007, 46, 3938.

[44] J. Liu, H. Xue, X. Huang, P.-H. Wu, S.-J. Huang, S.-B. Liu, W. Shen. Chin. J. Catal. 2010, 31, 729 . 
[45] a) H. Xue, X. Huang, E. Zhan, M. Ma, W. Shen. Catal. Commun. 2013, 37, 75; b) Y. Li, Q. Sun, S. Huang, Z. Cheng, K. Cai, J. Lv, X. Ma. Catal. Today 2018, 311, 81.

[46] P. Lu, Q. Chen, G. Yang, L. Tan, X. Feng, J. Yao, Y. Yoneyama, N. Tsubaki. ACS Catal. 2020, 10, 1366.

[47] K. Karl, B. B. South (Maverick Synfuels), US8779215B2, 2014.

[48] a) N. Wang, Q. Sun, R. Bai, X. Li, G. Guo, J. Yu. J. Am. Chem. Soc. 2016, 138, 7484; b) Q. Sun, N. Wang, Q. Bing, R. Si, J. Liu, R. Bai, P. Zhang, M. Jia, J. Yu. Chem 2017, 3, 477; c) L. Liu, M. Lopez-Haro, C. W. Lopes, C. Li, P. Concepcion, L. Simonelli, J. J. Calvino, A. Corma. Nat. Mater. 2019, 18, 866; d) L. Liu, U. Díaz, R. Arenal, G. Agostini, P. Concepción, A. Corma. Nat. Mater. 2017, 16, 132.

[49] a) M. C. Bacariza, I. Graça, J. M. Lopes, C. Henriques. ChemCatChem 2019, 11, 2388; b) M. Ronda-Lloret, G. Rothenberg, N. R. Shiju. ChemSusChem 2019, 12, 3896; c) I. Sreedhar, Y. Varun, S. A. Singh, A. Venugopal, B. M. Reddy. Catal. Sci. Technol. 2019, 9, 4478; d) R. G. Grim, Z. Huang, M. T. Guarnieri, J. R. Ferrell, L. Tao, J. A. Schaidle. Energy Environ. Sci. 2020, 13, 472; e) J. Zhong, X. Yang, Z. Wu, B. Liang, Y. Huang, T. Zhang. Chem. Soc. Rev. 2020, 49, 1385; f) Z. Ma, M. D. Porosoff. ACS Catal. 2019, 9, 2639; g) A. Álvarez, A. Bansode, A. Urakawa, A. V. Bavykina, T. A. Wezendonk, M. Makkee, J. Gascon, F. Kapteijn. Chem. Rev. 2017, 117, 9804; h) R.-P. Ye, J. Ding, W. Gong, M. D. Argyle, Q. Zhong, Y. Wang, C. K. Russell, Z. Xu, A. G. Russell, Q. Li, M. Fan, Y.-G. Yao. Nat. Commun. 2019, 10, 5698.

[50] F. Schneck, F. Schendzielorz, N. Hatami, M. Finger, C. Würtele, S. Schneider. Angew. Chem. Int. Ed. 2018, 57, 14482.

[51] R. A. van Santen, A. J. Markvoort, I. A. W. Filot, M. M. Ghouri, E. J. M. Hensen. Phys. Chem. Chem. Phys. 2013, 15, 17038. 
[52] a) C. Zhou, J. Shi, W. Zhou, K. Cheng, Q. Zhang, J. Kang, Y. Wang. ACS Catal. 2020, 10, 302; b) H. Li, P. Zhang, L. Guo, Y. He, Y. Zeng, M. Thongkam, J. Natakaranakul, T. Kojima, P. Reubroycharoen, T. Vitidsant, G. Yang, N. Tsubaki. ChemSusChem 2020, 13, 2060; c) X. Zhang, A. Zhang, X. Jiang, J. Zhu, J. Liu, J. Li, G. Zhang, C. Song, X. Guo. J. $\mathrm{CO}_{2}$ Util. 2019, 29, 140; d) J. Chen, X. Wang, D. Wu, J. Zhang, Q. Ma, X. Gao, X. Lai, H. Xia, S. Fan, T.-S. Zhao. Fuel 2019, 239, 44; e) P. Gao, S. Dang, S. Li, X. Bu, Z. Liu, M. Qiu, C. Yang, H. Wang, L. Zhong, Y. Han, Q. Liu, W. Wei, Y. Sun. ACS Catal. 2018, 8, 571; f) Z. Li, J. Wang, Y. Qu, H. Liu, C. Tang, S. Miao, Z. Feng, H. An, C. Li. ACS Catal. 2017, 7, 8544; g) J. Gao, C. Jia, B. Liu. Catal. Sci. Technol. 2017, 7, 5602.

[53] X. Cui, P. Gao, S. Li, C. Yang, Z. Liu, H. Wang, L. Zhong, Y. Sun. ACS Catal. 2019, 9, 3866 .

[54] S. Dang, S. Li, C. Yang, X. Chen, X. Li, L. Zhong, P. Gao, Y. Sun. ChemSusChem 2019, 12,3582 .

[55] a) A. Hwang, T. T. Le, Z. Shi, H. Dai, J. D. Rimer, A. Bhan. J. Catal. 2019, 369, 122; b) Y. Wang, W. Gao, S. Kazumi, H. Li, G. Yang, N. Tsubaki. Chem. Eur. J. 2019, 25, 5149; c) Y. Wang, L. Tan, M. Tan, P. Zhang, Y. Fang, Y. Yoneyama, G. Yang, N. Tsubaki. ACS Catal. 2019, 9, 895; d) T. Shoinkhorova, A. Dikhtiarenko, A. Ramirez, A. Dutta Chowdhury, M. Caglayan, J. Vittenet, A. Bendjeriou-Sedjerari, O. S. Ali, I. Morales-Osorio, W. Xu, J. Gascon. ACS Appl. Mater. Interfaces 2019, 11, 44133; e) A. Dokania, A. Dutta Chowdhury, A. Ramirez, S. Telalovic, E. Abou-Hamad, L. Gevers, J. Ruiz-Martinez, J. Gascon. J. Catal. 2020, 381, 347; f) J. Zhang, M. Zhang, S. Chen, X. Wang, Z. Zhou, Y. Wu, T. Zhang, G. Yang, Y. Han, Y. Tan. Chem. Commun. 2019, 55, 973; g) C. Wang, E. Guan, L. Wang, X. Chu, Z. Wu, J. Zhang, Z. Yang, Y. Jiang, L. Zhang, X. Meng, B. C. Gates, F.-S. Xiao. J. Am. Chem. Soc. 2019, 141, 8482; h) Y. Chen, B. Qiu, Y. Liu, Y. Zhang. Appl. Catal. B: Environ. 2020, 269, 118801; i) J. Wei, 
R. Yao, Q. Ge, Z. Wen, X. Ji, C. Fang, J. Zhang, H. Xu, J. Sun. ACS Catal. 2018, 8, 9958; j) Z. Li, Y. Qu, J. Wang, H. Liu, M. Li, S. Miao, C. Li. Joule 2019, 3, 570.

[56] a) A. Ramirez, A. Dutta Chowdhury, A. Dokania, P. Cnudde, M. Caglayan, I. Yarulina, E. Abou-Hamad, L. Gevers, S. Ould-Chikh, K. De Wispelaere, V. van Speybroeck, J. Gascon. ACS Catal. 2019, 9, 6320; b) M. C. Bacariza, M. Maleval, I. Graça, J. M. Lopes, C. Henriques. Microporous Mesoporous Mater. 2019, 274, 102.

[57] S. Goel, Z. Wu, S. I. Zones, E. Iglesia. J. Am. Chem. Soc. 2012, 134, 17688.

[58] a) F. Goodarzi, L. Kang, F. R. Wang, F. Joensen, S. Kegnæs, J. Mielby. ChemCatChem 2018, 10, 1566; b) A. Sápi, U. Kashaboina, K. B. Ábrahámné, J. F. Gómez-Pérez, I. Szenti, G. Halasi, J. Kiss, B. Nagy, T. Varga, Á. Kukovecz, Z. Kónya. Front. Mater. 2019, 6; c) L. Guo, Y. Cui, H. Li, Y. Fang, R. Prasert, J. Wu, G. Yang, Y. Yoneyama, N. Tsubaki. Catal. Commun. 2019, 130, 105759; d) A. Quindimil, U. De-La-Torre, B. Pereda-Ayo, J. A. González-Marcos, J. R. González-Velasco. Appl. Catal. B: Environ. 2018, 238, 393; e) H. Chen, Y. Mu, Y. Shao, S. Chansai, S. Xu, C. E. Stere, H. Xiang, R. Zhang, Y. Jiao, C. Hardacre, X. Fan. Catal. Sci. Technol. 2019, 9,4135 .

[59] J. Wei, Q. Ge, R. Yao, Z. Wen, C. Fang, L. Guo, H. Xu, J. Sun. Nat. Commun. 2017, 8, 15174.

[60] P. Gao, S. Li, X. Bu, S. Dang, Z. Liu, H. Wang, L. Zhong, M. Qiu, C. Yang, J. Cai, W. Wei, Y. Sun. Nat. Chem. 2017, 9, 1019.

[61] M. C. Bacariza, R. Bértolo, I. Graça, J. M. Lopes, C. Henriques. J. $\mathrm{CO}_{2}$ Util. 2017, 21 , 280.

[62] E. Gomez, X. Nie, J. H. Lee, Z. Xie, J. G. Chen. J. Am. Chem. Soc. 2019, 141, 17771.

[63] A. Westermann, B. Azambre, M. C. Bacariza, I. Graça, M. F. Ribeiro, J. M. Lopes, C. Henriques. Appl. Catal. B: Environ. 2015, 174-175, 120. 
[64] S. Walspurger, G. D. Elzinga, J. W. Dijkstra, M. Sarić, W. G. Haije. Chem. Eng. J. 2014, 242, 379.

[65] M. C. Bacariza, I. Graça, J. M. Lopes, C. Henriques. Microporous Mesoporous Mater. 2018, 267, 9 .

[66] a) H. Ge, B. Zhang, H. Liang, M. Zhang, K. Fang, Y. Chen, Y. Qin. Appl. Catal. B: Environ. 2020, 263, 118133; b) Z. Chen, Y. Hu, J. Wang, Q. Shen, Y. Zhang, C. Ding, Y. Bai, G. Jiang, Z. Li, N. Gaponik. Chem. Mater. 2020, 32, 1517; c) M. Zhou, S. Wang, P. Yang, C. Huang, X. Wang. ACS Catal. 2018, 8, 4928.

[67] a) Y. Tong, Y. Zhang, N. Tong, Z. Zhang, Y. Wang, X. Zhang, S. Zhu, F. Li, X. Wang. Catal. Sci. Technol. 2016, 6, 7579; b) S. Zhu, S. Liang, Y. Wang, X. Zhang, F. Li, H. Lin, Z. Zhang, X. Wang. Appl. Catal. B: Environ. 2016, 187, 11; c) J. Kianička, G. Č́́k, F. Šeršeň, I. Špánik, R. Sokolík, J. Filo. Molecules 2019, 24, 992; d) Y. Tong, L. Chen, S. Ning, N. Tong, Z. Zhang, H. Lin, F. Li, X. Wang. Appl. Catal. B: Environ. 2017, 203, 725 .

[68] a) Y. Hu, D. Rakhmawaty, M. Matsuoka, M. Takeuchi, M. Anpo. J. Porous Mater. 2006, 13, 335; b) W. Jia, T. Liu, Q. Li, J. Yang. Catal. Today 2019, 335, 221.

[69] G. A. Olah. Angew. Chem. Int. Ed. 2005, 44, 2636.

[70] a) H. Bahruji, R. D. Armstrong, J. Ruiz Esquius, W. Jones, M. Bowker, G. J. Hutchings. Ind. Eng. Chem. Res 2018, 57, 6821; b) G. Bonura, M. Migliori, L. Frusteri, C. Cannilla, E. Catizzone, G. Giordano, F. Frusteri. J. $\mathrm{CO}_{2}$ Util. 2018, 24, 398.

[71] F. Frusteri, G. Bonura, C. Cannilla, G. Drago Ferrante, A. Aloise, E. Catizzone, M. Migliori, G. Giordano. Appl. Catal. B: Environ. 2015, 176-177, 522.

[72] G. Bonura, C. Cannilla, L. Frusteri, A. Mezzapica, F. Frusteri. Catal. Today 2017, 281, 337. 
[73] a) A. Ateka, J. Ereña, J. Bilbao, A. T. Aguayo. Ind. Eng. Chem. Res 2020, 59, 713; b) M. Sánchez-Contador, A. Ateka, A. T. Aguayo, J. Bilbao. Fuel Process. Technol. 2018, 179, 258; c) G. Bonura, F. Frusteri, C. Cannilla, G. Drago Ferrante, A. Aloise, E. Catizzone, M. Migliori, G. Giordano. Catal. Today 2016, 277, 48.

[74] F. Frusteri, M. Migliori, C. Cannilla, L. Frusteri, E. Catizzone, A. Aloise, G. Giordano, G. Bonura. J. $\mathrm{CO}_{2}$ Util. 2017, 18, 353.

[75] D. Jean-Luc, S. Kazuhiro, A. Hironori. Chem. Lett. 1992, 21, 1115.

[76] a) J. Graciani, K. Mudiyanselage, F. Xu, A. E. Baber, J. Evans, S. D. Senanayake, D. J. Stacchiola, P. Liu, J. Hrbek, J. F. Sanz, J. A. Rodriguez. Science 2014, 345, 546; b) C. F. Shih, T. Zhang, J. Li, C. Bai. Joule 2018, 2, 1925; c) B. M. Tackett, E. Gomez, J. G. Chen. Nat. Catal. 2019, 2, 381.

[77] H. Li, C. Qiu, S. Ren, Q. Dong, S. Zhang, F. Zhou, X. Liang, J. Wang, S. Li, M. Yu. Science 2020, 367, 667.

[78] a) R. A. Kerr. Science 2010, 328, 1624; b) T. A. Moore. Int. J. Coal Geol. 2012, 101, 36; c) Y. Konno, T. Fujii, A. Sato, K. Akamine, M. Naiki, Y. Masuda, K. Yamamoto, J. Nagao. Energy Fuels 2017, 31, 2607.

[79] a) C. Hammond, R. L. Jenkins, N. Dimitratos, J. A. Lopez-Sanchez, M. H. ab Rahim, M. M. Forde, A. Thetford, D. M. Murphy, H. Hagen, E. E. Stangland, J. M. Moulijn, S. H. Taylor, D. J. Willock, G. J. Hutchings. Chem. -Eur. J. 2012, 18, 15735; b) S. Raynes, M. A. Shah, R. A. Taylor. Dalton Trans. 2019, 48, 10364.

[80] a) M. Ravi, M. Ranocchiari, J. A. van Bokhoven. Angew. Chem. Int. Ed. 2017, 56, 16464; b) M. H. Mahyuddin, Y. Shiota, A. Staykov, K. Yoshizawa. Acc. Chem. Res. 2018, 51, 2382; c) M. H. Mahyuddin, Y. Shiota, K. Yoshizawa. Catal. Sci. Technol. 2019, 9, 1744; d) M. B. Park, E. D. Park, W.-S. Ahn. Front. Chem. 2019, 7, 1; e) G. Zhao, A. Adesina, E. Kennedy, M. Stockenhuber. ACS Catal. 2020, 10, 1406; f) P. Zhang, X. Yang, X. Hou, J. Mi, Z. Yuan, J. Huang, C. Stampfl. Catal. Sci. Technol. 
2019, 9, 6297; g) S. Wang, S. Guo, Y. Luo, Z. Qin, Y. Chen, M. Dong, J. Li, W. Fan, J. Wang. Catal. Sci. Technol. 2019, 9, 6613; h) M. Shahami, D. F. Shantz. Catal. Sci. Technol. 2019, 9, 2945; i) Z. Fang, H. Murayama, Q. Zhao, B. Liu, F. Jiang, Y. Xu, M. Tokunaga, X. Liu. Catal. Sci. Technol. 2019, 9, 6946.

[81] a) Y. Shen, Y. Zhan, S. Li, F. Ning, Y. Du, Y. Huang, T. He, X. Zhou. Chem. Sci. 2017, 8, 7498; b) M. Yang, D. Fan, Y. Wei, P. Tian, Z. Liu. Adv. Mater. 2019, 31, 1902181.

[82] a) A. C. Rosenzweig, C. A. Frederick, S. J. Lippard, P. Nordlund, auml. Nature 1993, 366, 537; b) S. Sirajuddin, A. C. Rosenzweig. Biochemistry 2015, 54, 2283.

[83] a) A. A. Gabrienko, S. A. Yashnik, A. A. Kolganov, A. M. Sheveleva, S. S. Arzumanov, M. V. Fedin, F. Tuna, A. G. Stepanov. Inorg. Chem. 2020, 59, 2037; b) G. Wang, W. Chen, L. Huang, Z. Liu, X. Sun, A. Zheng. Catal. Today 2019, 338, 108; c) L. Burnett, M. Rysakova, K. Wang, J. González-Carballo, R. P. Tooze, F. R. GarcíaGarcía. Appl. Catal. A Gen 2019, 587, 117272.

[84] a) V. L. Sushkevich, D. Palagin, J. A. van Bokhoven. Angew. Chem. Int. Ed. 2018, 57, 8906; b) K. T. Dinh, M. M. Sullivan, K. Narsimhan, P. Serna, R. J. Meyer, M. Dincă, Y. Román-Leshkov. J. Am. Chem. Soc. 2019, 141, 11641; c) V. L. Sushkevich, R. Verel, J. A. van Bokhoven. Angew. Chem. Int. Ed. 2020, 59, 910.

[85] D. K. Pappas, A. Martini, M. Dyballa, K. Kvande, S. Teketel, K. A. Lomachenko, R. Baran, P. Glatzel, B. Arstad, G. Berlier, C. Lamberti, S. Bordiga, U. Olsbye, S. Svelle, P. Beato, E. Borfecchia. J. Am. Chem. Soc. 2018, 140, 15270.

[86] a) M. O. Ross, F. MacMillan, J. Wang, A. Nisthal, T. J. Lawton, B. D. Olafson, S. L. Mayo, A. C. Rosenzweig, B. M. Hoffman. Science 2019, 364, 566; b) M. Ravi, V. L. Sushkevich, A. J. Knorpp, M. A. Newton, D. Palagin, A. B. Pinar, M. Ranocchiari, J. A. van Bokhoven. Nat. Catal. 2019, 2, 485.

[87] V. L. Sushkevich, J. A. van Bokhoven. Catal. Sci. Technol. 2018, 8, 4141. 
[88] K. Narsimhan, V. K. Michaelis, G. Mathies, W. R. Gunther, R. G. Griffin, Y. RománLeshkov. J. Am. Chem. Soc. 2015, 137, 1825.

[89] J. Shan, M. Li, L. F. Allard, S. Lee, M. Flytzani-Stephanopoulos. Nature 2017, 551, 605.

[90] M. J. Wulfers, S. Teketel, B. Ipek, R. F. Lobo. Chem. Commun. 2015, 51, 4447.

[91] M. B. Park, S. H. Ahn, A. Mansouri, M. Ranocchiari, J. A. van Bokhoven. ChemCatChem 2017, 9, 3705.

[92] M. H. Mahyuddin, A. Staykov, Y. Shiota, M. Miyanishi, K. Yoshizawa. ACS Catal. 2017, 7, 3741 .

[93] K. Narsimhan, K. Iyoki, K. Dinh, Y. Román-Leshkov. ACS Cent. Sci. 2016, 2, 424.

[94] a) Y. Hori, Y. Shiota, T. Tsuji, M. Kodera, K. Yoshizawa. Inorg. Chem. 2018, 57, 8; b) P. Xiao, Y. Wang, T. Nishitoba, J. N. Kondo, T. Yokoi. Chem. Commun. 2019, 55, 2896; c) Á. Szécsényi, G. Li, J. Gascon, E. A. Pidko. ACS Catal. 2018, 8, 7961.

[95] a) V. L. Sushkevich, D. Palagin, M. Ranocchiari, J. A. van Bokhoven. Science 2017, 356, 523; b) K. D. Vogiatzis, G. Li, E. J. M. Hensen, L. Gagliardi, E. A. Pidko. J. Phys. Chem. C 2017, 121, 22295; c) N. K. Dandu, J. A. Reed, S. O. Odoh. J. Phys. Chem. C 2018, 122, 1024; d) M. H. Mahyuddin, T. Tanaka, A. Staykov, Y. Shiota, K. Yoshizawa. Inorg. Chem. 2018, 57, 10146; e) B. E. R. Snyder, P. Vanelderen, R. A. Schoonheydt, B. F. Sels, E. I. Solomon. J. Am. Chem. Soc. 2018, 140, 9236; f) H. V. Le, S. Parishan, A. Sagaltchik, C. Göbel, C. Schlesiger, W. Malzer, A. Trunschke, R. Schomäcker, A. Thomas. ACS Catal. 2017, 7, 1403; g) T. Ikuno, S. Grundner, A. Jentys, G. Li, E. Pidko, J. Fulton, M. Sanchez-Sanchez, J. A. Lercher. J. Phys. Chem. C 2019, 123, 8759; h) P. Tomkins, A. Mansouri, S. E. Bozbag, F. Krumeich, M. B. Park, E. M. C. Alayon, M. Ranocchiari, J. A. van Bokhoven. Angew. Chem. Int. Ed. 2016, 55, 5467. 
[96] a) G. Zhao, E. Benhelal, A. Adesina, E. Kennedy, M. Stockenhuber. J. Phys. Chem. C 2019, 123, 27436; b) M. A. Shah, S. Raynes, D. C. Apperley, R. A. Taylor. ChemPhysChem 2020, 21, 673.

[97] B. E. R. Snyder, P. Vanelderen, M. L. Bols, S. D. Hallaert, L. H. Böttger, L. Ungur, K. Pierloot, R. A. Schoonheydt, B. F. Sels, E. I. Solomon. Nature 2016, 536, 317.

[98] a) M. L. Bols, S. D. Hallaert, B. E. R. Snyder, J. Devos, D. Plessers, H. M. Rhoda, M. Dusselier, R. A. Schoonheydt, K. Pierloot, E. I. Solomon, B. F. Sels. J. Am. Chem. Soc. 2018, 140, 12021; b) J. Devos, M. L. Bols, D. Plessers, C. V. Goethem, J. W. Seo, S.-J. Hwang, B. F. Sels, M. Dusselier. Chem. Mater. 2020, 32, 273; c) U. Engedahl, H. Grönbeck, A. Hellman. J. Phys. Chem. C 2019, 123, 26145; d) R. Oord, J. E. Schmidt, B. M. Weckhuysen. Catal. Sci. Technol. 2018, 8, 1028; e) D. K. Pappas, E. Borfecchia, M. Dyballa, I. A. Pankin, K. A. Lomachenko, A. Martini, M. Signorile, S. Teketel, B. Arstad, G. Berlier, C. Lamberti, S. Bordiga, U. Olsbye, K. P. Lillerud, S. Svelle, P. Beato. J. Am. Chem. Soc. 2017, 139, 14961.

[99] a) A. J. Knorpp, M. A. Newton, S. C. M. Mizuno, J. Zhu, H. Mebrate, A. B. Pinar, J. A. van Bokhoven. Chem. Commun. 2019, 55, 11794; b) A. J. Knorpp, M. A. Newton, V. L. Sushkevich, P. P. Zimmermann, A. B. Pinar, J. A. van Bokhoven. Catal. Sci. Technol. 2019, 9, 2806.

[100] B. Ipek, M. J. Wulfers, H. Kim, F. Göltl, I. Hermans, J. P. Smith, K. S. Booksh, C. M. Brown, R. F. Lobo. ACS Catal. 2017, 7, 4291.

[101] J. Zhu, V. L. Sushkevich, A. J. Knorpp, M. A. Newton, S. C. M. Mizuno, T. Wakihara, T. Okubo, Z. Liu, J. A. van Bokhoven. Chem. Mater. 2020, 32, 1448.

[102] J.-F. Wu, X.-D. Gao, L.-M. Wu, W. D. Wang, S.-M. Yu, S. Bai. ACS Catal. 2019, 9, 8677.

[103] G. Qi, Q. Wang, J. Xu, J. Trébosc, O. Lafon, C. Wang, J.-P. Amoureux, F. Deng. Angew. Chem. Int. Ed. 2016, 55, 15826. 
[104] a) N. Agarwal, S. J. Freakley, R. U. McVicker, S. M. Althahban, N. Dimitratos, Q. He, D. J. Morgan, R. L. Jenkins, D. J. Willock, S. H. Taylor, C. J. Kiely, G. J. Hutchings. Science 2017, 358, 223; b) S. Grundner, M. A. C. Markovits, G. Li, M. Tromp, E. A. Pidko, E. J. M. Hensen, A. Jentys, M. Sanchez-Sanchez, J. A. Lercher. Nat. Commun. 2015, 6,7546 .

[105] J. Xie, R. Jin, A. Li, Y. Bi, Q. Ruan, Y. Deng, Y. Zhang, S. Yao, G. Sankar, D. Ma, J. Tang. Nat. Catal. 2018, 1, 889.

[106] Z. Jin, L. Wang, E. Zuidema, K. Mondal, M. Zhang, J. Zhang, C. Wang, X. Meng, H. Yang, C. Mesters, F.-S. Xiao. Science 2020, 367, 193.

[107] Y. Kato, H. Yoshida, A. Satsuma, T. Hattori. Microporous Mesoporous Mater. 2002, $51,223$.

[108] a) Y. Hu, M. Anpo, C. Wei. J. Photoch. Photobio. A: Chem. 2013, 264, 48; b) F. Sastre, V. Fornés, A. Corma, H. García. J. Am. Chem. Soc. 2011, 133, 17257; c) S. Murcia-López, M. C. Bacariza, K. Villa, J. M. Lopes, C. Henriques, J. R. Morante, T. Andreu. ACS Catal. 2017, 7, 2878.

[109] a) S. Ma, X. Guo, L. Zhao, S. Scott, X. Bao. J. Eng. Chem. 2013, 22, 1; b) V. Ramasubramanian, H. Ramsurn, G. L. Price. J. Eng. Chem. 2019, 34, 20.

[110] a) I. Lezcano-González, R. Oord, M. Rovezzi, P. Glatzel, S. W. Botchway, B. M. Weckhuysen, A. M. Beale. Angew. Chem. Int. Ed. 2016, 55, 5215; b) P. Tan. J. Catal. 2016, 338, 21; c) M. Rahman, A. Infantes-Molina, A. Boubnov, S. R. Bare, E. Stavitski, A. Sridhar, S. J. Khatib. J. Catal. 2019, 375, 314; d) I. Vollmer, S. OuldChikh, A. Aguilar-Tapia, G. Li, E. Pidko, J.-L. Hazemann, F. Kapteijn, J. Gascon. J. Am. Chem. Soc. 2019, 141, 18814.

[111] a) R. H. Crabtree. Chem. Rev. 1995, 95, 987; b) X. Zheng, P. Blowers. J. Mol. Catal. A: Chem. 2006, 246, 1. 
[112] a) N. Kosinov, A. S. G. Wijpkema, E. Uslamin, R. Rohling, F. J. A. G. Coumans, B. Mezari, A. Parastaev, A. S. Poryvaev, M. V. Fedin, E. A. Pidko, E. J. M. Hensen. Angew. Chem. Int. Ed. 2018, 57, 1016; b) I. Vollmer, B. van der Linden, S. OuldChikh, A. Aguilar-Tapia, I. Yarulina, E. Abou-Hamad, Y. G. Sneider, A. I. Olivos Suarez, J.-L. Hazemann, F. Kapteijn, J. Gascon. Chem. Sci. 2018, 9, 4801.

[113] A. Martínez, E. Peris. Appl. Catal. A Gen 2016, 515, 32.

[114] a) T. H. Lim, K. Nam, I. K. Song, K.-Y. Lee, D. H. Kim. Appl. Catal. A Gen 2018, 552, 11; b) K. Zhao, L. Jia, J. Wang, B. Hou, D. Li. New J. Chem. 2019, 43, 4130.

[115] J. Gao, Y. Zheng, J.-M. Jehng, Y. Tang, I. E. Wachs, S. G. Podkolzin. Science 2015, $348,686$.

[116] a) N. Kosinov, F. J. A. G. Coumans, E. Uslamin, F. Kapteijn, E. J. M. Hensen. Angew. Chem. Int. Ed. 2016, 55, 15086; b) S. H. Morejudo, R. Zanón, S. Escolástico, I. YusteTirados, H. Malerød-Fjeld, P. K. Vestre, W. G. Coors, A. Martínez, T. Norby, J. M. Serra, C. Kjølseth. Science 2016, 353, 563; c) I. Julian, J. L. Hueso, N. Lara, A. SoléDaurá, J. M. Poblet, S. G. Mitchell, R. Mallada, J. Santamaría. Catal. Sci. Technol. 2019, 9, 5927; d) N. Kosinov, E. A. Uslamin, L. Meng, A. Parastaev, Y. Liu, E. J. M. Hensen. Angew. Chem. Int. Ed. 2019, 58, 7068.

[117] a) P. Zhu, G. Yang, J. Sun, R. Fan, P. Zhang, Y. Yoneyama, N. Tsubaki. J. Mater. Chem. A 2017, 5, 8599; b) X. Huang, X. Jiao, M. Lin, K. Wang, L. Jia, B. Hou, D. Li. Catal. Sci. Technol. 2018, 8, 5740; c) K. Wang, X. Huang, D. Li. Appl. Catal. A Gen 2018, 556, 10; d) Y. Wu, L. Emdadi, E. Schulman, Y. Shu, D. T. Tran, X. Wang, D. Liu. Microporous Mesoporous Mater. 2018, 263, 1.

[118] P. Tian, Y. Wei, M. Ye, Z. Liu. ACS Catal. 2015, 5, 1922.

[119] Q. Sun, Z. Xie, J. Yu. Natl Sci Rev 2018, 5, 542.

[120] U. Olsbye, S. Svelle, M. Bjørgen, P. Beato, T. V. W. Janssens, F. Joensen, S. Bordiga, K. P. Lillerud. Angew. Chem. Int. Ed. 2012, 51, 5810. 
[121] a) H. Schulz. Catal. Lett. 2018, 148, 1263; b) M. A. Ali, S. Ahmed, N. Al-Baghli, Z. Malaibari, A. Abutaleb, A. Yousef. Catal. Lett. 2019, 149, 3395.

[122] a) X. Wu, S. Xu, W. Zhang, J. Huang, J. Li, B. Yu, Y. Wei, Z. Liu. Angew. Chem. Int. Ed. 2017, 56, 9039; b) X. Wu, S. Xu, Y. Wei, W. Zhang, J. Huang, S. Xu, Y. He, S. Lin, T. Sun, Z. Liu. ACS Catal. 2018, 8, 7356.

[123] a) S. Svelle, F. Joensen, J. Nerlov, U. Olsbye, K.-P. Lillerud, S. Kolboe, M. Bjørgen. J. Am. Chem. Soc. 2006, 128, 14770; b) M. Bjørgen, S. Svelle, F. Joensen, J. Nerlov, S. Kolboe, F. Bonino, L. Palumbo, S. Bordiga, U. Olsbye. J. Catal. 2007, 249, 195.

[124] P. Ferri, C. Li, C. Paris, A. Vidal-Moya, M. Moliner, M. Boronat, A. Corma. ACS Catal. 2019, 9, 11542.

[125] a) H. Guo, T. Ge, J. Lv, C. Du, J. Zhou, Z. Liu, Z. Hua. Eur. J. Inorg. Chem. 2019, 2019, 51; b) J. Zhang, L. Xu, Y. Zhang, Z. Huang, X. Zhang, X. Zhang, Y. Yuan, L. Xu. J. Catal. 2018, 368, 248.

[126] Y. Liu, F. M. Kirchberger, S. Müller, M. Eder, M. Tonigold, M. Sanchez-Sanchez, J. A. Lercher. Nat. Commun. 2019, 10, 1462.

[127] J. Chen, J. Li, C. Yuan, S. Xu, Y. Wei, Q. Wang, Y. Zhou, J. Wang, M. Zhang, Y. He, S. Xu, Z. Liu. Catal. Sci. Technol. 2014, 4, 3268.

[128] a) X. Jiao, X. Huang, K. Wang. Catal. Sci. Technol. 2019, 9, 6552; b) S. Wang, P. Wang, Z. Qin, Y. Chen, M. Dong, J. Li, K. Zhang, P. Liu, J. Wang, W. Fan. ACS Catal. 2018, 8, 5485; c) C. Wang, Y. Chu, J. Xu, Q. Wang, G. Qi, P. Gao, X. Zhou, F. Deng. Angew. Chem. Int. Ed. 2018, 57, 10197; d) T. Nishitoba, N. Yoshida, J. N. Kondo, T. Yokoi. Ind. Eng. Chem. Res 2018, 57, 3914.

[129] a) L. Zhang, S. Wang, D. Shi, Z. Qin, P. Wang, G. Wang, J. Li, M. Dong, W. Fan, J. Wang. Catal. Sci. Technol. 2020, DOI:10.1039/C9CY02419K; b) A. Molino, J. Holzinger, K. A. Łukaszuk, D. Rojo-Gama, A. E. Gunnæs, J. Skibsted, L. F. Lundegaard, S. Svelle, P. Beato, S. Bordiga, K. P. Lillerud. Catal. Sci. Technol. 2019, 
9, 6782; c) I. Yarulina, K. De Wispelaere, S. Bailleul, J. Goetze, M. Radersma, E. Abou-Hamad, I. Vollmer, M. Goesten, B. Mezari, E. J. M. Hensen, J. S. MartínezEspín, M. Morten, S. Mitchell, J. Perez-Ramirez, U. Olsbye, B. M. Weckhuysen, V. Van Speybroeck, F. Kapteijn, J. Gascon. Nat. Chem. 2018, 10, 804.

[130] a) M. Moliner, C. Martínez, A. Corma. Chem. Mater. 2014, 26, 246; b) M. Dusselier, M. E. Davis. Chem. Rev. 2018, 118, 5265.

[131] J. Zhang, Z. Huang, L. Xu, X. Zhang, X. Zhang, Y. Yuan, L. Xu. Catal. Sci. Technol. 2019, 9, 2132.

[132] a) Z. Liu, X. Dong, Y. Zhu, A.-H. Emwas, D. Zhang, Q. Tian, Y. Han. ACS Catal. 2015, 5, 5837; b) D. A. Ruddy, J. E. Hensley, C. P. Nash, E. C. D. Tan, E. Christensen, C. A. Farberow, F. G. Baddour, K. M. Van Allsburg, J. A. Schaidle. Nat. Catal. 2019, 2,632 .

[133] M. Yang, B. Li, M. Gao, S. Lin, Y. Wang, S. Xu, X. Zhao, P. Guo, Y. Wei, M. Ye, P. Tian, Z. Liu. ACS Catal. 2020, 3741.

[134] J. Wang, J. Li, S. Xu, Y. Zhi, Y. Wei, Y. He, J. Chen, M. Zhang, Q. Wang, W. Zhang, X. Wu, X. Guo, Z. Liu. Chin. J. Catal. 2015, 36, 1392.

[135] E. M. Gallego, M. T. Portilla, C. Paris, A. León-Escamilla, M. Boronat, M. Moliner, A. Corma. Science 2017, 355, 1051.

[136] C. Li, C. Paris, J. Martínez-Triguero, M. Boronat, M. Moliner, A. Corma. Nat. Catal. 2018, $1,547$.

[137] a) C. Sun, Y. Wang, A. Zhao, X. Wang, C. Wang, X. Zhang, Z. Wang, J. Zhao, T. Zhao. Appl. Catal. A Gen 2020, 589, 117314; b) L. Zhang, H. Liu, Y. Yue, U. Olsbye, X. Bao. Catal. Sci. Technol. 2019, 9, 6438; c) Z. Xu, J. Li, Y. Huang, H. Ma, W. Qian, H. Zhang, W. Ying. Catal. Sci. Technol. 2019, 9, 2888; d) J. Shao, T. Fu, Z. Ma, C. Zhang, H. Li, L. Cui, Z. Li. Catal. Sci. Technol. 2019, 9, 6647; e) Q. Sun, N. Wang, R. Bai, G. Chen, Z. Shi, Y. Zou, J. Yu. ChemSusChem 2018, 11, 3812; f) Q. Zhang, S. 
Xiang, Q. Zhang, B. Wang, A. Mayoral, W. Liu, Y. Wang, Y. Liu, J. Shi, G. Yang, J. Luo, X. Chen, O. Terasaki, J.-P. Gilson, J. Yu. Chem. Mater. 2020, 32, 751; g) R. Bai, Y. Song, Y. Li, J. Yu. Trends in Chem. 2019, 1, 601; h) Eva M. Gallego, C. Paris, M. R. Díaz-Rey, M. E. Martínez-Armero, J. Martínez-Triguero, C. Martínez, M. Moliner, A. Corma. Chem. Sci. 2017, 8, 8138; i) V. J. Margarit, M. R. Díaz-Rey, M. T. Navarro, C. Martínez, A. Corma. Angew. Chem. Int. Ed. 2018, 57, 3459; j) R. Martínez-Franco, C. Paris, M. E. Martínez-Armero, C. Martínez, M. Moliner, A. Corma. Chem. Sci. 2016, 7, 102; k) E. M. Gallego, C. Paris, C. Martínez, M. Moliner, A. Corma. Chem. Commun. 2018, 54, 9989; 1) Y.-L. Zhu, H. Dai, Y. Duan, Q. Chen, M. Zhang. Cryst. Growth Des. 2020, 20, 2623.

[138] a) N. Wang, Y. Hou, W. Sun, D. Cai, Z. Chen, L. Liu, B. Ge, L. Hu, W. Qian, F. Wei. Appl. Catal. B Environ 2019, 243, 721; b) S. Kim, G. Park, M. H. Woo, G. Kwak, S. K. Kim. ACS Catal. 2019, 9, 2880; c) E. M. Gallego, C. Li, C. Paris, N. Martín, J. Martínez-Triguero, M. Boronat, M. Moliner, A. Corma. Chem. -Eur. J. 2018, 24, 14631; d) N. Martín, Z. Li, J. Martínez-Triguero, J. Yu, M. Moliner, A. Corma. Chem. Commun. 2016, 52, 6072; e) R. Martínez-Franco, Z. Li, J. Martínez-Triguero, M. Moliner, A. Corma. Catal. Sci. Technol. 2016, 6, 2796; f) Z. Li, J. Martínez-Triguero, J. Yu, A. Corma. J. Catal. 2015, 329, 379; g) Z. Li, J. Martínez-Triguero, P. Concepción, J. Yu, A. Corma. Phys. Chem. Chem. Phys. 2013, 15, 14670.

[139] a) L. Schlapbach, A. Züttel. Nature 2001, 414, 353; b) Q. Sun, N. Wang, Q. Xu, J. Yu. Adv. Mater. 2020, DOI:10.1002/adma.202001818.

[140] a) D. Mellmann, P. Sponholz, H. Junge, M. Beller. Chem. Soc. Rev. 2016, 45, 3954; b) Q.-L. Zhu, Q. Xu. Energy Environ. Sci. 2015, 8, 478; c) M. Grasemann, G. Laurenczy. Energy Environ. Sci. 2012, 5, 8171.

[141] a) T. He, P. Pachfule, H. Wu, Q. Xu, P. Chen. Nat. Rev. Mater. 2016, 1, 16059; b) X. Gu, Z.-H. Lu, H.-L. Jiang, T. Akita, Q. Xu. J. Am. Chem. Soc. 2011, 133, 11822. 
[142] a) M. Martis, K. Mori, K. Fujiwara, W.-S. Ahn, H. Yamashita. J. Phys. Chem. C 2013, 117, 22805; b) F. Ke, L. Wang, J. Zhu. Nanoscale 2015, 7, 8321; c) H. Dai, B. Xia, L. Wen, C. Du, J. Su, W. Luo, G. Cheng. Appl. Catal. B Environ. 2015, 165, 57.

[143] M. Ojeda, E. Iglesia. Angew. Chem. Int. Ed. 2009, 48, 4800.

[144] a) F.-Z. Song, Q.-L. Zhu, N. Tsumori, Q. Xu. ACS Catal. 2015, 5, 5141; b) Z.-L. Wang, H.-L. Wang, J.-M. Yan, Y. Ping, S.-I. O, S.-J. Li, Q. Jiang. Chem. Commun. 2014, 50, 2732.

[145] a) Q.-L. Zhu, N. Tsumori, Q. Xu. Chem. Sci. 2014, 5, 195; b) J. Cheng, X. Gu, X. Sheng, P. Liu, H. Su. J. Mater. Chem. A 2016, 4, 1887.

[146] a) M. Navlani-García, M. Martis, D. Lozano-Castelló, D. Cazorla-Amorós, K. Mori, H. Yamashita. Catal. Sci. Technol. 2015, 5, 364; b) A. Gallas-Hulin, J. Mielby, S. Kegnaes. Chemistryselect 2016, 1, 3942.

[147] R. I. J. Amos, F. Heinroth, B. Chan, A. J. Ward, S. Zheng, B. S. Haynes, C. J. Easton, A. F. Masters, T. Maschmeyer, L. Radom. ACS Catal. 2015, 5, 4353.

[148] W. Supronowicz, I. A. Ignatyev, G. Lolli, A. Wolf, L. Zhao, L. Mleczko. Green Chem. 2015, 17, 2904.

[149] Q. Sun, N. Wang, Q. Bing, R. Si, J. Liu, R. Bai, P. Zhang, M. Jia, J. Yu. Chem 2017, 3, 477.

[150] A. Corma. Angew. Chem. Int. Ed. 2016, 55, 6112.

[151] a) S. Brandt, F. Sittel, M. Ernst, G. Stock. J. Phys. Chem. Lett. 2018, 9, 2144; b) W. Yang, T. T. Fidelis, W.-H. Sun. ACS Omega 2020, 5, 83.

[152] a) M. Moliner, Y. Román-Leshkov, A. Corma. Acc. Chem. Res. 2019, 52, 2971; b) Y. Li, X. Li, J. Liu, F. Duan, J. Yu. Nat. Commu. 2015, 6, 8328; c) A. Kumar, K. Song, L. Liu, Y. Han, A. Bhan. Angew. Chem. Int. Ed. 2018, 57, 15577; d) Y. Li, J. Yu. Chem. Sci. 2016, 7, 3472. 
[153] a) R. Gaillac, S. Chibani, F.-X. Coudert. Chem. Mater. 2020, 32, 2653; b) J. Li, M. Qi, J. Kong, J. Wang, Y. Yan, W. Huo, J. Yu, R. Xu, Y. Xu. Microporous Mseoporous Mater. 2010, 129, 251.

[154] Z. Hajjar, A. Khodadadi, Y. Mortazavi, S. Tayyebi, S. Soltanali. Fuel 2016, 179, 79.

[155] K. Tran, Z. W. Ulissi. Nat. Catal. 2018, 1, 696.

[156] E. M. Gallego, C. Paris, Á. Cantín, M. Moliner, A. Corma. Chem. Sci. 2019, 10, 8009.

[157] a) S. Wang, R. Li, D. Li, Z.-Y. Zhang, G. Liu, H. Liang, Y. Qin, J. Yu, Y. Li. J. Mater. Chem. B 2018, 6, 3254; b) X. Huang, C. Wang, Y. Zhu, W. Xu, Q. Sun, A. Xing, L. Ma, J. Li, Z. Han, Y. Wang. Microporous Mesoporous Mater. 2019, 288, 109573. 


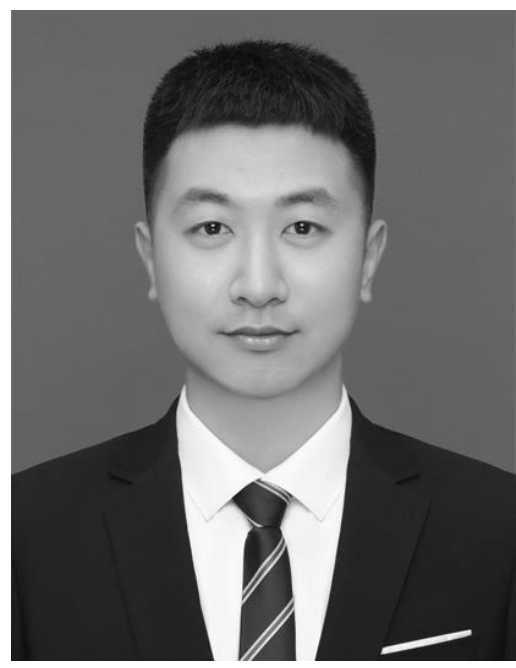

Qiang Zhang received his Ph.D. degree in Jilin University in 2019 under the supervision of Prof. Jihong Yu. He now works as a postdoctoral fellow in the group of Prof. Avelino Corma at the Instituto de Tecnologa Qumica (ITQ). His current research is focused on exploring synthesis methods for zeolites as well as their applications for catalysis.

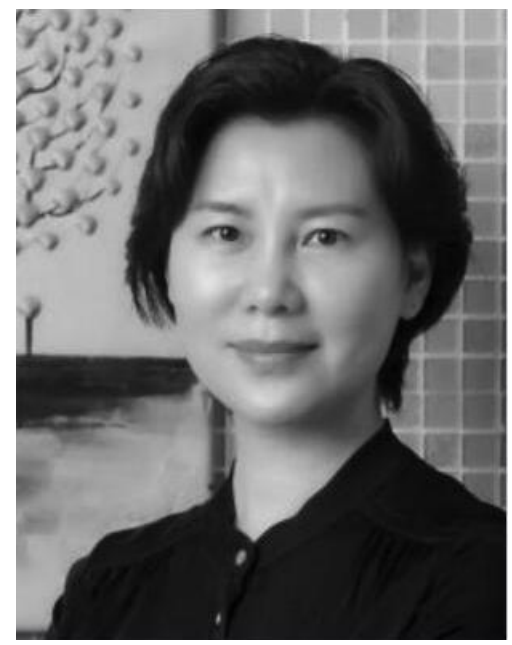

Jihong Yu received her Ph.D. in inorganic chemistry from Jilin University in 1995 and worked as a postdoctoral fellow first at the Hong Kong University of Science and Technology and then at Tohoku University in Japan during 1996-1998. She has been a full Professor in the Chemistry Department, Jilin University, since 1999. She was elected as a member of the Chinese Academy of Sciences in 2015, academician of TWAS in 2016, and member of Academiae Europaeae in 2019. Her main research interest is in the designed synthesis and application of zeolitic nanoporous materials in energy, environment, and other emerging fields. 


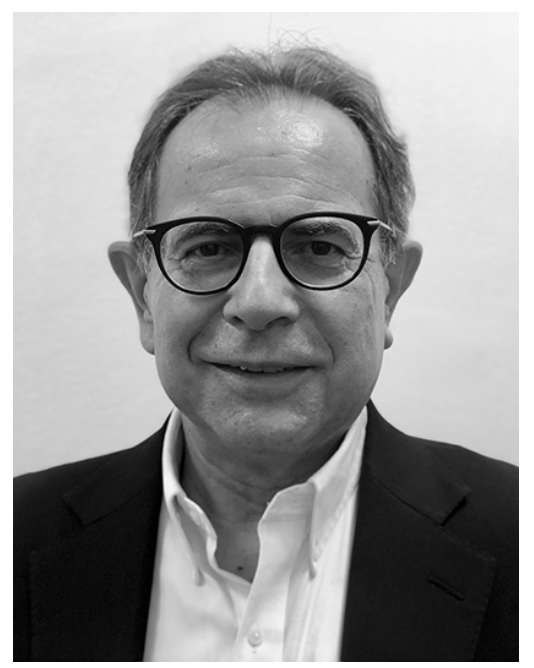

Avelino Corma studied chemistry at the Universidad de Valencia (1967-1973) and received his $\mathrm{PhD}$ at the Universidad Complutense de Madrid in 1976 with Prof. Cortés. He was a postdoctoral researcher with Prof. Wojciechowski in the department of chemical engineering at Queen's University (Canada, 1977-1979). Since 1990 he has been a professor at the Instituto de Tecnologa Qumica (UPV-CSIC) at the Universidad Politécnica de Valencia. His current research focuses on the synthesis, characterization, and reactivity of acid-base and redox catalysis. 
Zeolite catalysts play a pivotal role in $\mathrm{C} 1$ chemistry including conversion of $\mathrm{CO}, \mathrm{CO}_{2}, \mathrm{CH}_{4}$, $\mathrm{CH}_{3} \mathrm{OH}$, and $\mathrm{HCOOH}$ into various hydrocarbons (e.g., methane, lower olefins, aromatics, and liquid fuels) and oxygenates (e.g., methanol, dimethyl ether, formic acid, and higher alcohols) to meet the demand for energy and chemicals as crude oil reserves decline.

Title: Applications of Zeolites in C1 Chemistry: Recent Advances, Challenges, and Opportunities

Qiang Zhang, Jihong Yu,* Avelino Corma*

Keywords: Zeolite, C1 chemistry, Catalytic transformation, Hydrocarbons, Oxygenates

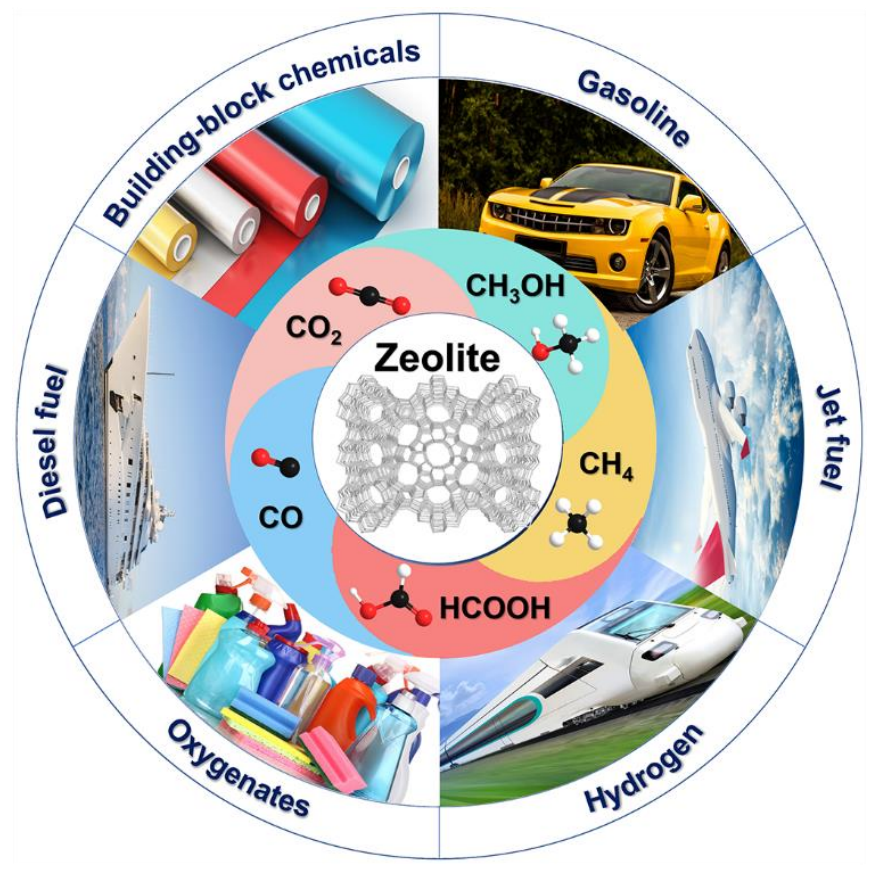

